Illinois State University

ISU ReD: Research and eData

Theses and Dissertations

3-4-2014

\title{
The Invisible Composition Classroom: The Reciprocity of Face, Identity, and Politeness
}

Pennie L. Gray

Illinois State University, graysrwe@frontier.com

Follow this and additional works at: https://ir.library.illinoisstate.edu/etd

Part of the Curriculum and Instruction Commons, Educational Methods Commons, Higher Education Administration Commons, Higher Education and Teaching Commons, and the Liberal Studies Commons

\section{Recommended Citation}

Gray, Pennie L., "The Invisible Composition Classroom: The Reciprocity of Face, Identity, and Politeness" (2014). Theses and Dissertations. 88.

https://ir.library.illinoisstate.edu/etd/88

This Dissertation is brought to you for free and open access by ISU ReD: Research and eData. It has been accepted for inclusion in Theses and Dissertations by an authorized administrator of ISU ReD: Research and eData. For more information, please contact ISUReD@ilstu.edu. 


\title{
THE INVISIBLE COMPOSITION CLASSROOM:
}

\section{THE RECIPROCITY OF FACE, IDENTITY,}

\section{AND POLITENESS}

\author{
Pennie L. Gray
}

178 Pages

May 2014

This study examines the role of face and identity as they arise in a first year composition classroom. Using the illuminating theoretical framework of linguistic politeness theory, new understandings of the social interaction in the composition classroom are unveiled. Specifically, through an analysis of the politeness strategies that students use during the peer review process, it becomes clear that students prefer to temper their critique of others' work rather than openly criticize that work. Students offer far more positive feedback than their peers' work perhaps merits, they minimize the revision work they suggest, and they downplay their own authority over one another's texts. Likewise, the instructor also uses strategies to address the face and identity needs of the students and their compositions. Through a case study analysis, the role of the composition instructor is examined and is found to be far more complex than initially imagined. The author of this study, through the process of self-study, determined that her own authority and expertise figured heavily into the interactions she had with students through their compositions. By adopting a non-prescriptive writing pedagogy, the instructor found that the balance of expertise between the student and the instructor 
shifted when students pursued their own topics and genres for their compositions.

Ultimately, the findings of this study point to the need for composition instructors to be ever-mindful of the invisible social layer of the composition classroom and how that social layer influences not only the interactions in the classroom, but also the compositions such settings generate. 


\title{
THE INVISIBLE COMPOSITION CLASSROOM:
}

\section{THE RECIPROCITY OF FACE, IDENTITY,}

AND POLITENESS

\author{
PENNIE L. GRAY
}

A Dissertation Submitted in Partial

Fulfillment of the Requirements for the Degree of

DOCTOR OF PHILOSOPHY

Department of English Studies

ILLINOIS STATE UNIVERSITY 
Copyright 2014 Pennie L. Gray 


\section{THE INVISIBLE COMPOSITION CLASSROOM:}

\section{THE RECIPROCITY OF FACE, IDENTITY,}

AND POLITENESS

PENNIE L. GRAY

COMMITTEE MEMBERS:

Janice W. Neuleib, Chair

Bob L. Broad

Susan M. Burt 


\section{ACKNOWLEDGEMENTS}

It takes a village to write a dissertation.

I could not have asked for a better dissertation committee - my very own Dream Team. Jan, your continued enthusiasm for my ideas kept me going when I felt discouraged or lost. Plus, you had a knack for sharing some pithy, insightful comment that echoed through my mind for days afterwards and that often changed the way I thought about a given topic. Thank you. Susan, I truly appreciated your genuine kindness in every facet of our work together. I thank you for your willingness to take on the cumbersome task of committee member and for your astute redirections - shared over delicious pizza at Medici_as I grappled with politeness theory. Bob, you have a talent for offering a response to my work that simultaneously uplifts and challenges me. You have set for me a model to follow as I continue working with students and their compositions.

To Sarah (the only professor to give me a B on a paper-a well-deserved B): You are an inspiration to me. Your educational insights are dead-on, and I hope to become one day the educational advocate you are. Thank you for broadening my understanding of pedagogy.

Patti, your encouragement meant more to me than you'll ever know. Thank you for listening to me ramble about my research for hours on end at Panera. You're my friend for more reasons than just our shared snarkiness and sarcasm. 
Melinda, there's nothing quite like working on a graduate degree in the stands at a swim meet, is there? Thanks for struggling through grad school with me and for being the only person at a swim meet willing to discuss rhetoric or enclitics at any given moment.

Mom and Dad, I bet you never thought I'd end up with a PhD, did you? Thank you for your continued support, your interest in my work, and most of all, for teaching me a strong work ethic. You are the most wonderful parents!

To the best in-laws in the world, Lesley and Tyler: You have been so encouraging, in spite of the fact that my work created work for Bill, too. Thank you for your continued support and for connecting me with Jane Tompkins.

To Robin, Irv, Jeanne, Leah, Jen, Kelly, and Moreena: Thank you for believing in me and for your ongoing, never-wavering support. It is a pleasure to teach and work alongside you.

Elijah and Andrew, were you not exceptional young men, I could have never done this. Thanks for putting up with hours and hours of me writing at the kitchen table, for my regular correction of your grammar, and for listening to long-winded explanations of writing, peer review, and other topics you have no interest in.

And, Bill. What can I say? You were more supportive than I could have ever asked. You gave me long stretches of time to write while you handled every other household task—cooking, cleaning, chauffeuring. You encouraged me and listened for hours as I read my writing to you just because I needed to hear it out loud. And thanks for lying and saying that what I wrote made sense (kind of) even when it didn't just so I didn't get discouraged. Most of all, thank you for your levity. You made me laugh when I needed to laugh ("Go for the C"), and you encouraged me to keep going when I felt like 
giving up and becoming a greeter at Wal-Mart. And while I appreciate your offer to come to my dissertation defense with a foam finger and face paint, I appreciate more that you didn't. I couldn't ask for a more wonderful husband. I love you.

P. L. G. 


\section{CONTENTS}

\section{Page}

ACKNOWLEDGEMENTS

CONTENTS iv

FIGURES Vi

CHAPTER

I. RESPONSE TO STUDENT WRITING: IDENTITY AND FACE 1

The Purposes of this Study 1

Identity in the Composition Classroom 5

Face in the Composition Classroom $\quad 8$

Response to Student Writing 11

Transparency and Truth-telling in Assessment and Response $\quad 17$

Formative Assessment $\quad 20$

Risky Writing 24

Conclusion 28

II. METHODS AND THEORETICAL FRAMEWORKS:

THE STRUCTURE OF THIS STUDY 31

Methods 31

$\begin{array}{ll}\text { Self-Study } & 32\end{array}$

Theoretical Frameworks $\quad 34$

Communities of Practice $\quad 34$

Linguistic Politeness Theory 36

Critiques of Brown and Levinson's

Politeness Theory 44

Does Universality Matter? 52

The Site and Context of this Study 55

Writing Processes $\quad 55$ 
Student Characteristics $\quad 59$

$\begin{array}{ll}\text { Conclusion } & 60\end{array}$

III. PEER REVIEW AND POLITENESS STRATEGIES 62

Students as Novices $\quad 62$

Peer Review: A Brief Overview 63

Goals and Benefits of Peer Review $\quad 65$

Peer Review Assignment Description 69

Peer Review and Risky Writing $\quad 71$

Politeness and Peer Review $\quad 77$

Analysis of Peer Review Politeness 85

The Politeness Profile of the Composition Classroom 89

Different Peers in the Peer Review Process 90

$\begin{array}{lll}\text { IV. TROUBLING THE NARRATIVES } & 94\end{array}$

Responding to Student Writing 94

The Students 99

$\begin{array}{lr}\text { Aaron } & 99\end{array}$

Karl $\quad 100$

Paul 101

$\begin{array}{ll}\text { Shannon } & 102\end{array}$

Instructor Authority and Student Response:

Acquiescence, Resistance, and Dismissal 103

Seeking Collaboration and Surrendering Expertise $\quad 127$

Risks for Students; Risks for Instructors 140

The Perils of a Non-prescriptive Writing Pedagogy 148

V. RECIPROCITY AND THE INVISIBLE COMPOSITION

CLASSROOM

Initial Goals of the Study 154

The Invisible Composition Classroom 156

My Emerging Understanding $\quad 160$

Limitations 163

$\begin{array}{ll}\text { REFERENCES } & 165\end{array}$

APPENDIX: Sample Student Composition 172 


\section{FIGURES}

Figure $\quad$ Page

1. Wolfson's Bulge Theory 86

2. The Invisible Composition Classroom 162 


\title{
CHAPTER I
}

\section{RESPONSE TO STUDENT WRITING: IDENTITY AND FACE}

\author{
The Purposes of this Study
}

In almost any composition classroom, there is much more going on than meets the eye. What appears to be a typical composition classroom unfolding quite naturally and effortlessly actually masks subtle social dimensions that can have a significant impact on the products such environments potentially generate. Composition classrooms are indeed complex, shifting social constructs with layers of meanings, interpretations, and manifestations.

At the beginning of each semester as I consider how I will approach my composition courses, I find I am eager and somewhat apprehensive about meeting a new group of students. I wonder how invested students will feel in the course, what skills they will bring, what interests they will have, and just exactly how I will manage to fill the entire semester with meaningful learning opportunities. In spite of more than twenty years of teaching experience, I approach each new course with a good deal of trepidation and insecurity. While my prior teaching experiences have taught me that, given enough time, attention, and energy, almost any classroom can become a place of comfort and trust, experience has also taught me that some classes and combinations of students are 
more predisposed to gel than others. In all reality, more than a mastery of the content, I worry about how well and how quickly I will be able to facilitate a new configuration of students into a cohesive unit - or even if students will come together as a cohesive unit. I realize fully that classes that coalesce under an overlay of trust, collaboration, and mutual investment yield the most productive and gratifying learning experiences, so creating this type of classroom is my ultimate goal; it does not, however, always happen to the extent I hope it does.

I would like to believe that there is a formula for creating a productive, cohesive classroom environment, but in fact, there are far too many contributing factors to espouse a formulaic approach to creating this cohesive environment. Indeed, each classroom is comprised of a unique amalgam of personalities, identities, goals, insecurities, and needs, and this unique amalgam necessitates an artful, flexible, and responsive approach to instruction. However, perhaps one way to move toward creating the classrooms I describe is through careful, intentional self-reflection.

Therefore, I have spent the past year reflecting on and analyzing the interactions, writings, and experiences that unfolded during a composition course I taught in the fall of 2012. My initial intention in analyzing this course was to focus on my assessment measures and to consider how my assessments influenced student compositions. While I did indeed evaluate my assessment practices over the course of the semester, I have since discovered even more interesting and compelling facets of the composition classroom, facets that I intend to discuss in this study.

One goal of this study, then, is to explore the ways that the social development of a classroom community influences the writing students attempt within that setting. More 
specifically, I intend to illuminate how the social dynamics of a classroom community are intertwined deeply with the kinds of risks students are willing to take in their writing.

Students do not write in a vacuum. They write, in part, in response to their own needs, their perceived understanding of the requirements of the course, and the feedback they receive from others within the classroom community. Furthermore, student writing is shaped and influenced by both obvious and subtle factors that emerge in the classroom context. By attending carefully to some of these factors, composition instructors may be better positioned to create the kinds of learning communities that generate student growth and engagement.

While I am not able to explore every nuanced aspect of a composition classroom, for some are discernible and others are not, there are some aspects of the classroom that I am able to examine. One such area is the way in which I respond to student writing. I recognize that I have a strong, nearly-palpable influence on what students write, how they approach the writing process, and how — or if — they revise their work. By attending to the social, interactive layer of the classroom known as teacher response, I can become more attuned to my influence on students' compositions. Another area I am able to examine is how students respond to one another's writing and the influence this has on students and the compositions they generate. Thus, for one portion of this study, I will explore the peer review process as it unfolded in my composition classroom.

Through my study of my composition classroom, I intend to illuminate as yet unacknowledged connections between the composition classroom's social environment and the actual compositions students write in these settings. To analyze the composition classroom, I intend to use linguistic politeness theory, developed by Brown and Levinson 
$(1978,1987)$, as an illuminating framework for this study and to draw on politeness theory to provide a vocabulary through which this examination can proceed. More specifically, I intend to explore how students' face needs emerged and influenced what transpired in the composition classroom, and perhaps how my own face needs emerged as well. I will examine the perceived face needs of students during the composing and responding processes and the strategies that interactants use to address these perceived face needs.

I contend that by examining the interplay between response to student writing (by the instructor and by the students) and politeness theory, new and illuminating insights can be unveiled. My goal is to reveal valuable considerations for helping students become engaged writers who are willing to take composition risks and ideally grow from those risks.

In addition to linguistic politeness theory, another valuable framework for this study will be Wenger's communities of practice theory. This theory will help me as I attempt to identify how the classroom community emerges, develops, and functions. By bringing politeness theory and communities of practice into conversation with one another, I hope to illuminate unexamined potentialities of composition classrooms that may inform the instructional decisions that are often made in these settings.

Ultimately, I intend to make the argument that within each unique composition classroom, a configuration of politeness strategies emerges through the response process that, under careful scrutiny, can reveal valuable insights into that particular composition community of practice. I intend to argue further that the classroom instructor plays a pivotal, although complex, role in nurturing that environment. Ideally, other composition 
instructors will benefit from this study by becoming more keenly attuned to the social dimensions of their own composition classrooms and in so doing become more effective teachers. The results of this study may guide and inform other composition instructors as they generalize my findings and apply them in their own classrooms.

Thus, I begin this chapter by examining key aspects of the composition classroom that factor heavily into this study. Among the concepts I will explore are: identity as it arises in a classroom; face and perceived face needs; teacher response to student writing; and student willingness to take risks in their writing, what I will refer to as risky writing.

\section{Identity in the Composition Classroom}

The concept of identity is decidedly difficult to define. The scope of this study does not permit a thorough exploration of identity in all contexts, so I will narrow my examination of identity to its emergence in a composition classroom - a writing identity of sorts. In order to elaborate on the role of identity in the composition classroom, I will first cast the composition classroom as a figured world.

As Holland, Skinner, Lachicotte, and Cain (1998) contend, a figured world is "a socially and culturally constructed realm of interpretation in which particular characters and actors are recognized, significance is assigned to certain acts, and particular outcomes are valued over others" (p. 52). Figured worlds hinge upon the individuals within them and how those individuals collectively create and interpret their worlds through the replication of contextually appropriate actions. A figured world is, at its core, socially and culturally created, honed, and enacted.

As individuals function in their figured worlds, they shape these worlds through their practices and their participation within those worlds (p. 53). In short, a figured 
world is "formed and re-formed in relation to the everyday activities and events that ordain happenings in it” (p. 53). These activities and happenings thus create a narrative for participants to reference and position themselves within. Furthermore, individuals form an understanding of themselves in and through these culturally defined worlds. In this way, figured worlds intersect with identities as identities are fashioned by figured worlds, and figured worlds are influenced by the identities within them. The relationship between figured worlds and identities is reciprocal.

The composition classroom is one such figured world in which identities arise. There is in a composition classroom a narrative, but that narrative is not fixed or wholly predetermined; it is also shaped mutually by the participants within it. A composition classroom narrative may simultaneously draw upon pre-existing composition narratives from prior experiences and generate its own unique narrative as a result of the influence of the individuals within the community. There are agreed upon roles in the figured world of a composition classroom, as well as outcomes that are valued or not valued, and varying degrees of significance assigned to particular acts. These factors come together to form the composition classroom narrative that reflects the unique classroom configuration.

It is within the figured world of a composition classroom that people's writing identities arise ${ }^{1}$. Writing identities develop in relation to the "practices and activities situated in historically contingent, socially enacted, culturally constructed 'worlds"' (p.

\footnotetext{
${ }^{1}$ There are admittedly many identities that students bring to a composition classroom. They may see themselves as students, contributors, readers, thinkers, or performers. Indeed, these identities interlinked, with one influencing the other. However, for the purposes of my study, I will narrow my focus to include only students' identities as they pertain to composition. I acknowledge, however, that no one identity stands completely independent from another.
} 
7). For the purposes of this study, I define writing identity as a sense of oneself as a writer. This sense of oneself is built upon inner activity and inner life while at the same time is influenced by the outside context of the composition classroom. Like the figured world of the composition classroom, the writing identity arises from within but is influenced simultaneously from without. Writing identities are "an outcome of living in, through, and around the cultural forms practiced in social life," in this case, the social life of the composition classroom (p. 8).

This writing identity, or sense of self as a writer, allows students to exert more or less control or agency over their behavior within the enacted narrative of the composition classroom, and in this way, identities mediate behaviors (p. 8). In the figured world of the composition classroom, social encounters are imbued with varying degrees of agency, and participants position themselves in relation to these encounters. For instance, a student may choose the degree to which he engages in the revision process-a subnarrative and mainstay of a composition classroom—-based upon his writing identity as well as other factors such as interest, need, and time. He brings with him an image of himself as a writer, and this self-image or identity interacts in unique ways with the expectations of the composition classroom. What emerges is a distinctive, specialized way of functioning for each student in the context of the specific composition classroom.

But students are not the only ones with an identity in the composition classroom. Instructors have identities as well, and the power that this social position affords weighs heavily in the figured world of the composition classroom (p. 41). The instructor's identity is shaped not only through the inner self of the instructor and the classroom context, but also through institutional expectations imposed on the instructor. Of course, 
in the narrative of the composition classroom, the instructor has the power to influence the actions of the students. While students certainly have agency and thus may not acquiesce to the instructor's behest, the pre-existing narrative of the classroom leans toward student compliance.

There are different ways, however, that identity is conceptualized. Identity can arise through and within figured worlds, as previously noted, but also in relation to "one's position relative to socially identified others, one's sense of social place, and entitlement" (p. 125). This layer of identity development, which reflects social power differentials, is an important consideration when reflecting on the role of the composition instructor in shaping students' writing identities. Yet both conceptions of identity-those that arise through figured worlds and those that arise in relation to social position within those figured worlds-intertwine and inform one another. I will examine the role of the instructor and the influence of her position in the classroom in chapter four of this study, but for now, it is important to note that the instructor and her identity figure significantly in the identities students claim for themselves.

As students enact their writing identities in the figured world of the composition classroom, they present to the other members of the community particular face needs, the topic of the following section.

Face in the Composition Classroom

Beyond an admittedly cursory understanding of identity, a familiarity with the notion of face is likewise important for this study. Like identity, face is difficult to define concisely divorced of contextual factors. However, it is helpful to note that identity and face are interrelated in that identity, at least in part, is expressed through face. 
Furthermore, face is ascertained, at least to some degree, through student work, in this case, composition, and the face a student presents in a composition classroom gives some indication as to the student's writing identity.

To develop a working definition of face, I turn to Goffman (1967) who defines face as "the positive social value a person effectively claims for himself by the line others assume he has taken during a particular contact" (p. 7). Goffman goes on to state that "face is an image of (the) self delineated in terms of approved social attributes" (p. 7).

There are a number of interesting and noteworthy aspects to Goffman's definition of face. First, Goffman rightly notes that understanding someone else's face is a highly interpretive endeavor. In fact, Goffman states that "others assume" their fellow interactant has taken a stance, or line, during an interaction (p. 7). Of course, others may make incorrect assumptions about the line someone has taken for himself, and a true understanding of a person's face is not available for the taking. Interactants do not wear their face as an obvious, perceptible cloak; they do not typically walk about telling others about the positive social value they claim for themselves. Instead, face is only partially ascertainable through observation, conjecture, interaction, and assumption. Thus, at least slight misinterpretations of face likely result in all interactions. Furthermore, a misguided interpretation of someone's face can lead to social missteps. How I, as a composition instructor, interpreted - and misinterpreted — students' presentation of face will be one focus of chapter four.

Another notable aspect of Goffman's definition of face is the casting of face as a positive image; it is the positive way we hope others think of us. Included in Goffman's definition of face is the idea that there exist "approved social attributes" (p. 7). These 
approved social attributes help shape the face a person claims for herself. As in all settings, in the figured world of the composition classroom, there are social attributes that are upheld and fostered. These approved social attributes help constitute the narrative of the composition classroom and additionally position individuals within that narrative according to their ability to meet those social attributes. For my purposes here, I define these social attributes through the lens of composition, so these attributes include such things as the ability to write well, a willingness to revise one's work, and strength in critical thinking, along with myriad other valued composition attributes.

The narrative of the composition classroom places value upon those individuals who are adept at writing, who bring a fresh and interesting perspective to their compositions, who approach the writing process with confidence and skill. For these adept students, a positive sense of face in relation to composition is natural. Students claim a positive self-image for themselves, and others within the classroom community typically respond to that self-image with affirmation and encouragement. This writing identity and positive face perception emerges, at least in part, through the social interactions in the classroom as students juxtapose their writing against one another's or against the instructor's benchmark.

But what of the student who comes into the composition classroom and is positioned negatively against the composition classroom narrative and accepted attributes? What about the student who does not have a positive image of himself as a writer? How does this student position himself in the class, and how do others respond to his perceived shortcomings? These questions point to the need for a more nuanced examination of the interactions in a composition classroom, an examination I intend to 
conduct in chapters three and four of this study when I bring Brown and Levinson's linguistic politeness theory to bear on both the peer review process and my response to student writing respectively.

Finally, Goffman contends that face arises through social interaction. While Goffman focuses primarily on face-to-face interactions as the site for claiming this positive self image, it is also possible for face to arise through the composing process. Because students' compositions are read by others - the instructor or peers during peer review_-student writing is inherently social, so while Goffman focuses on face-to-face interactions, I contend that face also arises through the composition process, a likewise social endeavor.

It appears that Brown and Levinson (1987) agree with Goffman's definition of face at least somewhat. They state, "the notions of face naturally link up to some of the most fundamental cultural ideas about the nature of social persona, honour and virtue" (p. 13). However, Brown and Levinson add that face can also include notions of shame and redemption (p. 13). Beyond that, Brown and Levinson further delineate the concept of face into two categories: positive face and negative face. A more thorough discussion of Brown and Levinson's politeness theory will be included in chapter two of this study.

\section{Response to Student Writing}

One crucial component of the figured world of the classroom is the sense of safety and trust that develops there. There are myriad ways that instructors create trust in the composition classroom, as many ways as there are instructors. In fact, the ability to create artfully a safe classroom environment emerges from a confluence of factors: the students, the instructor, the time of year, the community, the university, the department, the 
content. However, one particular practice in the composition classroom is uniquely positioned to threaten the burgeoning safety of the classroom: the unavoidable inevitability of assessment.

Assessment means different things to different people. To some, assessment is an institutional tool for sorting and classifying students according to their ability in particular areas. To others, it is quantification of student learning over the course of a semester. To still others, it is the ongoing feedback offered to students to guide and shape their learning. In short, the term assessment has been taken up in so many different ways and for so many different purposes, it has lost any precision of meaning. What assessment means depends on who is using the term, when, and for what purpose.

When assessment is conceived of as the quantification and reduction of a semester's worth of student effort, growth, and accomplishment into a letter grade or percentage, the damage potential of assessment is clear. Not only can looming summative grades be damaging to the composition classroom, their usefulness is minimal at best. In fact, "by themselves, grades lack the elaboration and context to make any cogent comment about student performance" (Yancey \& Huot, in Zak \& Weaver, 1998, p. 41), and often, course summative grades misrepresent student performance due to the oversimplified nature of a letter grade.

While summative grades are a necessary evil for most instructors, there may be ways of mitigating the potential damage they can do and making this inevitable quantification more palatable for students and instructors alike. For instance, the artful use of teacher response can mitigate the potentially negative effects of summative 
assessment because through teacher response, students gain a better understanding of their own performance in the course relative to the instructional expectations.

Response to student writing, I contend, is the most effective way to support students, respond to their face needs, and nurture their writing identities. When used with a keen awareness of the potential it holds, teacher response to student writing can become a pedagogical tool that furthers student growth. It can, when used judiciously and thoughtfully, increase students' willingness to take composition risks. In fact, at its most effective, teacher response can contribute to the sense of safety and confidence students feel in the composition classroom. When students believe that the instructor values their writing and is willing to encourage them, they may become more willing to try new things and to stretch themselves as writers.

Sadly, using teacher response to improve significantly student writing is a lofty, perhaps unattainable goal. As Knoblauch and Brannon (2006) note, "response to student writing is a meaningful pedagogical activity. . . (but) the results are inconclusive" regarding its ability to directly affect the quality of students' writing (p. 1). This is a disheartening reality. In fact, there is no large body of evidence that indicates that teacher response to student writing in any form has a measurable, long-term effect on the quality of students' compositions. Students may use feedback from the teacher in the short term to make superficial corrections to a paper, but there is little evidence to indicate that they apply that feedback to their writing habits over the long term, from one composition to the next (p. 1). In other words, response to student writing may make better writing in one instance, but it does not create better writers (p. 2). 
There are many reasons for this reality, but in part, student learning and growth is more cyclical than linear. It often takes multiple repetitions of a concept before a student is developmentally ready to hear or apply that concept. Just because a teacher asks a student to more carefully organize a specific essay does not mean that the same student will attend to organization in his next essay. Transference does not always occur.

Why, then, should teachers exert any effort responding to student writing? If there is no real assurance that students become better writers resulting from the feedback they receive, then why give the feedback in the first place? The answer: Because meaningful response to student writing addresses the face needs of the students and thus helps students know that their writing is valued. And when students believe that the instructor values what they have to say through their writing, they may be more inclined to keep writing. When students keep writing, they become better writers-good writers become great writers, in part, through practice. Teacher response, then, is not meant to create better writing, but to nurture better writers.

One strategy that I have found to be especially effective for responding to student writing is audio-recorded feedback ${ }^{2}$. This mode of responding to student writing allows me to communicate more effectively my appreciation of student writing. As Treglia (2009) and Trees, Kerssen-Griep, and Hess (2009) contend, the type of feedback students receive influences dramatically the degree to which they are willing to revise their written work and continue to grow as writers. In fact, "feedback affects performance by directing where its hearer focuses cognitive attention" (Trees, Kerssen-Griep, \& Hess, 2009, p.

\footnotetext{
${ }^{2}$ I recognize that some make a distinction between the terms response and feedback, but I will use these terms interchangeably throughout this study.
} 
399). I have found that audio-recorded feedback can be quite effective at encouraging students to remain engaged in the composition process, not only due to the content of the commentary I can offer, but also because this method allows my voice to do some of the more nuanced work of addressing students' face needs.

Because I use primarily audio-recorded feedback on student work, I turn to Chris Anson $(1997,2000)$, one of the early advocates of this response method. As Anson noted, audio-recorded feedback can help a teacher feel "a social dimension to (his) commentary that had been less present in ... written remarks" (1997, p. 106). Through audio-recorded feedback, students are able to hear the tone of the instructor's voice and from that, more accurately gauge the intention of the remarks. LaPlante and Ambady (2003), through an analysis of prosody during verbal criticism, found that "nonlinguistic aspects of politeness may be equally important" to the actual words being used (p. 435). In other words, the tone of voice and intonation patterns used during critiques potentially softens the blow of a negative comment and prevents the recipient from taking offense and perhaps disengaging from the revision process. Only audio-recorded feedback is positioned to do this nature of redressive work. Furthermore, LaPlante and Ambady found that the non-verbal tone used during criticisms could increase how polite a comment was perceived to be by the recipient. Thus, one of the primary benefits of audio-recorded feedback on student work is the potential it has to do some of the community building and face work that supports a safe classroom environment. Students can actually hear the instructor's intentions, intentions not to offend or frustrate them, but to help and support them. 
Beyond the use of audio-recorded feedback to communicate the intention of a comment through prosody, J. Sommers further notes the importance of audio-recorded comments in serving three functions: reinforcing the classroom setting and instruction; offering more detailed feedback; and giving students the comfort of "a voice they already (know) from class" (2013, para. 12). Audio-recorded response to student writing potentially improves students' relationships with the instructor and further situates teacher response in the classroom context, for instructors can more easily draw on prior conversations, past experiences, and the emerging understanding of the composition values of the figured world of the composition classroom. As J. Sommers found, audiorecorded feedback naturally embeds these kinds of temporal comments and creates a learning continuum that is organic to the unique composition classroom. Instructors can easily reference classroom activities and discussions; they can mention further resources that might help the students develop the paper; they can laugh, question, wonder. None of these responses typically (or easily) occurs in written commentary on student work. In this sense, then, audio-recorded response to student writing draws on conversations begun in the classroom and furthers those conversations in unique directions for each student - a level of differentiation not easily achieved through written margin or end comments, and certainly not through the summative assessment of student work. Furthermore, as J. Sommers noted, audio-recorded feedback "can transform the monologues into an actual response to what has been previously been said (sic), inviting a response from the student writer" and thus creating more of a dialogue between student and instructor (para. 80, emphasis in original). Response to writing becomes reciprocal. 
But perhaps one of the greatest benefits of audio-recorded feedback on student writing is the potential it carries for addressing not only a student composition, but also the student as well. A student's writing identity is always entangled in student compositions. Students invest a piece of themselves in every piece they write; even the most informational of texts carries the fingerprint of the author. For the novice student, writing compositions can be risky behavior indeed. No doubt, students need guidance, suggestions, and commentary to move their writing forward, but if students feel threatened by the commentary, it is more likely they will disengage from the writing process. Audio-recorded response, however, can address "both the subject of the written text and also the student who is receiving the comments" (J. Sommers, para. 81, emphasis in original), and in so doing, encourage the student to remain engaged in the writing process. Perhaps Broad says it best: "Contrary to the irresistible implications of quantification, the evaluation of writing is a critical and creative act carried out by some human beings upon the critical and creative work of others" (2009, p. 309); the use of audio-recorded commentary unveils the humanness of the response process and makes that process more humane as a result.

There are, of course, other considerations to take into account when shaping response to student writing: transparency and truth-telling and formative feedback, the topics of the next two sections.

Transparency and Truth-telling in Assessment and Response Bob Broad (2003) thoughtfully examined writing assessment at the university level in his book, What we really value: Beyond rubrics in teaching and assessing writing. Broad considered how educators determine and communicate their composition 
values. Using Broad's Dynamic Criterion Mapping, educators worked collaboratively at the university or department level to identify their own nuanced value system in an effort to be more truthful about how those values surfaced in their assessment practices and decisions.

While an in-depth consideration of the assessment processes at the university or department level is beyond the scope of my current research, there are nonetheless valuable lessons from Broad's work that pertain to the individual writing instructor. Chief among these lessons is the notion that when students know the rhetorical values held by the instructor, composition becomes a safer endeavor. This truth-telling that Broad advocates is a significant step toward creating classroom environments that foster composition risk-taking, for students do not merely guess about what is valued: they know. As Broad noted, "traditional rubrics and scoring guides prevent us from telling the truth about what we believe, what we teach, and what we value in composition courses and programs" (p. 2). Thus throwing off the constraints of narrow, confining assessment tools that do not echo the individualized needs and values of the figured world of the composition classroom is one significant step toward being more truthful with students and thereby supporting a safer writing environment.

Likewise, when instructors do not have to conform to a prescribed, universal assessment tool, space is created for them to examine and articulate their own values in composition, values that very well may differ from those of the institution, department, or other colleagues. Once an instructor identifies her own composition values, it is much easier for her to share those values with students and thereby support them as writers. 
In all reality, students already know that every writing task in every classroom requires a slightly (or vastly) different investment from them and that every instructor has slightly (or vastly) different expectations of students' writing. Honest acknowledgment of those facts by instructors can create a stronger sense of classroom safety and community and can fix the pedagogical target for students and teachers alike. As Broad assures writing instructors, "differences in interpretation and evaluation are not only inescapable, they are downright wholesome elements of everyday rhetorical experience, elements that we do harm to ourselves and our students in trying to conceal or extirpate" (in Huot \& O’Neill, 2009, p. 303).

Broad's sentiments are echoed by Anson, Dannels, Flash, \& Gaffney (2012) who further note that "writing and oral communication assignments. . take on variations and idiosyncrasies based on specific pedagogical strategies and learning goals (of each discipline); that is, they are purposefully adapted to their educational context" (para. 8, emphasis in original). I might add that these variations and idiosyncrasies likewise arise as the result to the multiple identities and face needs in each unique classroom.

If then, assignments and pedagogical strategies should be purposefully adapted to the unique context of a classroom, it makes sense to share that information with students and dispel the myth that all instructors and disciplines value the same things, in the same ways, and to the same degrees. Additionally, because each composition classroom is different from any other, it makes further sense that the values and expectations of the same instructor change each time an instructor teaches the same course, further illustrating the need for honest, transparent communication of the composition values of the classroom narrative. 
This goal of truthfully articulating clear expectations resonates with the findings of the National Survey of Student Engagement (NSSE) and the Council of Writing Program Administrators, two organizations that collectively determined that communication of clear expectations of the goals and criteria for writing tasks supports "deep learning. . . higher-order thinking and integrative learning" (Addison \& McGee, 2010, p. 153).

One aspect, then, of creating a safe composition classroom environment is espousing transparency and truth-telling regarding what is valued in student writing. When students understand the values, they can then choose how they wish to respond to those values and thus situate themselves and their writing identities in the unique classroom environment.

The goal of this truth-telling is not, of course, to shape every student writer into a carbon copy of the instructor. However, at the same time, I acknowledge that ultimately, I, as the instructor, wield a certain power in the classroom, and that power is manifested in the bestowing of a summative grade. By being more transparent with students regarding my idiosyncratic preferences within each classroom context, I move somewhat closer to creating a safe classroom environment where students are willing to risk themselves because they have a better idea of what they are risking.

Formative Assessment

Once an instructor has identified and communicated her values to students, she is better positioned to channel her assessment practices toward student growth. She is equipped to offer feedback on student writing that has the potential to benefit students; this formative assessment aligns with Wiggins' conception of assessment as educative. 
Wiggins (1998) contended that assessment can be so pedagogically grounded that it almost appears as if assessment is not even taking place: assessment becomes a nearlyinvisible part of the teaching process. In fact, assessment becomes "so unobtrusive to students and teachers, so seamless with teaching and learning, that it is visually indistinguishable from what takes place during good instruction" (Wiggins, p. 3). As Wiggins further contended, "the aim of assessment is primarily to educate and improve student performance, not merely audit it" (p. 7, emphasis in original). Formative assessment is uniquely positioned to accomplish the goals that Wiggins outlined.

As most composition teachers know, assessing and responding to student writing is a time-consuming task. In fact, when not enacted efficiently, composition assessment can become sheer drudgery to the over-worked but well-intentioned instructor. It stands to reason, then, that the assessment practices used by the instructor should be as expedient and instructive as possible, that assessment should be used as a pedagogical tool to enhance the instruction from the classroom and to offer individualized feedback that helps students shape their writing and remain engaged in the writing process.

To this end, timing of feedback on student writing must be considered. When instructors invest significant time and energy into the assessment of a final paper or project, that time may very well be misspent. When commenting on finished writing products, the teacher is the judge and, as such, the final word on the piece. Comments on final submissions, while most likely intended to guide students and help them improve as writers, are rarely effective in achieving these goals. Instead, "students who receive such comments on their papers may read them; however, they often do not write subsequent drafts in which they can act upon the comments, and thus the improvement desired by 
their teachers rarely occurs" (Ziv, in Straub, 2006, p. 94). Students may view these comments as "evaluations of their work and not as the responses of an interested adult reader" (emphasis in original, p. 94).

On the other hand, assessment and feedback that is formative and that allows for improvement in subsequent drafts is far more effective in helping students grow as writers. According to Williamson, "assessment is an ongoing and integral part of teaching, validated by our willingness to understand that we need to keep assessing each student as long as we are teaching him or her" (p. 77, in Huot \& O’Neill). The process of formative assessment, then, may not end until the student chooses to end it by no longer engaging in the revision process.

Clearly, assessment offered during the composing process is the most effective form of instructive, educative feedback. As Walvoord and Anderson advise, "only put your time into comments that reach students in a teachable moment" (1998, p. 123). Using feedback on student work in this way_during teachable moments - reframes the formative assessment process as instructive and educative in that students can still learn from and apply the feedback they receive. In short, "Comments on drafts or on works in progress are likely to be more worthwhile than extensive comments on final work" (p. 123). By offering extensive feedback on student drafts, composition instructors can better use their energies productively.

Likewise, Huot (2002) promoted a heightened awareness of formative assessment practices that emerge in all stages of the writing process. As he stated, much of our assessment should be "open, fluid, tentative and expectant—formative — as we work with a writer toward a potential text" (p. 65). Implied by Huot is the notion that assessment 
works best when there remains potential for improvement, in other words, during the drafting stages. Furthermore, by developing effective formative assessment practices, writing instructors can communicate their values during the writing process rather than as an end judgment in the form of a final grade.

However, perhaps the most important benefit of formative assessment is its potential to respond to students as fellow writers and in so doing, to respond to the students' face needs. When students receive a response to their writing as it develops, it is not only the writing that is responded to; it is the students and their emerging writing identities. A dialogue is initiated through formative assessment that creates space for the writer's growth and simultaneously nurtures the writer's face.

Thus, formative assessment is situated in the pedagogy camp, poised to do some of the work of instruction by offering students a response to their work, a response that not only rearticulates the instructor's values, but also offers suggestions and guidance as to how the student might move toward those values, should she choose to do so. It addresses the student's face needs and fosters her writing identity. In terms of expediency, it seems wise for instructors to expend their energy on formative assessment that helps students grow as writers rather than use feedback to merely justify evaluation.

Teacher response to student writing, then, carries incredible potential in the composition classroom. However, the process of responding to student writing is not free of complications, for responding to students' writing exacts an emotional toll from the teacher as she struggles to find the appropriate response for each student. Each student and each student's composition presents a new, unique, value-laden opportunity for the teacher to help shape a writing identity. However, the teacher also brings a piece of 
herself to this process - her experiences, her knowledge, her likes, and her dislikes. I will explore the complications and struggles of teacher response in chapter four of this study, but for now it is important to note that, like so many other aspects of the composition classroom, teacher response is more complicated than it initially appears to be.

\section{Risky Writing}

Formative assessment, transparency and truth-telling, and audio-recorded response to student writing are all avenues leading to one over-arching goal: to help students grow as writers and to take risks in their writing. When successful, composition classrooms make students feel valued, heard, and safe. When students feel safe in the classroom, they are more likely to take risks, and those risks may yield rich, interesting compositions.

Yet, the way risk-taking is conceptualized in the composition classroom is not the same for everyone. For instance, Berman, in his book Risky writing: Self-disclosure and self-transformation in the classroom (2006), advocated the kind of empathy and selfdisclosure in the classroom that often characterizes psychoanalysis and that yields, at times, writing for therapeutic purposes. This tendency toward personal writing promoted by Berman borders on the type of self-therapy most typically reserved for diaries and is successful only when there exists a close relationship between the students and the instructor.

Burnham (2001), on the other hand, seeks writing that aligns with expressive pedagogy, writing such as "freewriting, journal keeping, reflective writing, and smallgroup dialogic collaborative response to foster a writer's aesthetic, cognitive, and moral development" (in Tate, Rupiper, and Schick, p. 19). Expressive pedagogy places the 
writer and the writer's development at the center of the composing process and values a writer presence in all writing, research or otherwise (p. 19). As Berlin (2003) described it, expressive pedagogy maintains that "truth is conceived as the result of a private vision" that is developed through introspection in writing (in Villanueva, p. 262). This expressive pedagogy approach argues that all good writing is personal and allows each writer to express a unique voice (p. 206). The rub, of course, is that, with the writer located at the center of the composing process, there is a chance that the writer will become isolated, cut off from the composition community, left to her own devices to discover the truth for herself (Berlin, p. 267).

Both of these pedagogical approaches call for a degree of risk-taking on the part of the student as she engages part of herself in the writing process. Identity is at stake, and while there is indeed value in these pedagogical approaches and the compositions they generate, the risky writing I seek in my first year writing course is slightly different. Like the dispositions promoted by Berman and Burnham, I do seek to create environments in which students feel safe taking risks in their writing; however, I do not want students to feel compelled to reveal their personal journeys or feelings through their writing. Nor do I expect students to arrive at a personal composition truth in isolation.

Instead, I strive to create a classroom environment that encourages students to take a different kind of risk, a risk that very well may lead to failure. I hope to challenge students to try something new in their writing that they have not tried before, to experiment, to stretch, to grow. I seek to nudge students toward compositions that represent uncharted territory for them, be that attempting a new genre, writing to a previously unconsidered audience, or grappling with a new style. This type of risk is not 
the same as risk that arises from personal disclosure, but it is still risky writing behavior nonetheless. At stake: success or failure. I will explore some of the ways I attempted to move students toward riskier writing in chapter four of this study.

Moreover, I ask students to redefine themselves as authors, to reconfigure their writing identities, to situate themselves in relation to dominant cultural constructs. As Wallace (2011) noted, college composition courses should be an introduction to authorship, and as such, should help students understand what it means to have a voice in a culture as opposed to merely preparing them to participate in existing discourses of power (p. 229). Therefore, composition courses must allow for the negotiation of identity because "negotiation of identity is critical to authorship" (p. 229). Wallace terms the enactment of this shift in composition goals alternative rhetoric and implores composition instructors to support students as they risk themselves in "moments of unknowingness" and as students take up rhetorical agency to engage the dominant culture rather than uncritically surrender to it (p. 205). This redefining of the writing self necessarily requires a shift in pedagogy, for alternative rhetoric calls for an alternative pedagogy. Unlike some pedagogical approaches that promote "clean" writing unblemished by the author's identity, Wallace advocates writing that "bears some stamp of who we are, writing that understands what the dominant culture expects of it and takes a stand in regard to those expectations" (p. 206). Furthermore, as Berlin aptly stated, "in teaching writing, we are tacitly teaching a version of reality and the student's place and mode of operation in it" (p. 257).

One way that I attempt to support students as they take composition risks thereby developing their writing identities is by asking students to define for themselves the 
writing tasks they will take on during the semester. I will explain the writing process I used in my composition course in more detail in chapter two; however, it is important to note that students proposed their own topics and genres for each piece they wrote in my course. I then responded to their proposals and, when appropriate, attempted to nudge them toward deeper, riskier compositions. I tracked the types of compositions students wrote throughout the semester and encouraged students to write compositions about which they were passionate, but also which were different from the writing they have previously done. I will explore my response to student writing in chapter four of this study, but here I acknowledge that my attempts to help students take risks in their writing had some interesting and unexpected results.

It is safe to say that this stance in which student authors are encouraged to have a personal stake in their own writing and to take on new writing identities naturally leads to the understanding that college composition courses cannot provide all students with a prescribed, uniform set of skills for their future endeavors (Berlin, p. 213). Rather, college composition courses must in part unveil for students existing cultural hegemonies and help student authors situate themselves in relation to those hegemonies. This goal, then, is at the heart of the risky composition I hope to elicit from students enrolled in my composition courses. In short, my personal pedagogical aims include stretching students beyond their existing understanding of composition and themselves as writers. I seek to challenge preconceived notions and taken for granted assumptions. Ultimately, I attempt to support students as they take the risk of thinking differently.

The composition course I will focus on for this study was centered on the topic of homelessness. I will detail many aspects of this course in chapter two of this study, but 
the topic of homelessness was one helpful avenue that generated risk-taking by students. Because many students entered the course with preconceived ideas about homelessness and its causes, they felt relatively confident and comfortable with the content. One of my primary goals of the course, however, was to unseat these preconceived ideas about homelessness and to challenge students in their thinking. I often proposed questions and scenarios during class that unveiled the complications and mitigating factors involved in this societal issue, factors students had not previously considered. By challenging students in the content, I could then challenge them in their writing as they attempted to articulate their new understandings. In a way, the topic of the course highlighted for students that they were nascent learners about homelessness, which in turn highlighted their burgeoning writing identities. When students accepted their novice status, the writing process became riskier for all of them.

\section{Conclusion}

Yancy (in Huot \& O’Neill, 2009) highlighted the role identity plays in the composition classroom as well as the role that assessment plays in shaping student identities. In fact, she posed some crucial questions: "Which self does any writing assessment permit? Which self does an assessment construct?" (p. 132). This notion that assessment and identity are intimately entangled should give every writing instructor pause and encourage every writing instructor to recognize that the assessment work they do carries far more weight than simply a grade on a transcript. I myself have come to realize that writing assessment can only be humane and ethical if it accounts for the fact that, to a greater or lesser degree, students' identities are at stake in the process. Writing instructors are doing identity work with students as they respond their work. 
There have been many calls in the field to align assessment with pedagogy, calls from such researchers as J. Sommers, Yancey, Huot, O’Neill, and Wiggins, to name but a few. This desire to make assessment more pedagogically-bound, more humane, and more personal acknowledges the fact that assessment, especially formative assessment like response to student writing, should be instructive; it should teach.

I might argue, however, that assessment already does teach, whether we realize it or not. Indeed, students learn something about themselves, their place in the academy, and their place in the figured world of the composition classroom through the assessment and response processes instructors employ. When students receive summative grades with no feedback, or when they receive little feedback divorced from the classroom context, they learn something about their position and value in the academy and in the classroom. They realize, ever so gradually, that their voice is not entirely valued. On the other hand, when students receive a human, engaged response to their writing, they learn that theirs is a valued voice in the classroom and potentially in the academy. The way instructors respond to students and their writing teaches student who they are as writers and in so doing, helps shape their writing identities.

Thus, I propose that using teacher response as a pedagogical tool can create a safe writing classroom for students and their emerging writing identities. I regularly ask students to take composition risks that very well may end in failure as they grapple with new content and new writing challenges. But by articulating and communicating my values, using skillfully formative assessment and response, and using my own humanness as manifested in my voice, I might move closer to making my composition classrooms 
the safe writing contexts students — and their emerging identities — not only need, but deserve. 


\title{
CHAPTER II \\ METHODS AND THEORETICAL FRAMEWORKS: \\ THE STRUCTURE OF THIS STUDY
}

\begin{abstract}
Methods
For the purposes of this study, I define methods as the procedures used to conduct research, in this case, qualitative research in a composition classroom. There are myriad methods that facilitate the collection and analysis of data for research, but I will limit my methods framework to self-study. When I began this study, I hoped to use grounded theory to frame my research. Grounded theory, in short, argues in favor of anchoring "theory in social research itself-for generating it from the data" (emphasis added, Glaser \& Strauss, 2012, p. viii). This stands in contrast to other research methods that seek to verify an existing theory or that attempt to develop a theory and then gather data to support that theory. Within the grounded theory framework, the emphasis is on "theory as process; that is, theory as an ever-developing entity, not as a perfected product" (emphasis original, p. 32). However, as I progressed through my research, I drew significantly on existing theories such as politeness theory and communities of practice. Because of the influence of these other theories, I moved away from using grounded theory and instead relied on the self-study method for my data collection and analysis.
\end{abstract}




\section{Self-Study}

Self-study complements grounded theory in that the findings of self-study emerge through the data collection and analysis processes just as they emerge through the use of grounded theory. There are no preconceived notions about the outcomes of the research at the onset; rather the outcomes surface through the research process. Self-study, however, is focused on teachers and their practices in the classroom, so the goal of selfstudy is to inform and thus improve the classroom practices of the teachers.

Self-study is further characterized by a "spiral of questioning, framing, revisiting of data, and reframing of a researcher's interpretations" (Samaras, 2011, p. 11). Thus, self-study, like grounded theory, requires an open stance in which the teacher-researcher considers outside views, fresh possibilities, and a unique application of existing theoretical constructs. In self-study, the teacher-researcher discovers new knowledge through disciplined, systematic inquiry coupled with intentional reflection (p. 14). The self-study process, then, has practical applications to the classroom, whereas grounded theory may or may not be tied to a classroom context.

More specifically, self-study is focused on the unveiling of pedagogical nuances. It holds an “orientation toward one's practice. It is a questioning attitude toward the world, leading to inquiry conducted within a disciplined framework" (Freeman, 1998, p. 8). In fact, it is somewhat organic to the classroom in that, according to Samaras, "Research is what teachers do" (p. 9). Teachers conduct research informally every day in the classroom as they try new strategies and attempt to understand better some aspect of their own unique practice in the classroom (p. 9). 
This inquiry-driven self-study, however, creates a tension. Teachers' actions are informed by what they perceive to be the needs of the classroom, but self-study research requires teachers to question their very actions and the assumptions that underpin those actions (p. 86). This tension between practice and inquiry-into-practice is the foundation of self-study. It is a questioning, critical, self-reflective process that nudges teachers toward growth and a deeper understanding of their actions in the classroom. Self-study allows teachers to turn an inner eye toward their teaching, a process I engaged in and will explore in chapter four of this study.

Self-study, like many other research frameworks, espouses a variety of data collection avenues including journals or diaries, teaching logs, document collection, observation, and stimulated recall, to name a few (pp. 93-94). For my purposes, I will focus on data sets that include student writing (i.e. compositions, Author's Notes, peer review letters), transcriptions of my audio-recorded response files, student responses to a course survey, and anecdotal field notes from class and student conferences. Through this data collection and analysis, I will be positioned to triangulate my data— - to consider "multiple sources of information or points of view on the phenomenon or question" at hand (p. 96).

Furthermore, I will use multiple theoretical perspectives to analyze my data resulting in a theoretical triangulation in addition to data triangulation (p. 97). This theoretical triangulation will make use of the theoretical constructs of communities of practice and linguistic politeness theory in addition to the application of such concepts as identity and face. By applying these theoretical constructs, I will be better positioned to analyze the data and come to conclusions regarding my own practice in the classroom. In 
short, I will engage in self-study as I look for patterns that arise from the data and then contextualize these patterns through existing theories or slices of data with the end result being a better, more nuanced understanding of my own practice.

\section{Theoretical Frameworks}

There are many theoretical frameworks that potentially inform practice in the composition classroom, but for the purposes of this study, I will focus on two: communities of practice (Wenger) and linguistic politeness theory (Brown and Levinson).

\section{Communities of Practice}

Response to student writing has a role to play in fulfilling the pedagogical aims of the classroom, and particular types of response strategies meet these aims more effectively than others as noted in the previous chapter. In fact, the ideal response strategies broker a bridge between assessment practices and classroom environments, with effective response bolstering the classroom environment by making students feel valued, heard, and appropriately challenged.

Wenger (1998) provided some valuable insights into how these figured worlds of the composition classroom evolve and develop. While Wenger's research did not focus exclusively on composition classrooms, there are, nonetheless, some worthwhile applications of his findings. Wenger noted that communities of practice arise frequently within the school setting--on the playground, in the classroom, and, by extension for my own purposes, in the first year college composition classroom (p. 6). The joint enterprise of the community of practice of the classroom entails practices that build coherence and cohesion among students. In particular, Wenger outlined three processes that emerge 
during collaborative, communal learning: evolving forms of mutual engagement; understanding and tuning the enterprise; and developing repertoires, styles, and discourses (p. 95). All three processes have clear connections to composition and the classroom community, but the dual concepts of developing mutual engagement and developing a common discourse are especially pertinent to my research.

One focus of my research has been student peer review, an interesting blending of the response to student writing with the development of a classroom community. Students respond to one another's work, yet, at the same time, ideally take into account the face needs of their classmates. In the best scenario, students mutually engage in the peer review process in order to maintain a fair and equal investment of their time and energies but simultaneously sense and use a common discourse that allows them to politely critique the work of their peers, for to critique a peer's writing devoid of politeness and face sensitivity not only endangers the classroom community, but also reflects poorly on the student creating the critique.

To wit, Wenger reiterated the connection between composition and identity and the need for attending to identity issues during learning activities. As Wenger noted, identity is a "negotiated experience" (p. 149). "In the same way that meaning exists in its negotiation, identity exists—not as an object in and of itself—but in the constant work of negotiating the self" (p. 151). Learning is a transformative experience: it transforms who the learner is as well as what the learner can do and, as such, is "an experience of identity... It is a process of becoming" (p. 215). This process of becoming emerges notably in student writing as students invest a bit of themselves in what they write. Thus, 
during the critique of others' writing, a mutual learning experience, the reviewer must be aware to one degree or another that another author's identity is at play.

This notion that there is an interplay between identity, response, and classroom community necessitates the need for a more thorough examination of classroom dynamics. In fact, examining the social interactions in the classroom-interactions that entail both identity and face — may reveal some important understandings about how composition classroom environments evolve.

\section{Linguistic Politeness Theory}

In an attempt to examine further the social interactions of the classroom, I propose using linguistic politeness theory as one possible lens through which to reveal some of the nuances of these complex interactions.

Most notably developed by Brown and Levinson in 1978 and revised in 1987, linguistic politeness theory, drawing on previous theories of face from Goffman (1967) and politeness maxims from Grice (1975), posits that "patterns of message construction, or 'ways of putting things', or simply language usage, are part of the very stuff that social relationships are made of" (p. 55). Brown and Levinson thus propose linguistic politeness theory as a "tool for describing. . the quality of social relationships" (p. 55).

Thus, politeness is one way to facilitate the development of a learning community. Interactants construct their own messages in such a way so as to contribute to the emerging figured world of the composition classroom, and in doing so, help create stronger bonds that ultimately result in a strong community of practice. In short, politeness is one vehicle used to create a community of practice. 
Brown and Levinson suggested a Model Person (MP) who represents interactants in social situations. This Model Person possesses two properties: rationality and face (p. 58), and provides a reference model "for the description of culture-specific styles of verbal interaction" (p. 59). Rationality, according to Brown and Levinson, is "the availability to our MP of a precisely definable mode of reasoning from ends to means that will achieve those ends" (p. 58). Rationality allows the interactant to "choose means that will satisfy their ends" (p. 59). In the composition classroom, the ideal "end" is a strong classroom community that supports students as they take risks in their writing.

Rationality allows students to choose how they respond to one another to satisfy this end, and it allows me, the instructor to do the same as I attempt to respond to students in a way that supports their composition growth.

Regarding face, Brown and Levinson, as noted in chapter one, construct a more specific notion of face than Goffman — a definition of face that claims that interactants have two particular wants or needs: "the want to be unimpeded and the want to be approved of in certain respects" (p. 58). Brown and Levinson refer to this desire to be unimpeded as negative face. It is the basic claim to "territories, personal preserves, (and) rights to non-distraction" (p. 61). Positive face, on the other hand, represents the desire to be approved of. It is the "positive consistent self-image or 'personality' (crucially including the desire that this self-image be appreciated and approved of) claimed by interactants" (p. 61). Positive and negative face needs are addressed during social interactions as interlocutors respond to what they believe to be the face needs of their fellow interlocutors. 
This notion of face figures prominently in my research. Face is something that can be "lost, maintained, or enhanced" (p. 61) and requires constant attention during interactions; it is ever-present. Therefore, an awareness of the fact that face is at stake during interaction further points to the need to be keenly aware of the social development of the composition classroom if students are to engage in risky compositions. Students, no doubt, would be hesitant to take composition risks if they thought those risks would result in significant damage to their face and their emerging writing identities.

Thus, especially in the composition classroom, there is a mutual vulnerability of face, a vulnerability that arises most frequently during interactions that require a response to others' writing. When students respond to one another's writing, they are also responding to one another's writing identities within the emerging community of practice. The ways in which students respond to one another may contribute to or detract from this community of practice.

Furthermore, during social interactions such as response to others' writing, some actions inevitably threaten the positive and negative face needs of the interlocutorsactions referred to as Face Threatening Acts (FTAs) (p. 60). These FTAs are poised to endanger the social closeness of the classroom environment if they are not mitigated through the use of politeness strategies. Brown and Levinson outline five strategies that interactants may use to mitigate an FTA, strategies that correspond to the perceived degree of intensity of the FTA. Those strategies are:

1. Do the FTA directly (on record) without redressive action (baldly)

2. Do the FTA (on record) but with the redressive action of positive politeness

3. Do the FTA (on record) but with the redressive action of negative politeness 


\section{Do the FTA indirectly (off record)}

\section{Don't do the FTA}

When an interactant makes an FTA on record, it is clear to the hearer what the speaker intends to do or what the speaker needs. For instance, during peer review, the speaker may say, "Read my paper.” This statement leaves nothing open for interpretation; the meaning is clear and unambiguous and as such, it is on record (p. 69) and threatens the negative face of the hearer by making a specific request of the hearer. It is an imposition. These on record FTAs require the speaker to do the FTA with or without redressive action. When making a statement without redressive action (baldly), the statement is made in the most "direct, clear, unambiguous and concise way possible" ( $p$. 69), like the example above. These types of FTAs are typically used when: there is no fear of retribution from the hearer; there is an urgent situation; the FTA demands little from the hearer; or the speaker carries significantly more power than the hearer. For instance, in another example, if a small child is tottering toward a busy street, the parent may shout, "Stop!" This statement leaves no room for interpretation or debate. In this example, there is an urgent situation and the speaker holds considerable power over the hearer.

On the other hand, when an interactant makes a statement that is an FTA off record, there results more than one possible interpretation. These statements include such expressions as irony, metaphor, rhetorical questions, hints, and understatement (p. 69).

For instance, the speaker may say, "Gosh, I'm such an awful writer, and I never know whether my papers sound good." In this instance, the speaker implies that the hearer should help the speaker with the paper but does not explicitly state this desire. The 
speaker is making the statement off record so the meaning is somewhat negotiable and open to interpretation. While the meaning is ambiguous (p. 69), the statement still implies an FTA to the negative face of the hearer in that the speaker is imposing on the hearer by implicitly asking for help on a paper.

I will examine specific examples of the off record comments students made to one another during the peer review process in chapter three, but for now it is important to note that these types of off record comments arise frequently in the peer review process as students attempt to take their classmates' face needs into account during the face threatening peer review process. In fact, these off record FTAs are often a mainstay in a composition classroom as students attempt to negotiate an inherently face threatening act, such as a peer review, while simultaneously uphold the face needs of their peers. I will explore this difficult dilemma in more depth in chapter three.

When making a statement with redressive action, the speaker attempts to "counteract the potential face damage of the FTA by doing it in such a way, or with such modifications or additions, that indicate clearly that no such face threat is intended or desired" (pp. 69-70). These types of FTAs can be mitigated through the use of positive or negative politeness. Positive politeness, as the name indicates, is oriented toward the positive face needs of the hearer and thus "anoints" the positive face of the hearer (p. 70). For instance, returning to a previous example, the speaker might say, "You are such a good writer. Would you mind helping me with my paper?” In this example, the speaker anoints the positive face of the hearer by acknowledging a positive quality that the hearer may claim for him or herself. Thus, the FTA is minimized through the bolstering of the positive face of the hearer; the imposition is further mitigated by phrasing the FTA as a 
question. I will discuss the proliferation of positive politeness strategies students used in my composition course in chapter three.

Negative politeness, on the other hand, is oriented toward the negative face of the hearer and as such is "avoidance-based" (p. 70). Negative politeness often requires the speaker to acknowledge the imposition of the FTA through the use of apologies, selfeffacement, deference, hedges, or implications of non-coercion (p. 70). For instance, the speaker might say, "I know it's a lot to ask and you're terribly busy, but would you mind helping me with my paper?" In this way, the speaker acknowledges the imposition and leaves the hearer with a choice as to whether to help the speaker with the paper.

During the peer review process in my composition classroom, I noticed that students were highly reluctant to impose on their peers by suggesting lengthy, significant revisions to their compositions. I will explore their use of negative politeness in depth in chapter three of this study.

Brown and Levinson offer a formula for computing the weightiness or seriousness of any given FTA, which in turn informs the choice of politeness strategies needed (p. 76). The formula is:

$$
\mathrm{Wx}=\mathrm{D}(\mathrm{S}, \mathrm{H})+\mathrm{P}(\mathrm{H}, \mathrm{S})+\mathrm{Rx}
$$

In this equation, $\mathrm{Wx}$ represents the relative weight or seriousness of the imposition. It is calculated by considering three factors: the social distance between the speaker and hearer, represented by $\mathrm{D}(\mathrm{S}, \mathrm{H})$; the measure of the power that the hearer has over the speaker, represented by $\mathrm{P}(\mathrm{H}, \mathrm{S})$; and the degree to which the FTA is weighted as an imposition within the culture, represented by $\mathrm{Rx}$ (p. 76). 
More specifically, D is a "symmetric social dimension of similarity/difference within which S and $\mathrm{H}$ stand for the purposes of this act" (p. 76). According to Brown and Levinson, the "reflex of social closeness" is predicated upon the giving and receiving of positive face (p. 77). There is, then, a connection between the social closeness of a composition classroom and an emerging community of practice. When students begin to feel social closeness, the community of practice is more likely to flourish. Attention to the social distance between students can yield an indication of the emerging classroom community.

$\mathrm{P}$ is the relative power or the degree to which $\mathrm{H}$ can impose his own wants upon the $\mathrm{S}$ and arises from material or metaphysical control. The resultant politeness strategies used in situations of a wide power differential is typically deferential in nature. For instance, in the figured world of the composition classroom, there exists a significant power differential between the teacher and the students. The teacher, indeed, imposes her wants upon the students to one degree or another. This power differential then creates a disposition of deference from students toward the teacher. However, the power differential between the students is minimal and thus necessitate less deference during interactions.

Finally, R, the relative degree of imposition, is determined culturally and takes into account such factors as expenditures of services or goods (p. 77). In the composition classroom, the imposition is likely the writing itself along with the revision process. When students are asked to revise their work, their negative face is threatened and they are imposed upon. Thus, the relative imposition of the composition classroom reflects the extent of a recommended or required revision or the initial writing task. 
The politeness strategies any interlocutor chooses arise from a confluence of factors. The interlocutors weigh each of the factors present in a social situation and, almost subconsciously and instantaneously, choose the strategies that are appropriate given the unique social circumstance situated in the specific culture or figured world. In the composition classroom, the relative imposition of writing compositions and engaging in the peer review process remains constant for all students. Likewise, the power differential from student to student remains constant as well as does the power differential between teacher and student. However, what does not remain constant in the composition classroom is the social distance. The social distance students feel changes over the course of the semester.

As I will later describe, some students came to my composition class with an existing camaraderie, and this contributed to the ease with which they interacted. Others had no such connection. In this way, the social closeness of students varied within the class at any given moment. Furthermore, students developed a deeper social bond between one another over the course of the semester as they had more opportunities to interact with one another. Therefore, the social distance aspect of Brown and Levinson's weightiness formula will figure significantly in my analysis of the peer review process because the social distance of the class was not constant: it fluctuated.

According to Johnson and Yang (1990), politeness strategies can serve multiple functions in relation to the classroom environment. They not only mitigate FTAs that naturally occur in these environments, but they also "reflect and contribute to the classroom social environment;" they function "to build social solidarity with others and to soften comments that might otherwise be offensive" (p. 99). This description of 
politeness strategy usage echoes Wenger's ideas of mutual engagement and common discourses: as students engage with one another, they develop common discourse patterns that support those engagements and, ideally, protect the face needs of the participants. It is therefore likely that Brown and Levinson's politeness strategies can help create the communities of practice that Wenger describes.

\section{Critiques of Brown and Levinson's Politeness Theory}

I contend that an awareness of face and politeness theory will provide a valuable framework for understanding better my composition classroom as I engage in a self-study of my teaching. However, it is important to note that Brown and Levinson's politeness theory is not without its shortcomings. In fact, Brown and Levinson's politeness theory has not been completely and unilaterally embraced. In the years since Brown and Levinson outlined what they defined in their book title as "universals in language use," many others have denounced the universality of their theory, contending that it is anything but universal. In order to understand more fully linguistic politeness theory and its applicability and limitations, I now explore some critiques of the theory.

To begin, Matsumoto (1988) offered the Japanese language as but one example of the non-universality of Brown and Levinson's definition of face. According to Matsumoto, the notion of face as defined by Brown and Levinson is alien to Japanese (p. 404). "In a cultural tradition such as the Japanese, a person's main concern is not to claim and preserve his/her own territory. . . but rather, to become and remain accepted by other members of the group" (p. 407). Thus, Brown and Levinson's definition of face as consisting of the desire for approval of wants and the desire for preservation of one's territory does not take into account the Japanese recognition of one's place within the 
hierarchical social structure (p. 407). Brown and Levinson's definition of politeness is posited upon an individualistic or horizontal society wherein an individual's rights and needs often supersede those of the group; it "presupposes that the basic unit of society is the individual” (p. 405). In light of the hierarchical structure of Japanese culture, Matsumoto argued that such an individualistic conception of face cannot be considered universal across cultures and languages (p. 407).

Matsumoto took further issue with Brown and Levinson's politeness theory by complicating their distinct division between positive and negative face, again claiming this delineation as a Western construct and not universal across cultures. Citing a common Japanese expression translated roughly as "I ask that you please take care of me/treat me well," Matsumoto noted that some Japanese expressions blur the delineation between positive and negative face (p. 409). In Japanese society, the "acknowledgement of interdependence is encouraged. . . it is an honor to be asked to take care of someone in that it indicates that one is regarded as holding a higher position in the society" (p. 410). Whereas Brown and Levinson would claim this expression is an indication of negative politeness addressed to the negative face of the hearer, Matsumoto countered that the expression is oriented toward both the positive and negative face of the hearer simultaneously in that it is a request, but also a compliment at the same time. The expression acknowledges the positive face of the hearer by indicating that the hearer is capable of caring for the speaker, presumably because the hearer is higher in the social hierarchy. According to Matsumoto, Brown and Levinson's definitions of positive and negative face as distinctive concepts is problematic when applied cross-culturally and, as 
a result, Matsumoto claimed that Brown and Levinson's theory of politeness is not universal.

Mao (1994) added his voice to the chorus of dissenters regarding the universality of Brown and Levinson's theory of politeness. Proposing a more flexible point of view regarding politeness, Mao used Brown and Levinson's theory as a point of departure and, like Matsumoto, complicated the idea of positive and negative face. Mao situated his critique in the interactional nature of the construction of face. Mao also recognized the social structure of some Eastern cultures as hierarchical in nature and offered the dual Chinese concepts of mianzi and lian as the origin of the notion of face, with mianzi referring to one's social standing within a group and lian referring to one's accomplishments (p. 454). However, both mianzi and lian are "intimately linked to the views of the community and to the community's judgement (sic) and perception of the individual's character and behavior" (p. 460). In this way, face arises in relation to the larger society rather than as an individualistic endeavor or need. Thus, Mao adapted Brown and Levinson's theory by proposing the concept of Relative Face Orientation (RFO) to acknowledge the way one's face is recognized in interaction with and in relation to the larger society rather than as an individual. Furthermore, Mao contended that, in Chinese, face and politeness go hand in hand, whereas Brown and Levinson asserted that politeness strategies are means of upholding face.

A third significant critique of Brown and Levinson comes from Ide (1989) who likewise problematized Brown and Levinson's conception of face, particularly positive face and positive politeness. Ide proposed that the use of honorifics in some languages represents socio-pragmatically obligatory language that reflects lexically one's social 
standing (p. 227). Brown and Levinson's neglect of these aspects of politeness indicate that their theory is inadequate, according to Ide. To counter Brown and Levinson, Ide offered her own definition of politeness:

(T)he language usage associated with smooth communication, realized 1) through the speaker's use of intentional strategies to allow his or her message to be received favorably by the addressee, and 2) through the speaker's choice of expressions to conform to the expected and/or prescribed norms of speech appropriate to the contextual situation in individual speech communities. (p. 225) Ide's definition of politeness resonates with the ideal composition classroom in that students typically want their messages or classroom contributions to be received favorably by others in the class. Furthermore, Ide's definition upholds a community of practice in that the community members adopt mutual discourses that are satisfying and mutually beneficial to all members.

Additionally, according to Ide, in Japanese, speakers use honorifics to acknowledge the existing social standing of the interlocutors, and the use of honorifics in Eastern cultures is more a function of discernment - the ability to evaluate a social situation and use the correct honorific to acknowledge the other person's social standing in relation to the speaker's. Discernment, according to Ide, is not a choice but more a matter of social obligation. In this way, Ide situated politeness strategies squarely within the realm of the culture. Positive politeness in particular is less a strategy than a necessary component of the essence of communication in Japanese. 
However, Green (2002) countered this notion that politeness strategies are culturally bound. Instead, she called such notions "gross exaggerations which yield no benefit either to linguistic research or to intercultural understanding” (Unpublished manuscript, p. 3, used with permission). Instead, Green offered the idea of considerateness, which she defined as "behavior intended to make another person feel good, or avoid feeling bad, by respecting their autonomy and honoring their values" ( $\mathrm{p}$. 6). Considerateness, according to Green, is applicable to all cultures-Japanese, American, or any other. What changes, however, is how a culture or subculture ranks any given imposition. As social power and distance change, so, too, does the relative imposition of any given act. Green contended that there is little use for arbitrary strategies or definitions of face. Instead, the degree of imposition informs how considerateness is used in any interaction (p. 18).

This notion that strategy use does not follow a formula based on a particular culture will be useful to me as I explore in chapter three what I will call a politeness profile that emerged in my composition classroom.

Each of the preceding theorists--Matsumoto, Mao, and Ide- -highlighted the ways in which Brown and Levinson failed to account for cultural differences in their "universal" theory of linguistic politeness. However, other critiques of Brown and Levinson problematize their theory due to its failure to address some of the nuances polite behavior.

Meier (1995), in her critique of Brown and Levinson, offered a broad redefinition of politeness in which she noted that politeness is contingent upon context. She stated, “politeness can only be judged relative to a particular context and a particular addressee's 
expectations and concomitant interpretation" (p. 387). She then offered a more broad definition of politeness she termed Repair Work. The function of Repair Work is to "remedy any damage incurred to an 'actor's' image upon the establishment of a responsibility link between an actor and behavior which fell below the standard expected relative to a particular reference group" (p. 388). In other words, Repair Work is geared toward saving the self-image or face of the interactant. Meier then offered the concept of appropriateness as an alternative to politeness, a proposal that might, in fact, complement Brown and Levinson's contention that rationality underpins politeness, although admittedly, Meier did not set out to support Brown and Levinson. According to Meier, politeness must be predicated upon appropriateness, a notion that seems to align nicely with Brown and Levinson's use of rationality. Appropriateness can only be discerned through rationality, and rationality necessitates appropriateness. The two concepts are complementary.

In the end, Meier claimed that politeness is universal only in that "every society has some sort of norms for appropriate behavior, although these norms will vary" (p. 388). And the politeness strategies interactants choose must be informed by appropriateness and rationality.

This notion of contextually situated, appropriate linguistic behavior nicely complements the idea that composition classrooms are figured worlds. Figured worlds, as noted in chapter one, are socially and culturally constructed and are predicated upon contextually appropriate actions (Holland, Skinner, Lachicotte, and Cain, 1998, p. 52). Language is one avenue through which these figured worlds emerge, and these figured worlds rely upon the appropriate linguistic behavior of all participants to function well. 
Locher and Watts (2005) and Locher (2006) do not dismiss Brown and Levinson's theory outright but rather promote a more comprehensive, nuanced theory. Noting that Brown and Levinson's theory is concerned almost exclusively with the mitigation of FTAs, they posited that a theory of politeness must additionally consider the role of relational work, "the 'work' individuals invest in negotiating relationships with others" (p. 10). The relational work discussed by Locher and Watts is not always oriented to the "maintenance of harmony, cooperation, and social equilibrium" (p. 11) or the mitigation of FTAs. Rather, relational work also encompasses contentious situations or arguments. Therefore, "relational work comprises the entire continuum of verbal behavior from direct, impolite, rude or aggressive interaction through to polite interaction, encompassing both appropriate and inappropriate forms of social behavior" (p. 11). Locher further contended that some relational work is neither polite nor impolite but rather appropriate or politic, a term used by Watts (2003) (p. 255). Politic behavior "indexes a wide variety of forms of social behavior that include both non-polite and polite behavior" (p. 256). By including more nuances of interpersonal behavior, then, Locher and Watts expanded Brown and Levinson's theory to encompass "all forms of verbal interaction" (p. 29).

Moreover, they included "the discursive struggle over what is deemed by individuals to be polite" in their definition of relational work, and, like Meier, added that individuals must evaluate utterances based on their previous experiences and interactions. For instance, as Locher (2006) noted, "a speaker may very well aim at using politeness strategies, but there is no guarantee that the recipient will recognize this intention and interpret the level of relational work in the same way" (p. 253). According to Locher 
(2006), impoliteness relies on the interactants' gauging of what is appropriate based on previous interactions (pp. 250-251). Politeness arises through individual judgments predicated upon prior experience. Politeness, then, is necessarily unique to each situation rather than formulaic, pre-determined, or limited to a certain number of finite strategies. This conception of politeness echoes Green's definition as emerging not as a result of culturally necessary utterances but rather as a function of such factors as social distance and power differentials.

Spencer-Oatey (2005a) seemed to agree with Meier, Locher, and Watts in a broad sense stating that politeness "is associated in some way with harmonious/conflictual interpersonal relations" (p. 95). Spencer-Oatey, however, took into account the whole range of verbal behavior and arrived at what she termed rapport management (p. 95). She was interested in how interactants perceive politeness and subsequently judge the use of politeness by others (2005b, p. 336). Effective rapport management is contingent upon a mutual sensitivity between interlocutors and on balancing fairly the needs of the interlocutors (p. 338). This balancing of the needs is reminiscent of Wenger's notion of mutual engagement.

Additionally, Spencer-Oatey's rapport management included "not only behavior that enhances or maintains smooth relations, but any kind of behavior that has an impact on rapport, whether positive, negative, or neutral" (2005a, p. 96). Whereas Locher and Watts mentioned positive and negative goals of communication, Spencer-Oatey added a new dimension: neutrality. Spencer-Oatey claimed that interactants can have a neutral impact on the relationship that develops through interaction. According to SpencerOatey, "As people interact with each other, they make dynamic judgments as to whether 
their rapport has been enhanced, maintained or damaged" (p. 96). These "dynamic judgments" arise through the strategic consideration of transactional goals, those goals geared toward achieving a specific task, or relational goals, those goals geared toward nurturing relationships (2005a, p. 107). Of special interest to me in my self-study is the idea of nurturing relationships—-student-to-student relationships, and student-to-teacher relationships. I will explore how the social relationships in the classroom-relationships that arise in part through response to others' writing — created environments that nurtured composition risk-taking.

\section{Does Universality Matter?}

Clearly, each of these critiques of the universality of Brown and Levinson's politeness theory is valid; the theory is not universal, and Brown and Levinson agree. In fact, Brown and Levinson (1987) acknowledge that their strategies "were never intended as an exhaustive taxonomy of utterance styles, but rather as an open-ended set of procedures for message construction" (p. 21).

What underpins each of the previous critiques, however, is the notion that language and its uses, including politeness, impoliteness, non-politeness and the whole gamut of relational and repair work, are outcomes of the figured worlds in which they arise. The discourse of any given social situation emerges from that context and reflects the values of the participants - whether the participants value the individual, the individual's place relative to others, or some other relational consideration. To dismiss Brown and Levinson's politeness theory outright because it is not universal seems unnecessary and unwarranted, for the theory is flexible enough to be useful in a varietyif not all—contexts, as Green points out. 
In fact, I would argue that all politeness, indeed, all interaction, is contextually bound and that particular contexts generate what I have termed their own unique politeness profile that fits the specific needs and goals of that context. Just as language is contextually bound, so, too, is politeness. The ways in which politeness strategies are applied is contingent upon the speakers, hearers, and needs of the social context.

In light of this, it appears that one possible way to conceptualize politeness is to think of it not as an ironclad theory developed by one or two theorists, but rather as a collection of potentialities that yield a contextual, unique politeness profile appropriately suited to a given situation or figured world. The interlocutors collectively if unconsciously select the politeness strategies that best serve the unique needs of the context and their fellow interlocutors. In some contexts, more of one type of strategy is required; in others, less. As many have already maintained, no individual expression is inherently polite or impolite (Culpeper, Fraser and Nolan, 1981; Holmes 1995; Watts, 2003) (Spencer-Oatey p. 98). Rather, perceived politeness is predicated and contingent upon individual contexts and the interpretation of the interlocutors.

This contention then leads to one of my research goals: to illuminate the selfgenerated politeness norms of my composition classroom and then allow those norms to define the unique politeness profile that emerged in that context. By exploring the politeness profiles of my composition classroom, I move closer to determining the strategies students used to create a unique community of practice that supported the risky compositions students wrote during the course. I maintain that Brown and Levinson's politeness theory, as well as its numerous critiques and iterations, will be a useful starting 
point in understanding my composition classroom, my response to student writing, and the ways in which I used response to encourage students to take composition risks. In addition to exploring my response to students and their writing, I intend to examine how students responded to one another and their writing, for indeed, there is perhaps no classroom endeavor so heavily imbued with the potential for face threats as the peer review session or the more formal peer review letter. Therefore, the need for the skilled use of politeness strategies is crucial if the peer review assignment is to uphold the emerging social closeness of the classroom. Brown and Levinson offer a useful framework for understanding the mutual discourse that characterized my composition classroom environment.

Thus, I intend to use Brown and Levinson's politeness theory as a loose framework to illuminate the strategies students and I used as we attempted to create a cohesive community of practice. However, no one specific framework will shape my interpretation but rather each will serve as one slice of data for analysis. In order to keep my theory grounded, I will consider all applicable theories and data sets.

Through this data analysis, I will attempt to make the case that, in order for students to feel safe taking composition risks, they should have a safe classroom community, and politeness strategies help to create those kinds of safe communities. In the end, I hope to suggest a politeness profile that the community of practice generated based upon the unique needs of the community and the prior experiences each participant had negotiating politely these types of learning communities. Finally, I contend that all instructors would benefit from a careful examination of their own response practices to determine whether the strategies they use uphold the cohesive environment they may be 
attempting to foster and to consider how an awareness of politeness theory might lend itself well to this very endeavor.

The Site and Context of this Study

I will base my research on data I gathered while completing a teaching internship in the fall of 2012 at Midwest Liberal Arts University, heretofore referred to as MLAU. Through the Institutional Review Board protocols and processes at both Illinois State University and MLAU, I sought and received permission to use student work from twelve of the thirteen students enrolled in the course. For all citations from students, I will use pseudonyms to protect their identities.

\section{Writing Processes}

Composition courses at the university where I conducted my research are centered on a particular theme or topic, and the topic of my course was homelessness. The course, a writing intensive course, served not only to help students improve their academic writing, but also to give students an entry into the kinds of academic conversations that will characterize the rest of their college career and ideally their lives beyond the university.

The content for the composition course included a series of books about homelessness including a micro-ethnography, an autobiography, and one book about homelessness that students chose from a list I provided them. Additionally we watched a variety of documentary films that focused on topics such as the Mole People living in abandoned subway tunnels in New York City, mentally ill prison inmates who were released after completing their sentences, and near-homeless children from working poor families in California. 
MLAU requires students to write at least twenty-five pages of formal and informal text during their first year writing course. However, the university does not define nor dictate how the writing process should unfold. Indeed, there are many writing processes instructors may espouse for any number of reasons. Therefore, MLAU grants each instructor the freedom to design the course writing tasks as he or she sees fit. For my particular course, I designed the writing process below:

- A proposal: All students submitted a proposal for each composition they hoped to write. In the proposal, the students identified their intended audience, purpose, genre, possible resources, and approximate length of the proposed piece. Students submitted this proposal as well as all assignments through a university online course webpage.

- Audio-recorded feedback: I responded to each proposal with a brief, three to five minute audio-recorded response in which I offered suggestions for narrowing or widening the focus, gave ideas of resources students might consult, and encouraged students to consider a variety of venues, genres, and modes for their piece.

- First Draft: Students submitted the first draft of their piece after considering the feedback offered on their proposal. Included with each composition was an Author's Note in which the students detailed the process of writing up to that point, struggles they had encountered, and direction for the type of feedback they desired. 
- Audio-recorded response, textual response, and peer review: For the first draft, I offered significant feedback usually totaling approximately ten to fifteen minutes of audio-recorded comments. I responded to what, in my eyes, worked well with the piece, what seemed weak or incomplete, and where the student writer might take the piece in the next revision. I included brief textual comments as well using the Track Changes feature in Word to indicate in the draft itself surface feature errors or to make additional suggestions. Thus, students received both audio and textual feedback on all drafts. Additionally, I implemented a peer review process for the second and third compositions of the semester. I placed students in groups of three to four students and asked them to have someone other than the author read their piece aloud to the rest of the group. The peer review group then offered some initial verbal responses to the piece. After class, the members of the peer review group were required to write a one-page letter to the author of the piece in which they detailed more extensively their feedback ${ }^{3}$. This peer review letter was then emailed to the author within forty-eight hours of the in-class peer review.

- Revision: Students selected the feedback they found most helpful and revised their initial draft accordingly.

- Final Draft: Students submitted their revised draft for my response and evaluation. At this stage, prior to responding to the piece, I re-visited the feedback I previously offered on the draft, and I re-read the peer review letters pertaining to the piece. I attempted to ensure that I did not contradict my previous feedback and that I took into account the peer feedback.

\footnotetext{
${ }^{3}$ I have included a more detailed description of the peer review assignment in chapter three.
} 
- Audio-recorded feedback with an assessment: I once again composed audiofeedback and textual feedback on the piece and then offered an evaluation. Borrowing from David Wallace (2011), I ranked each piece as Continue Revising, Satisfactory, or Outstanding (p. 237). I made it clear in my feedback that the rating was preliminary in that students were always welcome to revise their final draft for a possibly higher rating.

- Subsequent Drafts (optional): Often, students did choose to revise their final drafts for re-evaluation. My policy was that if the revised piece was, for some reason, not as strong as the initial effort, the higher rating would remain. Therefore, I never penalized students for revisions and recorded only the highest rating to calculate the final grade for the course.

Clearly, the writing, response, and revision process for the course was rather involved and consumed considerable time on my part as well as the students' part. However, I looked at the time spent recording the audio-recorded feedback as instructional time. I intended my feedback to build upon concepts discussed in class and to tailor feedback to address concepts that pertained only to the recipient of the feedback. J. Sommers (2013), a proponent of audio-recorded feedback, analyzed the types of feedback he offered during one course and concluded that his comments fell into one of three categories: retrospective comments, in which previous classroom discussions were addressed; synchronous comments, in which the instructor shared reactions in-time; and anticipatory, which offered feedback regarding future writing. My feedback likewise included these categories, but it was the retrospective comments that allowed me to 
reiterate class discussions and thus use the feedback most effectively as an instructional tool. Additionally, my anticipatory comments allowed me to help guide students toward further growth, also an instructional move.

During class instruction, I spent time discussing rhetorical concepts with students and encouraging them to practice rhetorical awareness in their reading of course content, viewing of course films, and subsequent writing. Because students had little background in rhetoric, they at first struggled to apply rhetorical concepts such as audience awareness, enthymemes, ethos, pathos, and logos. They had little if any background in these basic rhetorical tenets, so I spent time building this foundation so that we could use them as points of departure in class discussion and composition. Furthermore, few students had anything more than a cursory understanding of homelessness and its causes, implications, and realities. Because the content of the course, both writing expectations and the topic of homelessness, was relatively new to students, the course represented a rich learning opportunity for students. Asking students to engage in so much cognitive stretching was taxing for them; my audio-recorded feedback was intended as a safeguard for students, offering encouragement, redirection, and appreciation for the work they were doing. It was, in short, my pedagogical attempt to support them as they took the risks I encouraged them to take.

\section{Student Characteristics}

There were a number of unique characteristics of this particular group of students that warrant mention. First, of the thirteen students ( 6 men and 7 women), five men were part of the same athletic team and as such had arrived on campus a week before classes began to take part in pre-season practice. These student-athletes had the opportunity to 
form a type of in-group within the larger group and had already begun to share some ingroup characteristics such as inside jokes and friendly teasing. Additionally, the entire class spent the first three days on campus traveling as a cohort from one orientation activity to the next, so by the time I met them, they were at least familiar with one another if not somewhat pre-bonded and cohesive as a group. Furthermore, these students were also my first year advisees, so I spent considerable time with them-one-on-one and as a group - helping them navigate the course selection process and acclimate themselves to campus living. Finally, the students who typically enroll at MLAU come from middle to upper-middle class families and have a history of academic success. All these factors contributed to the unique environment of this particular figured world of the composition classroom and what transpired over the course of the semester.

\section{Conclusion}

Each composition classroom is a unique entity, an assembly of individuals situated within a particular academic context, at a specific time, and for a common articulated purpose. My composition classroom was no exception. The unique combination of students - their talents, experiences, and goals - created a learning experience that cannot be replicated. Yet, there are characteristics of my composition classroom experience that may be applicable to other educational contexts. My goal in completing this self-study is to study my own practices in my composition classroom and to learn from those experiences how to be a better composition instructor- to unveil nuances in the composition classroom that might otherwise go unnoticed. However, my research may have a longer trajectory. Ideally, this research could benefit other composition instructors who struggle to engage students in risky writing, for some 
lessons that I learn about my own practice may prove helpful to others as we all seek the common goal of creating adept, engaged writers. 


\title{
CHAPTER III \\ PEER REVIEW AND POLITENESS STRATEGIES
}

\author{
Students as Novices
}

A crucial step toward first year composition students engaging in the risky rhetoric I seek is students' acknowledgment of their novice status in the university. As N. Sommers and Saltz (2012) note, students arrive on college campuses and encounter a new setting, a setting with presumably higher expectations from those of high school. They shift from being the most experienced students in the school to the least. In essence, they must "leave something behind and. . locate themselves in the realms of uncertainty and ambiguity" (p. 125). Fortunately, according to N. Sommers and Saltz, this new standing as novices actually positions students to be more successful in university academics as they pertain to writing: "freshmen who see themselves as novices are most capable of learning new skills," while those who eschew their novice standing often over-rely on their past writing experiences and simply replicate the writing they did in high school (p. 127). "Those freshmen who cling to their old habits and formulas and who resent the uncertainty and humility of being a novice have a more difficult time adjusting to the demands of college writing" (p. 134).

Therefore, when students willingly embrace their novice status, they are changed by what they learn, have new ideas, and understand that others are interested in reading. 
about these new ideas. Students are positioned better to take risks when they know that instructors and their peers embrace this kind of risk-taking and are willing to invest in trusting, safe classroom environments that generate such kinds of writing.

Of course, novice students require ongoing opportunities for growth, and feedback can help foster this type of growth. Without significant feedback regarding their writing, few students will make progress or grow as authors. While in the perfect world, every instructor would offer every student extensive, guiding feedback on each of their writing pieces, the reality is that time does not allow for this level of guidance. And, quite frankly, an instructor offering too much feedback to students can potentially create a type of composition learned helplessness in that the overuse of feedback can teach students that they are incapable of assessing their own writing and thinking critically about their own ideas. Thus, striking the right balance between too much or too little feedback is a delicate task.

\section{Peer Review: A Brief Overview}

Many instructors turn to peer review as one way to give students more feedback than they are capable of generating themselves and as an avenue for involving students in the response process. Originating both inside the academy in the form of literary societies and outside the academy in the form of self-improvement groups, the peer review process has been a mainstay of composition classrooms for over fifty years (Ching, 2007, p. 304). As Ching points out, one benefit of the peer review process is that it minimizes the "binary distinction between teacher authority and student autonomy . . . and reconfigures the participation of students and teachers in the practices of the writing classroom" (p. 314). By asking students to participate in the feedback process, the classroom 
environment can become more community oriented, a kind of "apprenticeship in which students participate alongside teachers" (p. 314). Furthermore, peer review allows students to "take an active role in evaluating the work of other students" rather than remaining passive recipients of teacher commentary (p. 314). Indeed, there are a number of potential benefits to the peer review process, but not everyone conceptualizes the peer review process in the same way.

What is accomplished during peer review depends largely on the goals the instructor holds for the process. In some instances, instructors hope to encourage students to think critically about their peers' writing and to offer feedback that reflects this critical thinking. Flores (2004), for instance, promotes what she calls a detached intellectualized space in the classroom in order to foster critical thinking about peers' writing devoid of emotional reactions. This goal of detached critical thinking creates interactions in which students do not praise the writing of their peers but rather "enter a dialogical exchange of argument with their own writing and that of their colleagues" (p. 267). The goal of this type of peer review is not to build classroom community but rather to support students as they engage in critical evaluation and response. In fact, Flores describes personal opinions about a peer's work as "manacles" that thwart the peer review process.

However, there is a downfall to this approach, as Jesnek (2011) points out: "When peer editors use little tact in relaying their comments and criticisms, writers often become unreceptive to the peer editing process altogether" (p. 23). While it is certainly possible to offer criticism borne of critical thinking in a kind, compassionate way, it is nonetheless more difficult to negotiate this balance. The struggle to offer kind critique is a struggle that is often unsatisfactorily resolved for many students who remain novices at this 
practice. Offering feedback without tact can shut down the writing process, and this outcome runs counter to my goal of increased student engagement.

\section{Goals and Benefits of Peer Review}

Promoting critical thinking is not always the goal of the peer review process; many composition instructors have different goals in mind. As Flynn (2008) notes, peer review has the potential to accomplish three different but related goals. It can: 1) engage students in the writing and revision process; 2) increase students' awareness of audience, drawing attention to the collaborative nature of writing and communication; and, 3) hone students' critical skills by enabling them to see what makes writing more or less effective (p. 65). These goals more closely align with my goals for my composition classroom than do the critical thinking goals described by Flores. I am interested in using the peer review process to help students improve their writing while simultaneously facilitating connections between peers. These peer connections can then lead to a more cohesive classroom environment, and when students begin to trust their peers through the peer review process, they may become more willing to take composition risks. Therefore, I encourage students to share their personal responses—intellectual as well as affectivethrough the peer review process.

While the peer review process is intended primarily to help the student whose composition is being reviewed, there are considerable benefits for the student who is conducting the peer review. For one, the peer reviewer learns to make evaluative and reflective comments on another's work (Cho \& Cho, 2009, p. 630). This type of critical thinking about another's work might transfer into thinking critically about the reviewer's own writing as well. In this way, students may arrive at the same critical thinking goal 
that Flores describes, but do so in a different way. As Cho and Cho contend, "Reviewers learn by explaining what makes peer texts good or bad, by identifying problems that exist in those peer texts, and then in devising ways in which those problems can be solved" ( $\mathrm{p}$. $630)$.

This type of learning is especially prevalent when peer reviewers offer feedback that focuses on the meaning of the text rather than the surface features such as spelling, punctuation, and grammar. When students attend to the meaning level of their peer's writing, it becomes more likely that they will likewise attend to the meaning level of their own writing. In fact, it is possible that students gain more from the process of reviewing their peer's work than by having their work reviewed (p. 640); it may be better to give comments than to receive them.

Furthermore, by encouraging students to review one another's work, the peer review process can serve instructional purposes. As students compare their own work to that of their peers, they become more aware of their own writing tendencies and habits. This process thus gives them a window into the areas of improvement in their own writing (Stellmack, Keenan, Sandidge, Sippl, Konheim-Kalkstein, 2012, p. 236).

Increased audience awareness is another benefit of the peer review process. Too often, students write to an undefined audience. They write into a vacuum, or in many instances, solely to the instructor. It is difficult to move novice writers into the realm of writing to real audiences, but the peer review process may provide one avenue for this shift. When students write with the awareness that one of their peers will be reading and commenting on their work, they begin to write differently. They start to imagine how others will view their writing. They begin to move out of their own realm and consider 
others' responses. As Cho and Cho state, "by reviewing peer drafts, student reviewers can develop a more accurate understanding of their readers" (Cho \& Cho, p. 631). Novice students may not have the ability to view their writing from a disembodied viewpoint, but the peer review process can facilitate this important shift by providing a much-needed alternative perspective (p. 631).

Of course, for the peer review process to be effective, students need some training and instruction. There is no lack of ideas for this training in the research perhaps because the type of peer review training an instructor chooses is highly contingent on the instructor's goals and aims as previously noted. However, one aspect that is especially important is to help students focus on the meaning level of the composition rather than the surface features. While some students are well-equipped to provide guidance on their peers' spelling, punctuation, and grammar, there are many who struggle with these aspects in their own writing. An all-too-common scenario is the one in which peers offer incorrect surface feature feedback to their peers, especially when the peer receiving that feedback is not willing to reject that feedback.

However, for many students, surface feature feedback may feel safer because identity is less at stake in this area than when students provide feedback about one of their peers' ideas. Surface feature feedback is low-stakes; but feedback focused on someone's ideas is high-stakes. Therefore, if instructors want students to engage in critical thinking and offer high-stakes feedback on the ideas of a given composition, it becomes even more important that students be well prepared for this approach. According to Flynn, students benefit from instruction in offering "descriptive not evaluative comments. In other words, they should avoid evaluating writing as 'good' or 
'great!' Instead, they should make specific, precise comments about what they observe or experience as readers" (p. 67).

Furthermore, Flynn offers that an instructor's transparency in assessment helps students move from surface feature feedback into more substantial commentary. By weighting content more heavily than surface features during assessment, instructors help students know where to focus their energies during their own writing as well as during peer review. One possible way of helping students focus on the meaning level of their own and their peers' work is to offer no point value for surface features in compositions. This is a strategy I have used with some success for a number of years in writing intensive courses. In my assessments, all value of a composition rides on the content and the content alone. Students can lose points for poor surface features, but they certainly do not earn points for this aspect of the composition. In other words, I only negatively assess surface features when those surface features interfere with the meaning of the piece. I deduct points from the final grade to reflect this lapse. As I explain to students, I assume that they will attend carefully to the surface features of their compositions in the interest of clarity, so there is no reason for me to allocate points for this aspect of their writing. Careful attention to surface features is a given; it is a courtesy to the reader. This shift in quantitative values helps students keep the importance of surface features in perspective and encourages them to focus on a deeper level of writing. I do give feedback and instruction on the surface features of students' writing because I want them to learn these mechanical aspects of composition and how surface features support the meaning of the text, but I make it clear to students that I am far more interested in their ideas. 
In spite of the call for specific training in peer review, I must acknowledge that this remains an area of growth for me. I do provide some training and instruction regarding peer review in class, but I rely heavily on my own feedback as a model for students to follow. I also offer an assignment description that outlines the process of peer review. I have included the entirety of the Peer Review Assignment Description below to illustrate both how I attempt to prepare students for this process as well as an indication of the growth I hope to have in this area. To wit, in the assignment description, I encourage students to comment on the surface features regarding how well the surface features support the composition (see second bullet point), but I may eliminate this recommendation so as to keep the focus on the content and meaning of the piece. My Peer Review Assignment Description reads:

\section{Peer Review Assignment Description}

During the semester, you will read and respond in writing to four of your classmates' Composition Pieces. The usefulness of this peer review process rests upon how well you and your peers are prepared to respond honestly and effectively to others' writing. Therefore, I offer these guidelines:

- One of the worst things you can do when offering feedback is to make blanket statements like, "It was good," or "I found this interesting." These types of responses, while perhaps reassuring, fall far short of being useful to the author. You are welcome to offer encouraging words to your classmates, but you must go much further if your feedback is to be effective. 
- Notice the surface features like punctuation and spelling. Do the surface features interfere with your understanding of the piece? Do you notice any errors that diminish the credibility of the author? Remember, making spelling or punctuation errors is not a moral failing; it reflects merely a lack of information that can be easily and kindly rectified.

- Note the way the author has chosen or organize his or her thoughts and ideas. Does the piece hold together cohesively or does it seem disjointed? If it seems disjointed, where does it fall apart for you? Where did you get lost? Transitions play a crucial role in revealing an author's thought process. How well does the author use transitions?

- Consider the argument that the author is presenting. Is there evidence of logical, careful thinking? If not, what seems to be missing?

- Think about the resources that the author brings to the piece. Are the resources appropriate, relevant, and credible? If not, what is missing? What suggestions would you make? Does the author incorporate the resources in a way that strengthens the piece?

- Consider the purpose, genre, and intended audience of the piece. Would this piece be effective in accomplishing its purpose?

An excellent way to offer feedback is to ask questions. Consider including questions in your feedback like: "What did you mean when you wrote. . .?" or "Can you make more clear to me?" or "Would it help if you were to. . .?" By asking questions, you allow the author to consider your feedback without forcing that feedback 
upon him or her. It is also helpful to paraphrase what you think the author is trying to do at various points in the piece. This helps demonstrate to the author how the reader is understanding the piece.

While there are many other types of responses you may offer, the above list covers a range of possibilities that may yield helpful feedback to the author. You will compose your response to your peer's composition in one of two ways: through a written letter (approximately one to two pages in length) or through an audio-recording using a program such as Audacity. You will email a copy of your response to your peer and to me within forty-eight hours of reading the piece.

\section{Peer Review and Risky Writing}

As noted, using the peer review process can hold any number of advantages in the composition classroom. It can give students a new understanding of audience, help them strengthen their own writing, and engage them in critical thinking about their own and others' writing. However, one of the most beneficial aspects of the peer review process I have witnessed is the ability of peer review to expose students to new ideas for future, perhaps riskier, compositions. A number of years ago, I abandoned the idea of having all students write the same genre and type of papers. Quite frankly, I grew tired of reading an entire batch of, say, persuasive essays. Certainly reading a class set of similar papers made assessment easier - I could, with little difficulty, compare the work of one student to another and know quite quickly how that student should be assessed. There was a comfortable standardization that took out much of the guesswork of assessment and feedback. However, writing in the real world is not nearly so constrained and prescribed. 
Rarely is a collective group of people expected to write the same type of paper about the same topic at the same time. Writing is far more rich, far more textured than that.

Therefore, I changed my approach to student compositions and, as previously noted, threw off the constraints of prescribed writing and asked the students to define their own writing tasks. As outlined in chapter two, I required students to send me a proposal for each composition they wrote. They chose the topic, genre, mode, lengtheverything about the composition except the broad topic of homelessness. I audio recorded feedback on the proposal offering students suggestions, resources, and encouragement. Then, students set about composing.

The resultant compositions were wide and varied, a virtual cornucopia of ideas. Among the topics students chose were:

- Why people "choose" homelessness, or if they really do

- College students' preconceived ideas about homelessness

- Schizophrenia and its connection to homelessness

- Types of assistance available to the homeless

- The omission of homeless women, specifically homeless mothers, from most texts about homelessness

- Individual encounters with homeless people

- Rural homelessness

- The potentially negative effects of homeless shelters

- The effects of homelessness on children

- The cycle of foster care and homelessness 
And those were just some of the topics from the first set of compositions. Other composition topics students pursued later in the semester included:

- How homelessness is portrayed in movies

- Homeless legislation

- The history of homelessness

- Multiple causes of homelessness

- Famous people who were once homeless

- Homeless veterans

- Teenage runaways

- Homelessness as a result of natural disasters

- Educational implications of homelessness and educational legislation in regard to homeless students

- Types of homeless shelters and programs

- The roles of race and gender in homelessness

- Personal encounters on our campus with homeless citizens

- Survival tactics of the homeless

I cannot help but believe that, had I chosen topics for students, my choices would have been far less rich, far less varied, and certainly far less interesting. Because students chose their own topics, they were invested fully in their compositions. I did not impose my own ideas, but rather facilitated their ideas and choices. Furthermore, these varied 
topics encompassed a number of ideas I knew very little about which, in turn, allowed me to learn alongside the students.

But beyond the varied topics of the compositions, students also pursued a host of genres for their topics. Students sought to align their topic with the most suitable genre. Some students wrote short stories to personalize some of the more prevalent issues surrounding the topic of homelessness. The short story genre allowed students to grapple with complex issues through the eyes of the characters in the story thereby requiring students to see topics from different perspectives. One student, a theatre major, wrote a series of vignettes for the stage, each vignette focusing on a different character who came into homeless for a different reason. This dramatic piece gave voice to the emotional reaction this student had to the study of homelessness. Another student conducted interviews regarding preconceived notions of college students regarding homelessness and wrote a powerful self-reflection about how prejudices shape people's understanding of complex topics such as homelessness. This student went on to write a final reflection at the end of the course in which she chronicled the shifts in her own thinking about homelessness over the course of the semester.

A number of other students chose to write newsletters or news magazines to focus on specific topics related to homelessness. This particular genre required students to consider the visual rhetoric involved in the magazine genre as opposed to the visual rhetoric of websites or more traditional texts.

One student, a nursing major, researched the genre for grant-writing and wrote a complete grant for a proposed mobile health care station for the homeless, a grant including a formal letter of introduction, statement of the problem, objectives, project 
description, evaluation of the program, budget, and timeline. I maintain that this particular project may serve her well in her future as a health care provider. Still other students chose multimedia genres such as websites and YouTube music videos.

While all students wrote at least one researched paper, and a few students wrote almost all researched papers, there were many more students who branched out into other genres. They challenged themselves to find appropriate genres for the topics they chose, and by designing their own composition projects, they engaged in important critical thinking and problem solving as they designed their own composition tasks. Some students wrote poems, still others wrote personal narratives, and one student--an elementary education major--wrote a children's book about the homelessness that resulted from Hurricane Katrina.

While I found all these projects worthwhile and interesting, two projects were especially intriguing to me. One student, after struggling to find a new topic, decided to write a letter to other students in the class who had expressed doubt about whether the author of one of our shared texts used a ghostwriter. This student composed a letter as if she were a representative of the publishing company of the book refuting the accusations of a ghostwriter presented during class. This complicated rhetorical task required that she not only recreate the contentions of her classmates about the authenticity of the authorship, but also adopt an appropriately professional tone and find textual evidence to refute those contentions. The student embraced the challenge, and the resulting composition (see Appendix A) was a thoughtful, thorough analysis of the book written in the voice of a publisher defending the author of the contested book. It was a memorable piece. 
But perhaps the riskiest composition of the semester came from a student whose major was as yet undecided, but who knew that he wanted to pursue a minor in music. Seeking a topic, this student drew on an experience from his childhood. When this particular student was four years old, he had an encounter with a street performer who was presumably homeless. The street musician asked the young child if he wanted to try playing his set of improvised drums, and the young child eagerly agreed. This encounter might have been long forgotten had his father not snapped a picture of the young child drumming with the street musician. This encounter, along with the student's passion for music, resulted in a composition that consisted of a series of three songs about a street performer, the very street performer the student met years ago. The three songs chronicled a day in the life of the street performer, moving from dawn to dusk. At one point in one of the songs, the street performer wonders whatever happened to that little boy who played his drums so long ago. The lyrics then took an interesting twist as the narrator shifted to the adult student who wonders whatever happened to that street performer who let him play his drums. The songs were, needless to say, quite moving for everyone who heard them. The student composed not only the lyrics, but also the music. He performed all instrumental accompaniments and recorded the songs himself.

I contend that never is writing more risky than when students present themselves and their passions to a group of their peers for review as this student did. In fact, at the end of the semester, I asked each student to share one composition or an excerpt from a composition with the rest of the class as a type of end-of-the-semester celebration. This student chose to share one of his songs in spite of having some of his own far less risky compositions to share. I propose that this student would not have written nor shared these 
compositions with his peers had there not been a strong sense of classroom community and rapport in the class thus making this decision easier and safer for him. However, I will revisit this notion of risky writing in chapter 4 of this study in order to reveal other considerations of this composition goal.

When composition instructors ask all students to write the same type of composition, in the same genre, at the same time, composition is relatively safe. Plus, it's easier and safer for students to critically evaluate their peers' writing, like Flores promotes. However, when we ask students to take risks, to try something new, to invest themselves in their writing, the peer review process becomes much more high-stakes and complicated. Students recognize that they are responding to not only a composition, but also, and more importantly, to their peers.

\section{Politeness and Peer Review}

An awareness of the identity issues at play in risky composition point to the need to approach the peer review process with more than a modicum of care. In order to build and preserve cohesiveness and rapport, students must offer responses to their peers' compositions tactfully and kindly. Yet, at the same time, students are aware of the fact that the peer review process is subject to the scrutiny of the instructor. In my case, students knew that I would read and grade their peer review letters. This type of peer review assignment places students in an uneasy conundrum. In order to satisfy the requirements of the peer review assignment, students must offer suggestions for improvement, suggestions that run the risk of offending their peers or implying that they lack writing ability. Because writers' identities are often entangled with their compositions, much is at stake through the peer review process as students attempt to 
meet the demands of the assignment while protecting their peers from hurtful feedback that threatens some aspect of their identity. As Johnson and Yang (1990) note, "to be overly critical (during peer review) might offend a classmate, but not to be sufficiently critical would not meet the requirements of the assignment" (p. 102). Thus, students rightly use caution when navigating this challenging rhetorical task.

Rather than offend their peers, Jesnek notes that most students prioritize social acceptance and the protection of peer relationships over offering critical feedback during peer review (p. 23). Brammer and Rees (2007) found similar results in their research on the peer review process. They found that building rapport among classmates is crucial to productive peer review; students rely on "a sense of shared community in order to develop dialogues of trust and to build confidence in their classroom peers" (p. 81). My own observations of students during peer review confirm these contentions. In fact, a careful analysis of the peer review letters students wrote in my composition course bear out Jesnek and Brammer \& Rees’ findings.

As noted in my description of the composing process in my first year composition class in chapter two, I collected peer review letters from students' second and third compositions, which were submitted during the sixth and ninth weeks of the semester respectively. Students were aware that I would be reading and grading their peer review letters.

I first noticed students' sensitivity to their peers and their correlated use of politeness strategies when I saw a pattern emerging in the letters: students were far more complimentary to one another than I thought was warranted based on the quality of the drafts. In short, students were employing significant positive politeness strategies in their 
peer review letters. To review, "Positive politeness is oriented toward the positive face of $\mathrm{H}$, the positive self-image that he claims for himself. It 'anoints' the face of the addressee" and indicates that the interactants have the same wants (Brown and Levinson, 1987, p. 70). One specific politeness strategy involves exaggeration, a strategy "often manifested by choosing words at the extremes of the relevant value scale" such as intensifying modifiers (e.g. absolutely, completely) (p. 116). Here is a small sampling of the kinds of comments students made to one another in their peer review letterscomments that exemplify intensified positive politeness. I have underlined the intensifiers and exaggerations students used:

- The way you describe homelessness is the perfect way to begin in my opinion.

- I really enjoyed your poem. (and later) I LOVE that final line you put in there about how at the end of the day, you're still a man. I feel like it really demonstrates the amount of dignity that's at stake in this story, and again it marries the idea that "them vs us" is actually "them AND us." It's brilliant.

- I thought you accomplished your purpose really well in this newsletter. I liked the layout very much, and the information was interesting and quite informative.

- I really love the idea of this piece. It's $\underline{\text { so }}$ original and something I myself never would have thought about doing. I really enjoyed the first song. You can't even tell that you never really have written lyrics before. They flow well throughout your songs and none of them need changing.

- I really enjoyed your music pieces! I thought that was a really creative way to do your third composition, as well as a good use of your particular set of talents. You 
have a lovely voice! (and later) The first piece, Night, sounded great. The piece was very beautiful and really conveyed the mood that I think you wanted to illustrate.

- You did a really nice job with both, especially the closing. I felt like you really wrapped up the piece.

- I really felt like overall this is a very strong rough draft.

- I thought that the idea of doing a found poem was really great! I learned a lot from it, and it was really creative.

- First off, really great job! I really love your idea for the children's book.

- One of my absolute favorite parts is the beginning when you say...

- Overall, this is one of the best rough drafts I have reviewed.

- I really enjoyed reading your piece. I applaud your creativity for choosing to write a letter instead of just another literary analysis. I really enjoyed your first body paragraph in which you dissected some of Tiny's sentence structure and grammatical errors.

- I honestly see this as final draft material. You use transitions very well, and you flow from topic to topic smoothly. Overall, I would be extremely satisfied with this paper.

- I loved the ending. It was really good. And I especially loved how you ended with the word period. I thought that was clever.

While Brown and Levinson specifically caution against quantifying politeness strategies, it is nonetheless difficult to ignore the fact that students used many positive 
politeness intensifiers in their peer review letters. In all, for the first set of peer review letters that students wrote for Composition 2, students used 70 positive politeness phrases or sentences in 24 letters. This averaged to 2.9 per letter. Additionally, students used the word really as an intensifier 18 times.

In the second set of peer review letters for Composition 3, students used 139 positive politeness phrases and sentences in 24 letters. This averaged to 5.79 per letter. Additionally, they used the word really as an intensifier 45 times. From the first peer review letter to the second, students nearly doubled their use of positive politeness phrases and sentences, and more than doubled their use of the word really to emphasize their praise. This significant increase in positive politeness strategies will figure prominently in my analysis shortly.

Another trend I saw emerge in the peer review letters was the recurring use of the word just. The use of this word can be categorized as a hedge. As Brown and Levinson state, "Normally, hedges are a feature of negative politeness ... but some hedges can have this positive-politeness function as well, most notably (in English): sort of, kind of, like, in a way" (p. 116). Furthermore, "These hedges may be used to soften FTAs of suggesting or criticizing or complaining by blurring the speaker's intent." These hedges are categorized as redressive actions: actions that give face to the addressee, that is, "that attempt(s) to counteract the potential face damage of the FTA by doing it in such a way, or with such modifications or additions, that indicate clearly that no such face threat is intended or desired" and that the interactants share the same goals (p. 69-70). Additionally, the speaker recognizes and respects the addressee's negative-face wants and will not (or will only minimally) interfere with the addressee's freedom of action. 
The first way students used the word just was to minimize the FTA to the negative face of the peer. This was especially evident when students made suggestions for changes in the others' compositions. Students sought to soften the blow of the imposition and to minimize the revision work they were suggesting. These kinds of comments are considered off record comments and seek to minimize the imposition of the suggestion (Brown and Levinson, p. 176, p.214). A colloquial way of conceptualizing these types of comments is to think of them as the students' way of saying, "It's no big deal, but. .." The suggestion that accompanies the use of this type of hedge is thus framed as only a minor revision requiring little of the writer. Here is a small sampling of the off record hedges students used in their peer review letters:

- I would suggest just doing a real basic search on homeless people and seeing what facts come up and going off of those.

- Also, I would suggest rearranging just a couple of the sentences in the paper so that they flow better and are easier to read.

- There were just a couple of words and commas that I added.

- You could always add a personal story of a homeless child to connect to the homeless youth, just an idea.

- I would just reread through your paper and make sure you're not being too repetitive with that.

- Also just a little thing: make sure you're putting your periods after your parenthetical references rather than at the end of the sentence. 
- Again, you had a great amount of information, now you just need to focus on making it stronger.

- After reading your composition piece, I have just a couple of slight suggestions.

- Other than that, there are a few spelling errors and spaces between periods, just little stuff that will not take you much time at all to clean up.

- It's just something to think about.

- There were just a few minor grammatical/spelling errors.

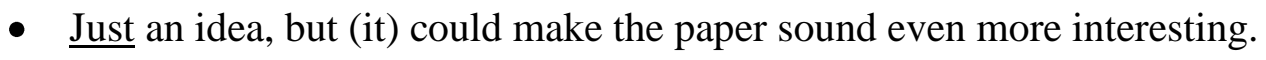

- This is just a tiny thing, but I would change the text color of the first two information slides. . . because the black blended into the background a bit which made it a little difficult to read.

- Anyway, I would just try to be consistent throughout.

I also noted students using the word just to minimize their own authority and thus their social distance from one another. This type of mitigation serves to help students create a certain camaraderie, a cohesiveness amongst themselves that downplays the differences in expertise between them. It allows students to remain at the same level and could be thought of as a self-deprecating move that serves to align the reviewer and the reviewed. A colloquial way to conceptualize these types of comments is to think of them as a way for the student to say, "But hey, what do $I$ know?" These mitigations fall under what Brown and Levinson might refer to as an out by making it clear that the peer reviewer does not expect the writer to follow the suggestion unless the writer wants to do so (p. 72). Here are some examples of students' use of this self-deprecation: 
- Again, in this paragraph you use the term "children" which isn't really wrong I guess, it just sticks out to me, so revisit it and see how you feel about it.

- Also, just a side note, this last page is when it really starts to be evident that you're sleepy and still writing, so check that out. I'm not judging or anything, just letting you know.

- (T)hese are just all the ideas that I have right now, but I can try to think of more if you really feel that you need it.

- $\quad$ This is just my opinion, feel free to leave the sentences way they are if you like!

- I have just a couple of suggestions for how to improve your project. Feel free to take them or leave them, they are just my opinions!

- Let me first say that any changes that I made in the paper were just ways that I thought would possibly make it flow a little more. You're not obligated to use my corrections, they're just suggestions.

- The changes that I made in your paper were either just small mistakes or sentence $\underline{\text { structure things. Obviously, it is completely up to you whether or not you want to }}$ use them.

- Once again, anything I say is just suggestions and you don't have to listen to them.

- $\quad$ Feel free to completely ignore these changes. They are just suggestions.

- You could always add a personal story of a homeless child to connect to the homeless youth, just an idea.

- $\quad$ Just an idea, but (it) could make the paper sound even more interesting 
In all, students used the word just 36 times in the first set of peer review letters, of which nineteen uses minimized the threat to students' negative face and ten uses minimized their own expertise and gave the speaker an out. In the second set of peer review letters, students used the work just thirty times, eighteen of which were addressed to the negative face of the peer and only four of which minimized their own expertise and offered an out. It is possible that the decrease in self-deprecating comments was the result of increased student confidence resulting from additional experience.

\section{Analysis of Peer Review Politeness}

To analyze these trends, I offer the theory of The Bulge, from Nessa Wolfson (1988). Wolfson contends that we can examine speech acts to get at "the social strategies people in a given speech community use to accomplish their purposes - to gain cooperation, to form friendships, and to keep their world running smoothly" (p. 31). Wolfson, using a middle class American speech community that is similar to my composition classroom, examined the differences in the kind and frequency with which interlocutors used politeness strategies. For her research, Wolfson focused on the distance aspect of the weightiness formula offered by Brown and Levinson. In particular, she found that "the two extremes of social distance — minimum and maximum—seem to call forth very similar behavior, while relationships which are more toward the center showed marked differences" (p. 32).

Wolfson went on to say that, "the more status and social distance are seen as fixed, the easier it is for speakers to know what to expect of one another" (p. 33). Furthermore, "what inequality of status and intimacy have in common is that in both situations, interlocutors know exactly where they stand with one another" (p. 34). Based 
on these findings, Wolfson posited that people who are either intimates or strangers use fewer politeness strategies because their relationships are seen as fixed. On the other hand, people who are non-intimates and non-strangers tend to use more politeness strategies as they seek to solidify their relationship. Thus, I might illustrate Wolfson's Bulge Theory as such:

Figure 1. Wolfson's Bulge Theory

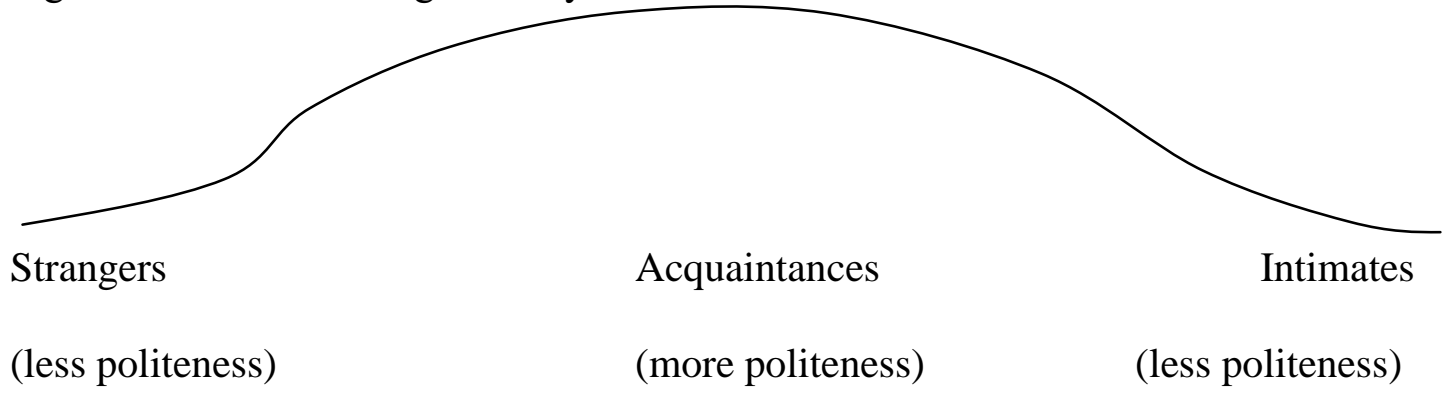

Of special note is Wolfson's finding that, combined with the research of D’Amico-Reisner (1983, 1985), "interlocutors who are in the Bulge almost never voice their disapproval of one another overtly" (p. 35).

Looking at the entire weightiness formula proposed by Brown and Levinson (Wx $=\mathrm{P}(\mathrm{S}, \mathrm{H})+\mathrm{D}(\mathrm{H}, \mathrm{S})+\mathrm{Rx})$, it appears that students shared the same level of power $(\mathrm{P})$ in the classroom; all students were first year students who shared the same amount of control over their work in the class and over one another. The relative imposition (Rx) asked of them was the same; everyone was required to write peer review letters and to follow the peer review assignment description. What was changing within the group was the social distance (D). As the semester wore on, students began to know one another better and to feel increasingly more comfortable with one another. In other words, the social distance was moving from stranger status toward intimate status. 
Based on this, I might surmise that students, as they attempted to move along the continuum toward more intimacy, began to employ more politeness strategies to stabilize and solidify their relationships with one another. It appeared that students were, on some level, aware of the tenuousness of their relationship with one another and were using caution when offering inherently face threatening feedback to one another during the peer review process. Students seemed hesitant to critique the work of their peers for fear of damaging in some way their burgeoning social closeness.

If I were to place students along Wolfson's continuum, I would place them just before the crest in the middle of the bulge; students saw one another on a regular basis and so were not strangers but were still in the process of establishing a more intimate relationship. They were not yet intimates. I suspect that students were nearing the crest of the bulge because most politeness strategies in the peer review letters were increasing as students attempted to solidify their tenuous relationship. As students grappled with the newness that is college - new content, new lifestyle, new academic expectations, new levels of independence - they may have sought to create a more secure, safe social environment in the composition classroom to help stabilize their experience.

To contextualize these findings within the classroom community, it may be helpful to consider once again Wenger's communities of practice. The "joint enterprise" of the community of practice of the classroom entails practices that build coherence and cohesion, one of which is a sense of mutual accountability as previously discussed. This mutual accountability might be evidenced in students' extensive use of politeness strategies in the peer review letters as they held one another accountable to contribute to the classroom community. Wenger also contends that "even when a community of 
practice arises in response to some outside mandate, the practice evolves into the community's own response to that mandate" (emphasis added, p. 80). Thus, the students' response to my mandate of the peer review letter was their own response. It was not one that was prescribed for them in the assignment description, but one that they created to fit their own aims. It appeared, then, that students were attempting to create a more cohesive community that supported not only the writing of their peers, but also their peers' identity development through the use of politeness strategies.

Cast through another lens, some of the hedging utilized by students might be considered rapport management as defined by Spencer-Oatey (2005a). Rapport is defined as "the relative harmony and smoothness of relations between people" (Spencer-Oatey, 2005b, p. 96), and rapport management is defined as "the management (or mismanagement) of relations between people” (p. 96). Spencer-Oatey builds upon and expands Brown and Levinson's notions of positive and negative face and incorporates other elements such as "the bases on which people make their social judgements (sic) in authentic interactions" (p. 336). Spencer-Oatey further contends that interactants may define what constitutes a face threatening act based on their affiliations with particular groups (p. 337). In other words, if someone considers him or herself closely aligned with a particular group, that person responds to threats to that group as if those threats were made toward themselves. Students, no doubt, felt a certain affiliation between themselves; they saw themselves as part of the same group. They therefore employed similar politeness strategies. They may have imagined the type of feedback they would have preferred and then, in turn, gave that type of feedback to their peers. In this way, it 
appeared that students sought to understand and interpret their peers' face needs and then responded to those perceived face needs with supportive politeness strategies.

Additionally, Spencer-Oatey maintains that "effective rapport management depends on mutual sensitivity and on each interlocutor finding an appropriate balance between meeting his/her own needs and the needs of others" (p. 338). The peer review requirement represents my needs, and students sought to balance my needs with the needs of their peers.

\section{The Politeness Profile of the Composition Classroom}

If, indeed, I hope to have students take risks - to challenge themselves and to, perhaps, challenge me as well — then one necessity is to ensure that students feel safe doing so. I need to make sure that the risks I ask students to take are reasonable risks and that they know that others in the class will respect and support those risks. By building classroom closeness intentionally, I might make the classroom a safer place and one that encourages students to stretch beyond prescriptive writing. One way I can help create this type of classroom community is through an awareness of the politeness strategies that I notice students using. I can first be aware of what the politeness strategies might indicate in terms of the closeness students feel. I might also use this information to adjust my practice so that students begin to feel more comfortable in the classroom. I can acknowledge that students use politeness strategies to create classroom community and therefore not prevent them from using those strategies because those strategies serve to create closeness in an inherently threatening assignment like the peer review letter.

I argued in the previous chapter that unique politeness profiles emerge within and from particular contexts based upon the needs and goals of the interactants in that 
context. It appears that my composition classroom was no exception to this contention. Indeed, a unique politeness profile emerged in this composition class, a profile characterized by students' overuse of positive politeness and extensive use of hedging in their peer review letters. In essence, students created their own constellation of strategies that responded to the somewhat uncomfortable requirement of critiquing their peers' writing. It is noteworthy that all peer review letters contained some examples of positive politeness and hedging, evidence of a consistent use of politeness strategies by all the students. It appears that students attempted to support their peers' efforts as they engaged in risky writing tasks, tasks that they designed and attempted to fulfill themselves. Thus, through the use of the polite peer review, composition was recast as a collective community endeavor that drew upon politeness strategies for its own unique identity.

If my composition classroom generated its own politeness profile through the peer review process, it stands to reason that other composition classrooms will develop their own politeness profiles as well, profiles that may differ from those of my classroom. An analysis of these unique profiles may help instructors gauge the social closeness students feel with one another, and may help inform instructors of where gaps exist in the social fabric of the class. By being attentive to how students use politeness strategies in socially threatening environments such as the peer review, instructors are better positioned to support the classroom cohesiveness and implement activities that strengthen the sense of safety in the classroom.

\section{Different Peers in the Peer Review Process}

I often encounter educators who bemoan the fact that their students simply will not critique honestly the work of their peers during the peer review process. I frequently 
hear instructors say things such as, "All students do is tell each other how great their compositions are. They refuse to be critical." In fact, prior to this study, I was one of those instructors who became frustrated that students were reluctant to offer candid critique of their peers' writing.

I now understand, however, that the "gentle critique" students often offer one another seeks to accomplish a different goal: students are attempting to build classroom cohesion and community, and being critical of one another unravels that goal. Students understand, perhaps more than their instructors, that delicate identity and face needs are at play in the peer review process, and their response to one another reflects this understanding. The peers in the peer review process have a mutual vulnerability of face.

On the other hand, instructors approach the composing and peer review processes for themselves quite differently from how students approach it. Most instructors come to their own composing processes with a good deal of experience and, most likely, success. In fact, a crucial requirement for any college instructor who teaches composition is a certain degree of writing proficiency. This writing experience makes the writing process for instructors somewhat less risky than it is for students since instructors have had many opportunities to hone their craft of writing ${ }^{4}$. Their writing identities are formed and solidified resulting in a certain confidence, a self-assurance that makes the composing process more natural and comfortable for them. The same cannot necessarily be said for students.

\footnotetext{
${ }^{4}$ Here, I acknowledge that many instructors feel a good deal of pressure to publish academic work in order to gain or maintain a reputation or standing at their university. However, this writing pressure is different from the pressure students may feel. Student pressure may result from insecurities about their writing, whereas instructors may feel pressure from the high stakes of publishing academic work.
} 
Additionally, most college instructors have a considerable amount of experience with critical peer review. From sending articles to peer reviewed journals, to reading colleagues' papers, to reading and responding to random friends' writings, the peer review process is second nature to most composition instructors. While critical peer review is rarely a fun experience, most college instructors know that the process can be incredibly beneficial, and most instructors have, quite frankly, survived this process mostly unscathed. Their writing identities can withstand this type of critique. However, these instructors have a number of things students do not: more experience, a stronger writing identity, and more power.

Finally, college instructors have far more choice in how they engage in the peer review process. They can typically choose when to submit a composition for peer review, and they can choose to whom to submit the composition. In fact, instructors can choose not to engage in peer review. In short, they control the entire peer review process, so the process is far less risky for them. Students, on the other hand, had far less power in the peer review process as I structured it in my composition classroom. I required them to engage in the process, I set the timetable, and I told them what to do during that process.

Taking all these factors into consideration leads me to conclude that the peer review process accomplishes different goals at different points in a writer's development. When writers are novices - as the students in my composition course were-the peer review process served a social function. It allowed students to support one another, to learn from one another, to build a certain degree of social cohesion.

As writers mature, however, the peer review process can become a useful tool for becoming a better writer. However, asking students to be critical of one another's writing 
before they are ready to withstand that kind of critique is, perhaps, an untenable goal. To expect students to engage in critical peer review in the same way the instructor engages in this process seems unfair and unrealistic because students bring a very different writing identity to the writing process than the identity of their instructors.

It appears, at least in my composition course, that students resisted giving one another candid critiques in part because their writing identities were still forming, a fact they seemed to be aware of at some level. Students knew they needed support and so shaped the peer review process to offer this support. Students, in a sense, created an organic response to the peer review process by keeping one another's face needs in mind. Their organic response resisted my artificial request of the critical peer review.

Therefore, it is important for me to keep in mind students' writing development and their writing identities when I design the peer review process. I am not willing to abandon altogether the peer review process in my composition classroom, but I must be clear about what I want students to get out of the process and ensure that my goals for the peer review process are aligned with student needs and student development. I now realize that in order for peer review to be successful in supporting risky writing, I must allow students to encourage, praise, and support one another. The peer review process as I now see it can serve to build classroom cohesion and expose students to new, interesting genres. And that, I believe, will be enough to make the process worthwhile. 


\section{CHAPTER IV \\ TROUBLING THE NARRATIVES}

\section{Responding to Student Writing}

The role of the composition instructor is multifaceted, and the multiplicity of this role can be difficult to negotiate. While it is the obligation of every composition instructor to help students improve the structure and presentation of their writing in such areas as punctuation, grammar, organization, and elaboration, instructors must also mentor students and nurture their emerging writing identities. Negotiating the tension between support and correction, guidance and redirection is one of the greatest challenges for most composition instructors. And when students delve into the realm of risky writing, the delicate balance between support and correction becomes even more difficult to negotiate.

Flynn (2008) noted that one way instructors can support students' risk-taking is by engaging in genuine dialogue with students about their writing. According to Flynn (2008) "When students feel that instructors are in dialogue with their thoughts, they themselves begin to take those thoughts more seriously and try to articulate them more clearly" (p. 67). This understanding that students benefit from a dialogic relationship with instructors points to the need for instructors to respond to student writing in ways that are engaging and supportive rather than merely evaluative or corrective. 
Using audio-recorded feedback to students is one avenue instructors can use to dialogue with students about their writing. When instructors make their intentions to support student risk-taking more apparent to students, they can then help students remain engaged in the writing process. The more students engage in the writing process, the more likely they will be to revise their work and the more likely they will improve in writing, for the greatest learning transpires between students' first attempt and their next.

Kerssen-Griep, Trees, and Hess (2008) uphold the need for instructors to respond in meaningful ways to student writing and thus explore the notion of mentoring students as they develop their writing abilities. Drawing on Golian \& Galbraith (1996) and Zimmerman \& Paul (2007), Kerssen-Griep, Trees, \& Hess define mentoring as “an individualized, mutually respectful relationship between a student protégé and an expert invested in guiding the student's professional and personal development" (p. 312). The notion of students as protégés is reminiscent of Sommers and Saltz's definition of students as novices as noted on Chapter 3.

But there is more that feedback on student writing can accomplish, especially when considering politeness theory. Beyond mentoring students and helping them recognize how others respond to their work, feedback on student writing, when done thoughtfully, can actually help students channel more cognitive energy toward their writing. As Kerssen-Griep, Trees, and Hess (2008) note, "Mitigating potential identity threats during feedback helps students direct their cognitive energies ... away from distracting issues of face protection and management" (Kluger \& DeNisi, 1996; Ryan \& Deci, 2000) (p. 314). By the same token, when the feedback students receive upholds their face needs, they are more likely to direct their energies toward improving their 
writing rather than becoming defensive and perhaps disengaging from the writing process altogether. This skillful feedback encompasses "the communication strategies people use in interaction to sustain or restore each other's preferred social identities" (Goffman, 1967) (Trees, Kerssen-Griep, \& Hess, p. 398). Thus, the best kind of feedback is a mentoring response in which there is "a high-quality social and reciprocal relationship where a teacher is seen to nurture students' intellectual growth, self-efficacy, resourcefulness, and sense of identity by helping guide their professional and personal development" (Golian \& Galbraith, 1996; Zimmerman \& Paul, 2007) (p. 315). This mentoring relationship that is attentive to the face needs of students stands in stark contrast to feedback that simply informs, manipulates, hectors, or attempts to befriend the student (p. 315). In short, skillful attention to perceived face needs during feedback is associated with a more supportive learning environment and a feeling of being mentored, and when students feel mentored, they tend to engage more in the writing process ( $\mathrm{p}$. 318). It seems, then, that one way to bridge the gap between assessment and learning is through the use of effective, skillful response to student writing. When the instructor conceptualizes the responding process as multifaceted, she can use her response to student writing to teach, to guide, to instruct, and it can become a powerful tool for student growth. The instructor thus enacts her pedagogy through the response process and the response process can likewise serve pedagogical aims.

I contend that when I responded to student writing in my first year writing course, I created the potential for disengagement or for engagement, for resentment or for encouragement. Students responded emotionally to the feedback they received, and my goal was to elicit a response that facilitated further engagement. However, of equal 
import was the fact that I also responded to student writing emotionally. In the below analysis of my response to student writing, I will explore the many ways I reacted to student writing and how that response affected or failed to affect the students' learning and growth.

To analyze the kinds of responses I offered students, I turned to the audiorecorded feedback I composed for students on all compositions. Because each student received anywhere from three to five audio files for each composition (i.e., one for the proposal, one for the first draft, one for the final draft, and, if the student revised the final draft, another for the revised final draft), and in all, thirteen students composed three to four compositions apiece, I created over 150 audio files during the semester. Attempting to analyze that many audio files (totaling over 1300 minutes) was beyond my capabilities.

Furthermore, the audio-recorded feedback was not the only feedback students received. As outlined in chapter two, in addition to an audio file, students received their original draft of the text with my highlighting and comments. As I read students' compositions and found things to discuss in the paper-things of interest, areas for further elaboration, surface features to be addressed - I highlighted the text and, at times, added a comment using the Track Changes feature in Word to elaborate on the highlighting. When I gave students audio feedback, I suggested they open up the document with my highlighting so they could follow along with my audio commentary. Certainly, my audio commentary contained more information than the highlighting of the text, but I was further able to address minor surface features using the Track Changes feature. In short, the students and I generated a great deal of data during the semesterlong course, perhaps too much data. 
Therefore, I narrowed my data set by focusing on students' second and third compositions. I focused on these compositions because they represented students in the process of growth. I viewed the first composition as a sort of baseline piece and so did not want to use the piece for my analysis. The second and third compositions represented students exploring their own writing potential; I was interested in how my feedback supported students' writing development. I chose not to analyze the fourth piece because I asked students to submit the fourth and final piece late in the semester, and, knowing that students would not have time to revise the piece, my feedback to them was slightly abbreviated because there was no potential for revision. Also, for the third composition, I asked students to use only their peer review feedback to revise their drafts, but students were always welcome to revise final drafts after receiving feedback and assessment from me. By providing feedback on only the final draft of the third composition, I was attempting to encourage students to rely more heavily on one another for helpful, constructive feedback on their drafts. I recognize that it would have been helpful to have at least some feedback from me on the third composition in case the peer feedback was not helpful, but because I read and assessed the peer review letters, I was able to monitor the feedback students were given by peers and intervene as needed. In fact, I did intervene in one case, but found that the peer review letters were sufficient in all others. Of course, students did receive feedback from me for their third composition, but only after they submitted their final draft, which they were welcome to revise.

I narrowed my data sample further by choosing four students for my analysis. I chose two students I considered reluctant writers, and two students I considered engaged writers. My intention was to examine the types of responses I offered students at both 
ends of the writing engagement continuum. Below is a brief introduction to each of the focus students. I have also included a summary of their first compositions so that a baseline of their writing and thinking is more evident.

\section{The Students}

The two reluctant writers, both male, demonstrated their reluctance to write throughout the semester in a number of ways: they had difficulty deciding on topics for their compositions; they struggled to meet the required page expectation for the course; and their final drafts were typically acceptable but not terribly strong. Neither of the students seemed to enjoy writing and tended to write about topics and in genres that were comfortable and somewhat familiar to them. It appeared that their writing took few risks.

The two engaged writers, one male and one female, were more confident in their own writing abilities and appeared more willing to take on riskier, unique composition projects. They tackled genres outside of the typical researched paper and adeptly navigated compositions that were rhetorically complex. They revised their work frequently prior to submission and became more animated during conferences when talking about their most recent projects.

\section{Aaron}

My first focus student was a reluctant writer I will refer to as Aaron ${ }^{5}$. During a conference mid-way through the semester, Aaron talked with me candidly about the fact that he had little experience with writing, especially the kind of writing expected at most colleges. He said that he was not expected to write much in high school and that he knew he was a poor writer. In spite of this, Aaron was eager to get as much feedback on his

\footnotetext{
${ }^{5}$ I have chosen to use pseudonyms for all subjects in order to protect their identities.
} 
writing as possible because he knew he would need to write throughout his college career, and he wanted to be successful in this realm. During class, Aaron was mostly engaged offering contributions to the class discussions about once per class period. He seemed genuinely interested in the topic of homelessness and often expressed his surprise about the topics presented in class.

For his first composition, Aaron had difficulty narrowing his topic. His piece was entitled What is a Home?, and represented Aaron's attempt to define homelessness. This piece indicated to me that Aaron was beginning to realize that his nascent understanding of homelessness was too simplistic and one-dimensional. Aaron drew on two of the required readings from class as resources but did not bring any other resources into the piece. Aaron's first composition essentially summarized both course texts and included some reflective comments from Aaron. While the piece helped me understand Aaron's emerging thinking about homelessness, it lacked depth and a clear focus.

\section{Karl}

The second focus student was likewise a reluctant writer I will refer to as Karl. Karl was less forthcoming about his prior writing experiences and was, in fact, less forthcoming about many things. He remained very quiet during class discussions and offered contributions only four or five times during the entire semester. He often doodled and looked down during discussions, so it was difficult for me to gauge his interest or preparedness for class. Nonetheless, Karl was somewhat confident in his own writing abilities and mentioned that, while he did not love to write, he did not think he was a poor writer, either. He appeared to be ambivalent about the feedback I offered him. 
Karl's first composition was a short story about an encounter Karl had with a homeless man. His goal for the piece as expressed in his Author's Note was to "help people see that not all stereotypes about homeless people are true." The story was two pages long and showed me that Karl had a knack for using interesting vocabulary, but struggled with some of the mechanics of writing such as comma usage, pronoun usage, and verb tense. Because the end of the story remained somewhat unclear, I also noted to Karl that more elaboration was needed to make the point of the story more understandable. After reading his first composition, I realized that Karl needed to work on making his ideas and intentions clear in his writing.

\section{Paul}

The third focus student, whom I will call Paul, was an engaged writer who took a special interest in the topic of homelessness. He was attentive during class discussions, and while he was not the most frequent contributor, he did offer interesting insights about once per class period. He seemed to be a confident writer and willingly moved beyond the traditional researched paper early in the semester. He appeared to welcome my feedback and used most of my suggestions in his writing. However, he did not revise his work as often as he could have and thus did not realize the full potential of some pieces.

Paul's first composition, entitled The Negative Impact of Homeless Shelters, explored the ways homeless shelters possibly perpetuated homelessness. This thoughtful piece made the argument that because most homeless shelters do not provide sufficient support to help people overcome homelessness, shelters actually encourage homelessness by meeting immediate needs and not preparing residents for long-term solutions. Paul drew on such theoretical frameworks as self-efficacy theory, self-worth theory, and time 
perspective theory to inform his argument. The resultant piece was thoughtful, informed, and well-written and showcased Paul's critical thinking skills.

\section{Shannon}

The final writer I focused on was an engaged student named Shannon. Like Paul, Shannon entered the composition classroom with many of the prerequisite skills required of a first-year college student: she was a strong critical thinker, an active contributor to the class, and an adept writer. During class discussions, I regularly if unconsciously counted on Shannon to offer a unique perspective or interesting counter-argument that served well my goals for the course. In this way, Shannon was almost a co-facilitator in the course whether she realized it or not.

Shannon's first composition focused on how the portrayal of homeless women differed from that of homeless men in texts about the homeless. More specifically, Shannon was interested in why there were so few books about women who were homeless. In my audio-recorded response to her proposal, I encouraged Shannon to delve into the topic, and I sent her a few articles and recommended a book to her that looked at similar issues. I helped her flesh out the idea saying, "If there are children involved, it becomes very complex. Homeless women are more likely (than men) to have children with them that they are responsible for caring for." Shannon was clearly enthusiastic about her topic; in fact, I cautioned her about hyperbolic language in her initial draft of the piece because her passions became a distraction to her argument. But Shannon's motives in the piece were clear: she noted that her purpose for the piece was to educate herself about the topic, to satisfy her own question. I responded to this purpose saying, "I like that that's your purpose because as the semester goes on, you'll be more informed 
and maybe be able to pursue some other purposes for the writing that you do." And that is exactly what happened as the semester unfolded.

\section{Instructor Authority and Student Response:}

Acquiescence, Resistance, and Dismissal

Instructor response to student writing can take many forms, as previously noted.

Yet, the goals underpinning response are typically the same: to help students improve their writing and to help students understand how an audience perceives their writing. These goals presuppose that the instructor has more expertise in composition than the students, and this greater amount of expertise carries with it a certain degree of authority. Ask almost any first year student in a composition course to point to the person in the classroom with the greatest expertise in the area of writing, and almost all —if not all— students would point to the instructor. Ask those same students who has the most power in the classroom, and they would likewise indicate the instructor. This combination of expertise and power positions the instructor as the default authority in the classroom.

Of course, many instructors, myself included, take measures to minimize their authority in the classroom and thus to more evenly distribute the power of the classroom. For instance, during class discussions, I ask students to take turns facilitating discussions, and rather than contribute and add my ideas, I take copious notes as students grapple with topics that arise from readings and class activities. Only after the students have finished discussing a topic do I share my own thoughts, and sometimes not even then. Often, I withhold my own ideas so as to leave space and opportunity for students to construct their own understandings and meanings. While it takes some time for students to adjust to 
this lack of participation from their instructor, eventually they begin to take ownership over class discussions and no longer turn to me for approval or confirmation.

Withholding my expertise when responding to student writing is a different consideration, however. Students fully expect me to guide them and help them become better writers. Indeed, many students express frustration when they receive little or no feedback on a composition. They expect the instructor to comment, to correct, to guide, to suggest. That is the nature of the instructor-student relationship in a composition classroom. Therefore, I do not adopt the same stance with compositions as I do with class discussions. I remain heavily involved in the students' writing processes-perhaps too involved at times, a concept I will explore below.

As I examined my responses to students' writing, it is clear that I did exercise my authority when it came to their writing. Rarely did I withhold my expertise; I felt entitled to guide the students and help them become stronger writers. For instance, when working with Aaron, I became quite involved in helping to shape his writing.

For his second composition, Aaron used a previous conversation he had with his cousin to develop his idea for a topic. Apparently, Aaron and his cousin were talking about the area in Los Angeles referred to as Skid Row, so Aaron decided to pursue that topic for his second composition. In his proposal, Aaron wrote ${ }^{6}$ :

The question I hope to answer is what is skid row and what happens at skid row. I might right an article about skid row. The modes I plan to use are other articles and maybe try to find some

\footnotetext{
${ }^{6}$ I have made the editorial decision to include samples of students' writing verbatim to give an indication of their writing abilities at various points in the semester. I will not indicate errors in their writing with the (sic) comment so as to maintain the flow of their writing.
} 
first hand people who have lived or seen skid row. The length of my paper will be between $4-6$ pages. The purpose of my composition is to inform myself and the reader about skid row. My cousin and I were talking and he started talking about skid row and I felt it would be an interesting topic for my paper.

In fact, Aaron shared his interest in Skid Row with the class through a course requirement in which students brought some type of resource to class that might interest others and further our exploration of homelessness. Aaron brought in a video he found on Youtube entitled Spending the Night on Skid Row in Los Angeles. The video portrayed a group of evangelical Christian young adults who spent the night on Skid Row evangelizing and attempting to help those who resided there. The class had a lively discussion of this video, grappling with whether the filmmakers, who at times were giddy, at times serious, were ethical in spending the night there and evangelizing to the residents. The class grappled with the motives of the moviemakers, and the class' discussion of the video added new momentum to Aaron's project.

In my feedback to Aaron on his proposal ${ }^{7}$, I asked a few questions to guide his writing process. I asked, "How do you define Skid Row? I think some clarification of your terms is one of the first things you'll want to do." I further advised him to "maybe come up with some questions about what you want to learn about it." Aaron was interested in honing his research skills, a goal I fully supported. I ended my feedback to

\footnotetext{
${ }^{7}$ I have chosen to streamline the transcription of my feedback to students by eliminating the verbal fillers like um and ah that seem to arise frequently in my audio-recorded feedback. I have made this editorial decision to make it easier to read the transcriptions. However, I have chosen to include repetitions, run-on sentences, and other less precise language in order to capture accurately the tone of my feedback to students.
} 
him saying, "Your purpose is to inform yourself and your reader about Skid Row. I would say, go ahead and dig around and see what you can find. But first define your terms. Keep me posted, Aaron. I'll look forward to seeing a draft of this."

From the beginning, I exercised a certain authority over Aaron's second composition. I attempted to guide not only his writing process, but also his thinking process. In truth, I was very interested in Aaron's topic and tried to convey that to him in my feedback. However, I also wanted him to do some of the thinking needed to structure the paper such as defining terms, developing guiding questions, and finding relevant information. I knew Aaron needed some extra support as a writer, so I attempted to give him that support by drawing on my own expertise as a writer.

When Aaron handed in his first draft, I was encouraged. Although the paper was only two and half pages long, it represented significant growth from his first composition especially in terms of its focus. I started my feedback to Aaron by saying,

I noticed in your Author's Note that you said that you think this is the better of the two pieces, and I'm inclined to agree with you. I think you're getting, you're getting a handle on this it seems like. I can see, I can see improvement in your writing most definitely and so I think that's encouraging.

My first goal in my feedback was to acknowledge what Aaron himself had already noticed: his writing was improving. In fact, Aaron's composition focused quite clearly on Skid Row; every sentence was pertinent to the topic and focused on informing himself and the reader about this area in Los Angeles. Whereas his first composition 
lacked focus and a purpose, this second composition represented strong focus and a more coherent organization.

Because this composition also went through the peer review process, I used the feedback of a peer reviewer to reiterate one of my own points. I said, "I think I'm gonna' echo what Karen said, too, in her feedback. I think there's a lot of room in here for expansion. You said you kind of hoped for four to five pages, and I think you can easily get that if you delve more deeply into your sources and allow them to inform what you want to say." So, while the piece was quite focused, it lacked the depth needed to be a substantially researched paper.

I offered some guidance for adding this depth:

You have a statement in here I found really interesting. You say, "Hospitals are also adding to the problem by dropping off some homeless patients and some non-homeless patients in Skid Row." That, I think, warrants a whole lot of explanation. I think that is fascinating because then that opens up a discussion about how different social structures are contributing to the problem, which I think is really interesting. And then, what makes the hospitals do that? Why are the hospitals doing that? Who in the hospital's doing that? Is it the ambulance drivers — or whatever? You know, I think that is a really fascinating area that I could see you developing in this paper.

I intended for my feedback to Aaron to show him areas where he could develop his thinking and delve deeply into the topic. I focused more on his thinking and less on 
the writing mechanics of the piece. I wanted Aaron to know that I was excited about his growth, excited about what he already wrote, and excited about the possibilities I saw in the piece. At this point in the response process, I was guiding Aaron by pointing out where he could further his thinking. Because I had already seen growth in Aaron's writing, I felt encouraged to offer even more suggestions to him, to allow him to benefit from my expertise.

However, when Aaron handed in the final copy, my feedback to him changed. On the final copy, I offered extensive feedback on the mechanics of the piece. In fact, I was quite directive in places. I said things like, "You simply must have a Works Cited page," and I told him to include transitions "to help me understand how the idea before relates to the one afterwards." While each of these suggestions was valid, upon listening to my feedback again, I was struck by how I changed abruptly the focus of my feedback from engaging with his ideas on his draft to a deconstruction of his syntax on the final submission. I again asked him to define what Skid Row was; I asked him to edit such minute details as changing his wording "nothing is being changed" to "nothing has changed"; I demonstrated how he could combine sentences to make the paper flow better; and I took issue with how he referred to the homeless as "these homeless people." In fact, I mentioned the way he referred to the homeless a total of three times during the twenty minutes of recorded feedback. Then, ironically, I gave him this advice about one passage:

It seems like that sentence is just extra because it's saying the same thing you've already stated. So, I don't think you need that sentence at all because you have that idea restated frequently here. So, I don't think that's a really necessary sentence so I would 
recommend that you actually just take that sentence out. Because

you don't want to keep repeating the same idea because then

people get frustrated as they read it. Instead, you want to offer the

same idea from different perspectives perhaps, or more

information as you go on.

Clearly in this example, I needed to heed my own advice. In the end, I recorded a great deal of feedback for this composition, certainly too much for this student.

In reflecting on my feedback, it appeared to me that I moved beyond guiding Aaron and instead took a much more directive approach. Rather than offering him ideas to explore as I did with his draft, I dictated corrections. I exerted my authority and expertise quite strongly, losing sight, at least for a moment, of the fact that Aaron was the author of the paper, not me.

I believe I crossed the line between guidance and directiveness; I entered the realm of pushiness in my feedback on Aaron's final draft. By being so directive, I robbed Aaron of the dialogic engagement that audio feedback has the potential to generate. For a moment, I lost sight of what I perceived to be Aaron's face needs and focused on what I thought Aaron needed, not what Aaron may have desired for himself. I lost sight of his perspective. Of course, there was little to dialogue about when discussing the mechanics of writing, but striking a balance between being directive and dialogic would have been more beneficial for Aaron, no doubt. My feedback on his draft indicated that I was eager to read more of what he had to say; my feedback on his final copy indicated that I was more concerned with how he said what he said. Mechanics became far more 
consequential to me on the final copy. I am left to wonder whether it was fair for me to shift my feedback to Aaron so dramatically.

That said, despite of my genuine desire for the student to be successful, I lost sight of the fact that there are limits to what students can learn at any given moment. Students are not receptacles for knowledge who eagerly accept and implement every suggestion they are given. They need to focus instead on only one or two things at a time. I gave Aaron entirely too many things to focus on, even though they were only surface feature corrections. I might have been better off focusing my feedback on the most significant of his errors rather than attempting to address every single error.

Of course, in a slight nod to his ownership of his own writing, I did tell Aaron that he did not need to accept all my suggestions. I said, "You absolutely have the right to decide what you want to use of the suggestions, and that's how the writing is yours, right?" However, I went on to say, "There are some things that I suggest that you absolutely have to do, and so not using the word you is one of those things" for a research paper. I added, "Very few papers let you use the word you."

I did acknowledge the growth I saw in the final draft, but this acknowledgment did not come until the end of the audio file, perhaps after Aaron had quit listening. I said, I'm glad to see that you're bringing another source in here, because when you can bring three or four or five different sources to bear on the same topic it sounds much more credible. It sounds much more believable and it sounds like you've done your research. What you're trying to do is bring together three or four or five 
sources together to see how they speak to each other. . to create one larger argument.

I went on to discuss the idea of gentrification and how Aaron could incorporate that concept into the paper. In the end, I told Aaron that I considered the paper to be a Continue Revising, the lowest of the three possible rankings. Fortunately, Aaron did indeed revise this final draft and resubmitted the paper.

When I read the revised final draft of his paper, I shifted my focus once again, this time commenting primarily on the content and not on the surface features. This shift was due in part to the fact that Aaron had corrected most of the surface feature errors I pointed out in my previous feedback, a clear indication of Aaron's willingness to implement my suggestions and in so doing, acknowledge my expertise. I said to Aaron, You're working here to kind of engage with the idea here of gentrification. I think it's interesting how earlier in the paper you talk about how hospitals will just release people to Skid Row, and there's a similarity there to gentrification in a way in that they're just moving the problem from one place to another which is what I think you're trying to kind of get at. In this sentence here, "When you kick one homeless person out of one area they become someone else's problem in another area," it seems like you're kind of trying to hint at the idea that things like gentrification and what the hospitals do or Skid Row in general are just these surface treatments of the problem — putting a Band Aid on the problem. 
This notion that there are no simple solutions to complex problems was a theme we discussed frequently in class, so my feedback to Aaron here represented a temporal comment gleaned from class discussions (J. Sommers, 2013). By responding to Aaron's ideas, I realigned my feedback to respond to what I perceived to be his face needs. And as a result, Aaron may have felt more encouraged, more acknowledged, more valued as a student.

Furthermore, it seemed that I changed my roles as I offered Aaron feedback: I attempted to keep Aaron engaged in the writing process; I attempted to help him improve the mechanics of his writing; and I attempted to help him recognize the complexities of homelessness in terms of gentrification and the health care system. I wore apparently many composition hats - encourager, editor, mentor. All the while, I attempted to keep his face needs in mind. I addressed his positive face by talking about my own interest in his chosen topics and by elaborating on a concept he presented; I addressed his negative face needs by acknowledging that he had the right to not revise if he so chose. But clearly, the way I attended to his perceived face needs was most evident when I engaged with Aaron's ideas rather than the mechanics of the paper.

This raised the issue of whether instructors can take into account a student's face needs when giving directive comments about the mechanics of writing. While making suggestions for revision was a face threatening act toward Aaron's negative face, and I attempted to mitigate those threats in some instances, there was little room for positive politeness in response to the surface features of a composition. Rarely if ever do composition instructors offer glowing praise for a well-used semicolon or other surface 
features. Rather, appropriate use of surface features is an expectation that is often addressed only when it is lacking.

Fortunately, Aaron was a good sport and took my suggestions to heart. He had a genuine desire to improve his writing, and as a result, he was open to my guidance. However, Aaron's eagerness to improve as a writer in fact fed my overexertion of my authority. Because I knew Aaron wanted my direct feedback, I gave it to him, and in the process, I robbed Aaron of some of his own autonomy as an author.

My response to Paul and Shannon was slightly different: my directness was tempered with an appreciation of their existing writing abilities, and thus my response to them implicitly acknowledged their ownership over their own writing to a certain extent. Still, Paul and Shannon remained mostly open to my guidance and expertise.

For his second composition, Paul explored the effectiveness of workplace training programs in curbing homelessness. Paul decided on a newsletter format for this piece and said in his proposal,

The purpose of this piece is for me to investigate the contrasting arguments on whether or not workforce training programs actually help the homeless re-enter the workforce. This piece may go hand in hand with my first piece, as I mention workforce training programs do indeed help the homeless re-enter the workforce. In this piece, I will look at both sides of the spectrum and present the information in a researched newsletter form. I responded to Paul's proposed project with enthusiasm, saying, "I like how you've drawn on your first composition to inform your second composition. I think this is 
a really good idea and something really worth looking at." I reminded him of a conversation we had during a writing consultation about roadblocks the homeless face in securing employment and told him I was pleased that he was willing to look at both sides of the issue. I finished my feedback on his proposal saying, "I'm eager to see what you come up with."

Paul's first draft was a compact, one-page newsletter that looked mostly professional and polished. He used different font sizes to distinguish sections and included borders and lines to make the piece more readable and to differentiate one topic from the next. He formatted the newsletter to include long, narrow columns of text like those in other news media. His placement of pictures was a bit awkward, there was too much white space in some places, and there were a number of surface feature errors, but for a first draft, it was quite strong and presented an interesting argument. Because Paul sent his composition to me as a PDF, I was unable to use the highlighting or Track Changes to note surface feature corrections, so my audio feedback to Paul was nearly twice as long as usual at just over twenty minutes.

My comments on the draft responded to a concern Paul voiced about the piece. I said,

You said that you had trouble establishing a stance on workforce training programs as a whole. And so my first thought is, then, would you have, you know, kind of a newsletter that has maybe two sides--one side in favor and one side against? So that this whole idea that you have a hard time taking a stance on it - maybe it isn't necessary that you take a stance. Maybe it's necessary that 
you lay out the argument and let the audience take a stance on it.

So that's one thing, and that would be a rhetorical move that you could make, where you maybe withhold your own idea, right? You withhold your own opinion on it in order for the audience to make that choice.

It is worth noting here that as I responded to Paul, I began to mitigate my own authority. I asked questions rather than gave directives. I used the word maybe to allow Paul the freedom to make his own choices about the piece. I stammered, saying things like "would you have, you know, kind of a ..." Gone was the assertive tone and direction I used with Aaron, replaced by hedging and indirect suggestions.

Furthermore, in addition to acknowledging his autonomy over the piece by minimizing my own authority, I engaged Paul in a brief discussion of rhetoric that reiterated concepts we discussed in class just before the draft was due. I wanted to nurture in Paul — an already strong student, thinker, and writer — a rhetorical awareness that would help him craft his own arguments and critique those of others. I also discussed how this particular genre lent itself to the use of images that could do some of the rhetorical work for the piece. I offered Paul suggestions on formatting the piece to make it appear more professional, and I suggested some concepts he could explore as he sought to broaden his arguments. However, I never gave Paul directives like those I gave to Aaron.

When I received the final draft, I expected the same one-page newsletter with more elaboration and corrected surface features. What I received surprised me. Paul completely reformatted the newsletter to make it appear more like a short trade magazine 
entitled Workforce. In the seven-page magazine, Paul expanded his investigation of workplace training programs to include both the pros and cons of these programs thus leaving room for the reader to decide about whether the programs were helpful. $\mathrm{He}$ developed further the articles about homeless youth, employers' perspectives, and how the homeless could sustain employment once acquired. He finished the magazine with an article about a man named Ted Williams, a former radio show host who became homeless only to be re-discovered a few years later. The story of Ted William's life, while not directly connected to workforce training programs, nonetheless added a contemporary, timely feel to the news magazine, a rhetorical move appropriate to the genre.

Paul, it appeared, was open to my suggestions but also exercised his own autonomy over his writing. He implemented some of the suggestions I gave him, but he also took the piece in a new direction, a direction of his own choosing rather than mine. Paul's confidence as a writer was evident in his final draft, a confidence that was likewise evident in his decision to not revise the final piece further.

Like Paul, Shannon was open to my suggestions on her work. She took seriously my suggestions and in so doing, reaffirmed my authority in her writing process. In fact, Shannon was more receptive to my expertise than Paul. Shannon's second composition focused on movies made about people who were (or perhaps still are) homeless. In her proposal, Shannon asked, "What is it like, as a homeless or once homeless individual, to watch your life made into a movie that many people will make millions of dollars on?" While Shannon would not necessarily have been able to gauge what that experience was like for the individuals involved, a fact that I noted in my feedback on her proposal, the 
idea for the composition was, nonetheless, quite interesting. Shannon decided to focus on three films: The Pursuit of Happyness, The Soloist, and The Blind Side. It was interesting to note that each of these films began as a book and was then adapted for the screen. It was this aspect of the individuals' stories - the filming and the money generated by these films - that especially interested Shannon. She even asked in her proposal about what it would be like to watch others make a movie "about an extremely difficult time in your life, and to watch people get rich from your story."

In her Author's Note for her first draft, Shannon noted that one purpose of the piece was to "provoke questions regarding the ethics behind this type of film making," and I responded to her purpose with enthusiasm. I said,

I think that's just a really fascinating question, Shannon, I really do. I like it. I think it gets to a lot of, a lot of ethical issues that, I think, translate well into other discussions, so not just movies, but you can look at books, or even documentaries, and we can look at the movie The Released and we looked at Dark Days, and all those kinds of things. Even reading Criminal of Poverty — where is that line, right? I like that you're willing to wrestle with some of those ethical issues because I think that makes for really interesting reading and it gets me thinking.

It is important to note here that my response to Shannon was similar to how I might respond to a colleague who just proposed an interesting research project. I was enthusiastic, engaged, and eager to hear how Shannon would develop this topic. 
After reading the piece and considering the argument Shannon put forward, I remained enthusiastic about the piece. I said to Shannon, "I was, I was just really interested as I read the whole thing. I was really interested as I read along which is a testament to the writing and to the content." My praise of the piece was quite effusive, and indeed, it was an interesting piece to read. It was easy to address my comments to Shannon's positive face needs. She and I were on the same page, metaphorically.

However, when Shannon ended the piece, she ended with the question she originally raised: Is this type of film making ethical? While Shannon spent four full pages exploring the specific films and considering the response of the subjects to the films, she never came to a conclusion about the ethicality of the film genre. In the last few moments of my feedback, I said to Shannon,

So the question of Is it ethical? that you end with . . . I think, I think you might need to say something else here. Kind of like-I don't know what, but-I don't know but I think it needs to go somewhere now. It feels like it needs-you need to come to some kind of conclusion rather than just raise the question.

Like my response to Paul's newsletter, my response to Shannon was hesitant and questioning. I did not give a suggestion, but rather raised questions for Shannon to consider. While I did tell Shannon that she needed to come to a conclusion, I did not give her direction as to what that conclusion might be. And my hedging in my response further indicated my attempt to mitigate my authority and expertise and allow Shannon to maintain ownership over the piece. 
In response to my prompting, Shannon attempted to address the ethics question.

Her final submission read in part:

Is this ethical? I believe that this is difficult to determine without direct information from these people themselves. There are too many factors to make a definitive statement on this issue, such as: Who profits from these films? Where does the money that is generated by the movies go? These questions provoke thought on the rights of the homeless and mentally ill. One must operate on a case-to-case basis with these films to learn whether or not their making was ethical.

I appreciated Shannon's attempt to elaborate on the thesis of her paper and to delve into the ethical question, although her response was less than satisfying to her and to me. I responded to her attempt by first acknowledging that it was difficult to come to a definitive conclusion based on three films, but I nonetheless pointed out that she was already moving toward at least a preliminary conclusion that was more satisfying. I said to Shannon,

I see that you tried to grapple with some of the questions you proposed for this paper. I think they're important questions. Your choice of films and so forth really illuminates the different possibilities that there are in terms of the ethics. Certainly, you concluded that the Chris Gardener situation is ideal because he was involved in the film ... Ethical research methods involve the participants and vet the results of the research, in this case, the 
film, through them. When you don't vet the film or book through them, then you run the risk of misrepresenting them and marginalizing them in the process. That's kind of where you're going in your paper, it seems.

Shannon apparently considered my feedback, because her conclusion in the next submission of the paper re-sequenced some of the content and made the ethical argument a bit more conclusive. After a discussion of where the money generated from the films actually went, Shannon wrote,

In The Pursuit of Happyness, Chris Gardner was involved actively in the process of filmmaking, and was consulted frequently. This can be seen as an ideal ethical situation for a movie about a homeless individual. Michael Oher's experience with The Blind Side was certainly less than ideal, and could even be considered an unethical filmmaking endeavor. Nathaniel Ayer and his experience, if he had any, with The Soloist is difficult to classify as either moral or immoral. One must operate on a case-to-case basis with these films to learn whether or not their making was ethical. For this composition, Shannon obviously considered my suggestions and revised her paper to reflect her consideration of my suggestions. In fact, all three studentsAaron, Paul, and Shannon — took my suggestions into account; they acknowledged my authority, and they responded by acquiescing to one degree or another. They did not appear to resist overtly my suggestions and instead acted upon them. By responding to my suggestions, students indicated that they either believed that my suggestions were 
worthwhile, or they knew that, politically, it was best to do what the instructor suggested. I may never know why students implemented my suggestions, but it is clear that Aaron, Paul, and Shannon took my suggestions seriously and attempted to acknowledge my authority by aligning their revisions with my suggestions. However, not all students did this. Take Karl, for instance.

For his second composition, Karl decided to write a two to three page researched paper about whether the homeless still live in freight cars as some homeless did in previous historical periods. Given Karl's interest in history, the topic did not surprise me. In my feedback on his proposal, however, I tried to encourage Karl to broaden his topic. I cautioned him that if his only goal was to find out whether people still lived in freight cars and he learned that the answer was no, he had nowhere to go in the paper. Instead, I asked him to investigate where people who were homeless historically found shelter. By broadening the topic, I told him, he could write more than just a page or two. I told him that I had a number of books on the subject that he was welcome to borrow. I said, "You're kind of looking at this in terms of history, so I've got some really good books that look at where homeless people have lived throughout history that would be really helpful for you, so please feel free to borrow them." I even offered to bring them to class for him to peruse. I then reiterated to Karl that the topic was interesting, but that he would need to expand the topic in order to have a substantial researched paper. In my response to his proposal, I made many demands on Karl, in essence threatening his negative face. I asked him to invest more time and more energy to develop his topic and delve more deeply into his research. 
Yet, one of the first things I noticed about Karl's draft that he submitted a few weeks later was its brevity. He wrote just over one page of double-spaced text about the transient lifestyle of the homeless in our nation's history. Rather than expanding the paper to include the kinds of living arrangements that the homeless sought as I suggested, he instead stuck to his original topic and delved into the history of the homeless who "rode the rails." It was interesting that Karl eschewed my guidance and pursued his own more narrow topic. He responded to my threat to his negative face-my suggestions and my directives — by not responding. He dismissed my authority—outright. What was perhaps more interesting, however, was that Karl did not take me up on my offer of resources and instead sought his own research to inform the paper. In my feedback on his draft, I responded to the brevity of the piece, saying, "You'll need to flesh this out and make it probably five to six pages. So, I look at this as just kind of kernels of information for you to elaborate on. And there's a lot of space for movement here."

I was attempting to encourage Karl to elaborate on his ideas, but at the same time let him know that his topic was interesting. I went on to say, "I find it, I find it, a really fascinating topic that you've chosen." Later in my feedback, I reiterated the potential of the piece:

I think, I think it has some potential but it's going to take a lot of development and a lot of work to get it there. So let me know if you want to sit down and talk through this or if you want to borrow a book or two from me that will give you further information that might be really helpful for you. 
In all, I offered Karl resources three different times in my feedback, but he never took me up on my offer. Karl's negative face needs remained foremost in our composition relationship up to this point. I threatened his negative face and encouraged more effort, and he mostly ignored my face threat and my suggestions.

When Karl handed in the final draft, he had expanded the piece to two doublespaced pages, so he had elaborated on the topic, but only to a small extent. My response to Karl's final draft, however, was more emotional than academic: I was mildly annoyed with Karl. I knew the topic had tremendous potential; I had offered him resources, ideas, suggestions, and guidance. I fully expected him to hand in at least four to five pages of text. Yet, he still maintained his autonomy and completed the composition as he wanted to on his own terms. In fact, he ignored or rejected outright one of my suggestions for revision: I had noted on his draft that the phrase "dirty city sidewalks" was somewhat offensive and that he should consider rephrasing that part of the sentence. In the final draft, the original phrasing remained. I wrote in my in-text comments next to that phrase, "Still offensive."

In my audio feedback on his final draft, I elaborated on comma usage and explained why his overuse of commas made the piece more difficult to read. I gave him specific advice on revising his comma usage and offered explanations as to why his comma usage was confusing, including commentary about why commas were used in some cases but not in others. I recommended he consult a good handbook to help him with this aspect of his writing. I then pointed out how he used a comma correctly at one point in the composition in order to show him that at times he did use commas correctly, a very small nod to his positive face needs. 
Regarding citation format, I took Karl to task. I said, "You've just got numbers thrown in here and I have no idea what that is. That is bordering on plagiarism." I talked about elaboration (again) and the use of transitions, and I mentioned - for the fourth time-that the paper needed more development: "I will reiterate that there is a lot of room for development here. You just assume that the person reading this knows what you're talking about."

It was little wonder that Karl chose not to revise the paper further. All I offered him in terms of feedback was corrective. It seemed there was little I liked about the paper beyond the topic. This analysis of my feedback indicated that I did not take Karl's face needs into account in the same way I took Aaron's into account. I offered far more correction than encouragement, and when I asked Karl to elaborate, I did so directly. In contrast was my response to Aaron when I suggested that he elaborate on the notion of gentrification. The tone of my response to Aaron was far more encouraging and excited, whereas the tone of my response to Karl was remedial and directive. Perhaps I was responding less to Karl's paper than to the fact that he rebuffed my prior suggestions and thus pushed back against my threats to his negative face.

Of course, there was the possibility that Karl did not listen to my audio-recorded feedback on the draft and thus did not hear my threats to his negative (and sometimes positive) face. I found areas where Karl revised something that I suggested he revise, but I remain unclear as to whether he revised the composition by looking at my highlighting on the text of the draft, through his own volition, or as a result of the feedback. For instance, Karl included the following sentence in his draft: "These men and I only say men because nearly no women hopped the freights, were without a home, but were 
willing to work for their food." I highlighted the phrase, "I only say men because nearly no women hopped the freights," in this sentence to indicate that the wording was awkward, perhaps incorrect, or at the very least unnecessary. In my audio feedback, I said, "In your second paragraph, you use the word I, and you say, 'I only say men because' yada, yada, yada. That doesn't work. I think an introductory sentence leading into this sentence would be much better that talks about the fact that it was primarily only men." Karl did revise this section to read:

The first men to head westward on trains in search of a place to live did so following the Civil War. Many men, especially in the south, returned home to find their houses destroyed. The numbers also increased with the recession of 1870. (3) These men were without a home but were willing to work for their food.

It remains unclear to me whether Karl revised this section in response to my audio-recorded comments or simply by eliminating the phrase because I drew his attention to it by highlighting it. Certainly, the revised section was stronger, but the improvement could be attributed entirely to Karl's revision process, not my suggestions. Whatever the case, Karl left many of my suggestions unheeded. In the end, I said, If you choose not to revise, that's fine. You always have that choice. I hope you come back to this and work on it a bit more and flesh it out a bit more. Clean up your citations and surface features. So, revise if you feel so inclined. If you're happy with this and want to move on to your next piece, you're welcome to do that as well. 
While I certainly gave Karl a nod of acknowledgement that the paper was his and thereby respected his negative face needs, I nonetheless did my best to shape the paper myself. My words indicated that Karl owned the paper, but the overall tone of my feedback seemed to transgress the line of ownership. I attempted to push Karl into revision with my detailed, critical suggestions, but my attempt failed. In spite of the fact that all students were welcome to continue the revision process well after the final draft was assessed, Karl chose to move on to his next composition and not revise the piece any further. I do not begrudge him this decision, although I am mildly surprised by my own emotional reaction to his rejection of my feedback.

Yet, I should not be surprised that Karl chose to keep his composition so brief. His proposal was quite clear regarding the length of the piece. He wrote in his proposal, "It will be approximately two or three pages. The purpose will be for me to learn more about homeless people." Karl did indeed accomplish what he set out to do despite my prodding that he do more.

This analysis so far indicates that students responded to my authority in different ways. Aaron, a weak writer who was eager to improve, appeared to implement every one of my suggestions. He enthusiastically acquiesced to each suggestion, each bit of direction, each correction. It appeared that he fully acknowledged my authority over his writing. Paul and Shannon likewise acknowledged my suggestions, but my suggestions for them were far less directive. Nonetheless, they also acquiesced to my authority. They appeared to take seriously my ideas and made every effort to respond to me. While Paul declined further revisions of his final composition, indicating a slight resistance to my ongoing suggestions, he nonetheless did take some of my suggestions into account. 
Karl, on the other hand, strongly resisted my suggestions - or perhaps he dismissed them altogether. I suspect that Karl did not take the time to listen to the audio feedback I sent him; he dismissed not only my response, but also, implicitly, the value my response might hold for him. He seemed quite satisfied with his writing the way it was, and therefore revised only those aspects of it that seemed relevant to him.

Working with Aaron, Paul, and Shannon reified my existing conception of my own authority. I saw my role in the classroom as the expert, the guide, the authority, and these three students confirmed that classroom narrative. Only Karl troubled that narrative. He, of the four focus students, was the only one to present a counter-narrative to teacher authority. Of these four students, only Karl exhibited true ownership over his work, and in all honesty, this student autonomy proved to be incredibly vexing to me. Of all students enrolled in the course, Karl is the one who haunts my conscience. But should he? Karl's response to my feedback raises questions perhaps every composition instructor should consider: Who owns a student's writing? Is it solely the student who owns it; is it the instructor; or is it both? How much response is appropriate on student writing? How much guidance should composition instructors give? Is there a way to give guidance without appropriating student writing? While Karl was, undoubtedly, the most challenging student I taught that semester (and perhaps ever), he nonetheless raised important questions for me by troubling an existing classroom narrative, that of teacher authority.

\section{Seeking Collaboration and Surrendering Expertise}

Tangentially related to the notion of instructor authority is the idea of expertise. As previously noted, the composition classroom narrative presupposes that the instructor 
holds considerable expertise about writing as well as about a variety of other subjects. Because my composition course focused on the topic of homelessness, students assumed that I not only had considerable expertise about writing, but that I also had considerable expertise about the topic of homelessness. Indeed, I do most likely know more about both of these topics than the students entering my classroom. While I am a bit of an autodidact concerning homelessness, I have invested considerable time and effort formally studying composition, specifically teaching writing at the college level. Therefore, students are right to assume that I have more expertise than they do in these areas.

There is a problem, however, when one person in an academic relationship possesses more expertise: others in the relationship are inclined to defer to that expertise and minimize their own potential contribution. As a result of this disparate distribution of expertise, collaboration becomes more difficult.

Collaboration is often a mainstay in such academic endeavors as composition. The word itself, with the prefix col- meaning together and the base word labor meaning work, indicates that two or more people are working, or laboring, together. The very word collaborate implies a relatively equal degree of expertise between the parties involved. Thus, the nature of a composition classroom, with an expert instructor and novice students, makes the prospect of collaboration in this environment all the more difficult.

In spite of this, I was able to establish a productive collaboration with one of the focus students: Shannon. When Shannon submitted her proposal for her third composition, I noticed that she was pursuing a similar genre as her previous compositions: a researched paper. In part, she stated in her proposal that she planned to 
address the question, "What are the federal laws currently in effect regarding homelessness?" She further stated that she wanted to learn about this topic because she felt she knew little about the topic and knowing more might help her better understand some of the course content. I supported Shannon's idea initially, but when we met for a writing consultation, things changed.

Shannon came to the writing consultation quite prepared. She had already researched homeless legislation and had answered her initial question for the piece herself. As we talked about the piece, I asked her, "How will writing this piece help you as a writer?" Shannon struggled to answer my question. In fact, after a bit more discussion, Shannon and I agreed that she had already accomplished her purpose for writing the piece: to learn about homeless legislation. We also concluded that another researched piece like this would not stretch her as a writer.

Based on our conversation, we decided that her goal for her third composition had already been met and writing the piece would have been far less beneficial than pursuing a different topic or genre. It is important to note that I did not, at that time, have an alternative assignment in mind for Shannon. I wanted Shannon to stretch herself as a writer, but at the same time, I wanted her to pursue a topic that interested her. Our relationship was not characterized by differing levels of expertise; it was characterized by a problem that we were both interested in mutually resolving. It was a collaborative relationship at that point.

Shannon and I continued to discuss other topics, and it did not take us long to revisit a topic we had just discussed in class. The class had recently engaged in a debate about the authorship of the text Criminal of Poverty, an autobiography of a young woman 
who quit attending formal school at the age of eleven. (I mentioned briefly this discussion and Shannon's composition in response to the discussion in chapter three.) Most students in the class maintained that the author, Lisa Gray-Garcia a.k.a. Tiny, could not have possibly written the book because no one could write as well as Tiny without formal education. Shannon was one of the few students who countered this contention saying that she did not believe the book was very well-written at all, evidence that Tiny did indeed write the book by herself. Shannon grew intrigued with the idea of writing a refutation to members of the class who thought Tiny had a ghost writer. According to my anecdotal notes about our writing consultation,

Shannon seemed much more excited about the prospect of changing her topic to this one; she said she had already learned what she wanted to learn about the McKinney-Vento act by reading articles, and she thought this type of argument paper (about Tiny as an author) might be more fun and interesting. Shannon mentioned that she was fairly good at literary analysis in high school, so she felt confident pursuing this new topic. Additionally, Shannon was an English literature major, so the paper was a worthwhile way for her to use her strengths and at the same time, stretch herself as a writer. After a bit more discussion, Shannon decided to write a letter in response to a fictional person who allegedly wrote to the editor of the City Lights Foundation Publishers, the publishers of Criminal of Poverty, to complain about the fact that Tiny had to have used a ghost writer. Shannon agreed to do a little research about the publishing company and the publishing process and then try her hand at the composition. 
In her Author's Note for the draft of this composition, Shannon mentioned that she had an easy time finding evidence to back up her contention that Tiny wrote the book, but she said she struggled to make the letter sound believable and professional. Therefore, I focused my feedback on the tone of the letter. At one point in the letter, Shannon, acting as the editor of City Lights Foundation, wrote, "There is no reason for the credibility of the City Lights Foundation to be attacked. We are an independent bookstore/ publishing organization devoted to allowing the voices of America's alternative culture to be heard." I suggested that Shannon remove the word attacked and instead use more indirect language such as called into question. I stressed the importance of remaining emotionally neutral in the letter and to not give voice to the frustration she might feel. I also discussed such surface features as punctuation and the use of the above slash. In the end, though, I told Shannon that the letter was mostly effective in accomplishing her persuasive goal. I said, "So I found that the thinking that you probably had to do to compose this really interesting. It was probably kind of fun to, you know, to address a non-existent letter. So I think it's a believable letter format."

The true test of the believability of the letter, however, came during the peer review process when one of Shannon's classmates, a proponent of the ghost writer theory, read her composition draft. While the peer reviewer offered some suggestions for improvement in her peer review letter, she ended with this comment: "Over all I feel like you did a good job strongly backing up your argument. I was one of those people who had my doubts, but after reading your piece, I could see how she wrote this."

Shannon's other peer reviewer echoed those sentiments. Although the second peer reviewer originally agreed with Shannon that Tiny wrote the book herself, he still upheld 
the credibility of the letter saying, "As for creating a believable letter format, I think you succeeded. As a reader, I would have totally believed that the City Lights Foundation wrote this response letter. You should consider showing this to the non-believers in our class!”

In her final revision, Shannon aligned the surface features of the letter with the letter's purpose: she ensured that the surface features were correct, and when needed, she added more examples to support her claim. For instance, she revised the abovementioned passage to read, "There is no reason for the credibility of the City Lights Foundation to be questioned. We are a non-profit, independent bookstore and publishing organization devoted to allowing the voices of America's alternative culture to be heard." Shannon ended the letter writing,

You make valid and respectable points to the contrary, but let me assure you that what you saw as Miss Gray-Garcia's writing prowess is simply an illustration of the skills she has acquired in many years of public speaking and her work with Poor Magazine. Thank you for your feedback; we at the City Lights Foundation always appreciate a dedicated reader sharing their thoughts.

The composition was overall quite effective and a valuable experience for Shannon, a student poised for challenging rhetorical tasks. Moreover, my collaboration with Shannon to develop the idea for this composition was quite gratifying. Our meeting was much like a brainstorming session between two equal participants with a mutual goal. 
My primary intention in using audio recorded feedback was to mitigate somewhat my own authority over the students and their writing. I was hoping to establish a more dialogic relationship with students about their writing — a stronger collaboration. However, upon examining students' response to my audio feedback, it is clear that this mode of delivering feedback was not equally effective in establishing a dialogue with all students. While many students indicated that they found the audio feedback quite helpful, not all students benefitted from it. For instance, it was not until over half-way through the semester that I was able to develop some kind of collaboration with Karl, and this nearcollaboration arose not from the audio recorded feedback, but rather from a writing consultation. As I previously noted, I doubted whether Karl listened to the audio feedback I gave him, but I did not realize this possibility until after the semester was over and I had the opportunity to analyze the data from the course. Until then, I assumed that Karl listened to my feedback but chose to dismiss it. However, I gained a new perspective on Karl when we met for a writing consultation about his third composition.

For this third piece, Karl attempted a new genre: poetry. In his proposal, he mentioned that he wanted to answer the question: How do homeless people live? According to his proposal, Karl intended to use articles to help him answer his question, and the purpose of the poem was "to educate people about homeless in a way that might be easier for them to understand." In my feedback on his proposal, I mentioned that he did not need research to write the poem, but that he could pursue research for his final piece of the semester instead. I also mentioned that we could talk further at our writing consultation the following week. 
Karl sent me a draft of his poem prior to our writing consultation, and I responded to the poem with enthusiasm in my audio-recorded feedback:

I've noticed something I really like about this poem is the rhyme scheme. I liked that a lot as I read it. It has a nice rhythm to it. I think your peer reviewers pointed out that you change your pronoun usage. That's kind of interesting. You know what might be kind of cool? I don't know, but that pronoun usage almost makes me think that it would be cool to have two poems side by side, one of which uses they, and one of which uses you. Kind of how the outside world might see a homeless person. Just a thought.

Clearly my feedback was focused toward what I perceived to be his positive face needs. I was supportive of Karl's idea, and wanted him to know that I wanted him to be successful. I continued my feedback by reminding Karl of a concept we had recently discussed in class: the ways in which the homeless were "othered" by the outside world.

I then turned my attention to the surface features of the poem and found only a few errors. I pointed out one place in the poem where the wording was a bit awkward, and I reminded him that his spelling of passersby was incorrect (i.e., passer byes). I went on to explain how to pluralize words like passerby, father-in-law, and the like. While I remained concerned that Karl was falling far short of the 25 pages of text required for the course, I was encouraged that he was using his strong vocabulary to craft a moving poem. My feedback to him on the poem was far more responsive to what I saw as his face needs than my previous response to the researched paper. I tended to respond to the emotional 
investment he seemed to make in the poem rather than to any other feature of the composing process.

It was during our writing consultation that Karl shared with me that he modeled the poem after the famous Frost poem, Stopping by Woods on a Snowy Evening. Until this point, I had not realized that the rhyme scheme and structure of the two poems were the same. Therefore, I suggested to Karl that he include a description in his author's note of his writing process while composing the poem and illuminating the fact that the poem was modeled after Frost's poem. Karl seemed to think that was a good idea and assured me that he would add this narrative to the poem for the final submission.

Interestingly, Karl was quite open to my suggestions, suggestions that were clear threats to his negative face. I imposed on him more work, yet he readily accepted this work. Perhaps Karl was eager to make his writing process and intentions more clear to the reader - to me. Perhaps he was excited about his work on the poem and was willing to pursue the project further. Or perhaps Karl genuinely wanted to improve his writing throughout the semester but preferred the face-to-face interaction to the audio recorded feedback.

As was his pattern, Karl was a man of his word: he did include a two-page narrative in which he elaborated on his composing process and his intentions for the poem. In my feedback, I said, "The Frost style in that particular poem is so quiet and pensive and peaceful. You, you kind of - the tone of this is similar in a way, so I, I like that they're similar that way." I went on to tell Karl about the specific word choices he made that especially resonated with me and how certain words would elicit a moving 
reaction in the reader. I was encouraged by Karl's progress. In my notes about his third composition, I wrote,

(Karl) added $2 \frac{1}{2} 2$ pages of explanation that really helped flesh out his thinking and the decisions he made. Nicely articulated explanation that helped me appreciate the poem much more; (I) suggested very minor changes to poem (passer byes to passersby); (I) also suggested changes to author's note so its surface features are correct.

By comparing Karl's response to my audio feedback and our writing consultation, it becomes more evident that Karl eschewed my audio feedback and revised his writing based on our interactions and my highlighting of his drafts. For instance, I noticed that, on the final draft, Karl left the word passer byes uncorrected in spite of my fairly lengthy explanation in the audio feedback of how it should be spelled and why. There were some other suggestions I made in the audio feedback in terms of word choice that Karl apparently ignored in spite of the fact that the corrections were simple and required little effort. The suggestions Karl did act upon were made either through highlighting of the text itself or through one-on-one conversations during writing consultations.

While my writing consultation was the most collaborative interaction I had with Karl, it nonetheless fell short of the ideal instructor-student collaboration. In fact, of the four focus students, Shannon was the only student with whom a more mutual collaborative relationship emerged. While working with Aaron and Karl, I remained the authority, an authority that Aaron responded to and an authority that Karl, essentially, ignored except for our writing consultation. In both of these instructor-student 
relationships, I possessed either equal or greater expertise. However, my expertise was called into question when Paul submitted his proposal for his third composition.

Based on his first two compositions, I learned some valuable insights about Paul: he was a strong critical thinker; he was willing to take some risks in his writing; he had solid research and writing skills. Because it was clear to me that Paul began the class with many of the skills I was charged with teaching him, I was comfortable with Paul's unorthodox proposal for his third composition: a song series of three songs about the life of a street musician, a composition I discussed in chapter three. Paul stated in his proposal that he hoped "to address the question of how a homeless person might feel during different stages of their life." He went on to say, "If all goes well, I hope to have a concept EP (extended play) of at least 4-5 songs." Paul stated that his purpose in the piece was to "combine one of my passions, music, with the course material in a way that is both informative and something that people can emotionally connect to."

Because I knew Paul to be a strong writer, I was comfortable giving him latitude on the piece. In my feedback, I shared my excitement about the piece with Paul.

I am really excited about this idea of combining your passion for music with what we've been talking about in class. I'll be interested in a reflective piece that talks about your process ... Music is rhetorical too, so think about why you chose the different instruments and the notes or melody. Think about how the music itself that supports the message you're trying to convey — how the music itself is persuasive in some way. 
In all honesty, there was very little I could offer Paul in response to his proposal. I had no experience writing music or lyrics, I had never critiqued musical compositions, and I did not have the same experiences as Paul to inspire this composition. I offered him all I could: some guidance on the rhetorical aspects of the musical pieces. In this case, my role was simply to respond to Paul's idea and little else. My response to him was geared primarily to his positive face needs; I wanted to encourage him and tell him that I approved of the piece and of his ideas. But I had nothing else to offer him: no expertise, no suggestions, no guidance.

For the draft of this composition, Paul submitted the fully finished song series. He shared these songs with me and with his peers for the peer review. Both peers showed their appreciation of the piece through their peer review letters. They seemed impressed by his talent. One peer reviewer said,

I really love the idea of this piece. It's so original and something I myself never would of thought about doing. I really enjoyed the first song. You can't even tell that you never really have written lyrics before. They flow well throughout your songs and none of them need changing.

The other peer reviewer appeared to struggle a bit to give suggestions, saying, "It is hard for me to give you too much specific feedback like this because I have no experience whatsoever with song writing, but I will try to help you in any way that I can." She went on say that some of the lyrics were difficult to understand, but she blamed that on the sound quality of her computer. 
My feedback on the draft was similar to the peer review comments: I was hesitant, I hedged my comments, and I struggled to offer any kind of suggestions. The most direct critique I offered was this:

I'm trying to think if, if, there's something, you know, I don't know, something different that you could do with that lyric because that was the one I kind of like get what you're saying with that one, and I'm guessing that you're saying, like you know a wedding type thing but, it, you know—-that was probably the only place in all the lyrics in all the songs that didn't quite work for me in that one. So, do with that what you will, but I really like this and I like the shift that it has.

My hesitancy was clear. Because the songs had already been recorded in a small sound studio Paul had in his home, the pieces were finished compositions in a very real sense. They were not merely submissions of lyrics and musical scores; they were finished, performed pieces of music. When composing the feedback, I found myself wondering whether I should mention the above concern about the lyrics, doubting whether Paul would go to all the trouble of re-recording the songs to take into account my suggestion. Perhaps his peers felt the same way as they responded to the pieces.

Both Paul's peer reviewers and I exhibited a lack of expertise in responding to Paul's composition. None of us knew much about music, and we all deferred to Paul to decide what, if any, revisions were needed. In the end, Paul did include a reflective piece with the songs and explained that the songs followed a circular construction: 
These three songs represent what is known as a "song cycle." They are meant to have a unified theme and be performed as a sequence. Also, as in Pink Floyd's record, The Wall, the final song ends where the first song begins, thus bringing the album full circle. While the theme, homelessness, is apparent, I chose to follow the sequence of a possible day in the life of this street performer.

Paul ended the reflection by citing the lyrics from one of the songs: "Perhaps this is the start of a journey to seek him out and tell him how much I appreciate him. 'I know [he] made a difference to me."”

As Paul's instructor, I was completely out of my element. I had no expertise to offer him, and therefore our relationship was not collaborative. The roles of student and instructor had flipped: I became the student with less expertise, and Paul, with his superior musical knowledge and experience, became the instructor.

\section{Risks for Students; Risks for Instructors}

In all honesty, Paul was an easy to student to have in class: he was engaged, he was serious, he took risks. Or did he?

Paul caused me to re-examine how I define risky composition. I maintained in chapter one that students grow by taking on new composition challenges, that their identities and face needs are ever-present in the composing process. However, it occurred to me that the risks Paul took, particularly in writing the songs, were less risky than I originally imagined. He was, after all, an accomplished musician. He minored in music, he played a variety of instruments, and he had a small recording studio in his home. Music, it appeared, was not a new genre for Paul. Therefore, I question whether the 
writing, performing, and recording of his song series was terribly risky for him because it was something that was familiar and comfortable for him.

I now realize that what was risky about Paul's compositions was not the compositions themselves, but rather my assessment of and response to the compositions. I was the one taking the risks. My unease with responding to his work was evident in my feedback to him as I struggled to respond to what I perceived as a very personal composition. I had difficulty offering anything but encouraging comments addressed to his positive face needs because Paul's expertise had completely outpaced my own in this genre. When making suggestions, I hedged my comments, stammered, and in the end, told Paul he did not really need to change anything. Indeed, his was a very personal composition, but I am not entirely convinced that it was risky. I do not believe that Paul felt uncomfortable creating the song series. In fact, I imagine that he felt relatively confident that his song series would impress the rest of us who were far less talented musically. Paul demonstrated his confidence in his musical pieces by choosing one of the songs to share with the class on the last day of class when each student shared an excerpt or short composition piece. Paul was, to some degree, a performer. I now realize that it may have been riskier for me to respond to his piece than it was for him to compose it. In my mentoring relationship with Paul, we switched roles: I began as the expert and he the novice, but this composition caused me to become the novice and Paul the expert.

Certainly not all students possessed the depth of expertise in a particular area that Paul did. In fact, the expertise that students such as Aaron and Karl possessed did not translate well into the composition classroom. While both Aaron and Karl were interested in history and business, neither expressed a significant interest in writing. In fact, both 
were quite reluctant. Considering how reluctant writers experience the composition classroom has allowed me to re-conceptualize how I think about risky writing.

In short, if risk could be quantified, Aaron and Karl took the bigger risks in the composition course. They immersed themselves, to one degree or another, in a task where they had considerable struggles and little expertise. Writing was not necessarily an enjoyable activity for them. Yet, they persevered throughout the semester-long course.

While I would not have blamed Aaron for disengaging from the work of the course, he remained engaged through the end of the semester, and as a result, his writing did improve. In fact, by his third composition, Aaron and I began to establish a more collaborative relationship, one characterized by less correction from me and more ownership of his writing by Aaron. Aaron's continued engagement in the risky task of writing was beginning to show.

For his third composition, Aaron focused on people who had overcome homelessness to become highly successful. In his proposal for the piece, Aaron wrote, "I want to do a piece on famous homeless people. I was thinking maybe getting like 5 famous people that became homeless and writing a 1 to 2 page article on each of them." This particular composition was similar to a previous composition submitted by another student in the class. The other student, Renee, developed a website that focused on film stars and their previous experiences with homelessness. Aaron was aware of this website, and the website may have sparked his interest in the topic. This possibility of one student's composition serving as a catalyst for another student's idea speaks to one benefit of the peer review process as noted in chapter three. 
Because Renee already explored one facet of this topic, I suggested that Aaron visit Renee's website to get some ideas of the kinds of things he might consider as he did his research. But I also said, "I would encourage you to look beyond movie stars and maybe look at people who were famous for other things like maybe inventors, or politicians, or leaders in some way." My goal was to help Aaron use another student's composition as a model, but still use his own ideas and interests to create his own, unique composition. I offered other suggestions as well. I said, "You could also see whether or not those people who have been homeless are active in any organizations that work to stop homelessness." I cautioned him,

You may need to clearly establish the purpose of the paper. The problem is that there are many, many, many people who never make it out of homelessness. The people who are famous and who used to be homeless probably didn't struggle with mental illness or other things like that. So be careful about making it sound like "They did it, why can't you?"

Following the submission of the draft, Aaron and I met for a writing consultation and he received written peer review feedback on the piece from two of his classmates. It was during our writing consultation that Aaron shared with me his struggles with writing and his perceived inadequacies in this area. I wrote in my anecdotal notes, Aaron shared that he didn't do much work in high school; he called himself lazy and said that he never really had a teacher who pushed him to improve; he doesn't like writing and prefers things like history; we talked about how he's not necessarily lazy but instead 
maybe avoids things he thinks he's not good at. He said, "I just never really had a teacher who pushed me and challenged me to be a better writer." "I was just lazy, I guess. I hated writing. I'd much rather be reading about history and stuff."

These comments made it clear to me that Aaron especially needed encouragement that he could grow as a writer; he also needed specific feedback in how he might go about accomplishing that growth. Aaron's insecurity as a writer made it clear to me that I needed to take his positive face needs into account as I responded to him. He needed encouragement and confirmation that he was improving as a writer, that his efforts were appreciated by me.

This writing consultation with Aaron further highlighted for me the risk that Aaron was taking each time he submitted a composition. His efficacy regarding his own writing was quite low, and I suspect that he anticipated failure each time he attempted a composition. He was insecure, yet he remained active and engaged. Perhaps, then, Aaron more so than Paul is the kind of student every composition teacher wants in her classroom.

When Aaron submitted the final draft of his third composition, I noticed significant improvement in his ability to sustain a longer discussion on a topic. He clearly stretched himself by submitting six and a half pages of text. "You're definitely moving in the right direction," I told Aaron in my feedback, a nod to his positive face needs.

Aaron stated in his Author's Note that he struggled to find information about his topic of overcoming homelessness, so I reiterated information that our library liaison shared with the class regarding the information cycle. I reminded him that the topic he 
chose did not lend itself to peer reviewed academic journals because it was a contemporary topic and had not been the subject of academic research. I reminded him again that the subjects of his paper were the exceptions rather than the rules, and as such, did not represent a trend or point to a solution to homelessness. I said, "You may be having trouble finding academic resources because there really isn't anything out there about this because, number one, it's the exception rather than the rule, and number two, it's more current and just not out there in academe, you know, being researched." Once again, I offered Aaron a temporal comment that reiterated a concept from class (J.

Sommers, 2013). I also noted that Aaron did not include a thesis statement until the very last paragraph of the composition. I said in my feedback,

It was in the conclusion that I found your thesis statement, kind of the whole topic of the paper. The very last sentence:

"Homelessness is not an easy challenge to defeat, but there are few-I think you mean maybe a few—-there are a few that have, have, but not all live up to the lives of these people." You can hear that maybe when I read it I kind of stumbled over the words a little bit but I think what you're trying to say is homelessness is not an easy challenge to defeat, but there are a few individuals who have overcome homelessness to lead extraordinarily exceptional lives, or successful lives, right? So that seems to be, really, your thesis statement. Now, I didn't find that until I got to the very end really. I encouraged Aaron to make the point of the paper more directly at the beginning and to perhaps rephrase his thesis statement so it was a bit more clear. I went on to offer 
suggestions for formatting his sources and clarifying a few sections that were hard to follow due to a lack of elaboration. But I ended my commentary by saying, "You stretched yourself here. You've delved much more deeply, I think, into a topic. And so I see you definitely making progress. I can see why you like this one the best of the three that you've written. It's your strongest in terms of development."

My feedback to Aaron indicated that I still wielded a certain degree of authority over his work, but my acknowledgement of his growth indicated that his own expertise was increasing, that he was becoming a stronger writer.

Aaron did revise this piece, and in his revision, he stated his thesis much earlier in the paper; he elaborated in one area that was previously unclear; and he rearranged a few ideas so the paper flowed better. My feedback to Aaron on the revised final was very positive. I noted that he improved his citation format, clarified some confusing and vague sections, and ended up with a much stronger piece.

Then, in a much more collaborative gesture, I talked to Aaron about my own strategies for writing. I told him that when I find an article that applies to my paper, I start a document that I call Notes and I type up quotes and citation information for that article. I went on to tell him that,

Then I can just cut and paste those citations to make my Works Cited page. Now, that slows you down in your research because you're documenting everything as you go, but when you're done, the paper comes together really nicely. So, I have a document like that for every piece I write. 
I also shared with Aaron another practice I found helpful: saving all the parts of an essay I deleted in a document that I entitle Scraps. I explained to Aaron that I hate to delete completely any section of a paper I write, so I just cut from the original document what I no longer want and paste it into my Scraps document. Then, I can revisit the Scraps document to determine whether those deleted pieces actually do belong in the finalized piece. Thus, in my feedback to Aaron, I served as a mentor sharing tricks of the trade and tips that worked well for me.

My response to Aaron through the entire semester never felt risky to me. I approached my responses with confidence and assuredness that I would have something of value to share with Aaron. Aaron, on the other hand, no doubt approached each composition with a good deal of trepidation, for he took risks each time he set about writing a composition. By the end of the semester, as his writing improved, we began to develop a more collaborative relationship in which I shared my own writing strategies.

In trying to empathize and understand what this experience might have been like for Aaron, I think about how I might have responded to a semester-long course in an area where I have little ability—say, math or engineering. I imagine that my continued engagement in such an endeavor, while perhaps honing my skills in that area, would take a toll on my enthusiasm, my confidence, and indeed, my sense of self-my identity. Therefore, in retrospect, I applaud Aaron for persevering through the semester and continuing to engage to varying degrees in a process that was challenging for him.

This analysis thus far points to the need to be ever-aware of what expertise and understandings students can share with me. I have always given a nod to what students can teach me, but often what they teach me is something new in terms of the course 
content. When I teach a content-centered course, I can always count on students presenting new ideas to the class and me. For instance, I knew very little about Skid Row until Aaron decided to write about it.

However, when I took the time to become attuned to the nuances of my interactions with students and my responses to their writing attempts, I learned much more about my role as a composition instructor. Only through the careful analysis of my response was I able to unveil the lessons students had to teach me about my authority in the classroom, the potential for collaboration, and the true risks of a composition classroom—risks for instructors, and risks for students.

\section{The Perils of a Non-prescriptive Writing Pedagogy}

For this particular composition course, I made the pedagogical decision to have students determine their own writing tasks, a process I discussed in chapter two. I wanted students to take ownership over their own writing, and I wanted students to engage in the critical thinking required to develop an idea for a composition. I also wanted students to feel less intimidated by the composition process by having a say in the length, genre, and mode of their own writing. These goals, I believe, were met for most students in my first year composition course. While at the beginning of the semester, many students struggled to define their own writing tasks, by the end of the semester, most students had many composition ideas they were interested in pursuing. The struggle for them became choosing the best option.

Because I embraced this non-prescriptive writing pedagogy, students were able to tailor their writing to their own needs, strengths, and interests. They were able to highlight their expertise by designing compositions around those areas. Students 
demonstrated their strengths by engaging with such genres as websites, newsletters, grants, short stories, researched papers, and, of course, music. Through this nonprescriptive writing pedagogy, composition became slightly less risky for students.

However, when I made this pedagogical decision, I did not anticipate nor predict the difficulties I would have responding fairly to these varied compositions. While I thoroughly enjoyed reading the range of compositions students submitted, and I genuinely appreciated the creative and interesting ways students represented their knowledge of homelessness, I nonetheless struggled to respond to students in a way that I considered to be fair and ethical. In particular, I found myself in quite a dilemma when responding to the more creative compositions, especially those for which I had little expertise. I have already discussed my discomfort responding to Paul's song series, but there were other compositions that likewise challenged me. One student's four-act play was rich in terms of character development and dialogue, but the surface features made it difficult to read at times. The author, a theater major, clearly enjoyed writing the piece, but as a composition instructor, I struggled to respond to the student in a way that demonstrated my appreciation of her ideas, but also helped her hone her writing skills. Furthermore, my background and expertise in the theater arts is minimal at best, so I was even out of my element when it came to commenting knowledgably on the quality of the play itself.

A few other students wrote short stories based on experiences they had with someone who was homeless. These compositions were quite emotional and effusive in many ways, so responding to the compositions and the students became a difficult balancing act for me; I tried to appreciate their intentions but at the same time, help them 
understand that at times, understatement is more effective than overstatement. Likewise, I struggled to respond to the range of genres students presented to me, genres such as websites and newsletters. I have little background in these particular genres, so my expertise was somewhat limited to what I could generalize from my own background in the general principles of composition.

But beyond my limited expertise in some genres, the core of my response dilemma was the fact that students were submitting very personal compositions. They were heavily involved in the entire composing process: they designed the composition, they researched the topic, and they wrote the composition. They were indeed invested deeply in their own writing. And while nurturing this degree of student ownership over their own writing is a laudable goal for a composition instructor, it is not without its perils. When students have more ownership over their own writing, the risk of response to student writing is magnified.

No doubt, if all students wrote the same type of prescribed composition, my response to those students and their writing would be considerably easier. By comparing the compositions to one another, it is much easier to determine who excelled at the composition and who fell short, so the actual assessment of the work becomes much more streamlined. In fact, in one writing intensive course I teach for the education department, students do write the same type of compositions throughout the semester, and responding to those compositions is far less perilous than responding to my first year students. In my education course, I can easily determine the quality of each composition as soon as I finish reading it. I can respond to students by pointing out aspects of their compositions that are particularly strong or particularly weak because I have a great deal 
of experience —or expertise — reading those particular kinds of compositions. I often facetiously tell students that I can spot an A paper at fifty yards, I have read so many of them. Of course, in spite of my vast experience reading and assessing these papers, I still audio record my response to students and give them a detailed rubric so that they know what I saw as their strengths and weaknesses - I am committed to being as transparent as I can be through my response processes. In any case, I never feel out of my element when grading compositions for the education class, but my first year writing course was an entirely different experience for me.

This discussion, then, raises important questions about student autonomy and instructor response. Among those questions: Is it fair to compare the writing of one student with the writing of another, even when both students have written compositions in response to the same prompt or assignment? Who should take the bigger risks in a composition classroom, students or instructors? How much autonomy over their own writing is best for students? Certainly, there are more questions that this discussion may generate, but for my own purposes, I am compelled to grapple with the notion of student autonomy over their writing.

First, it occurs to me that how student writing is assessed and responded to may never be entirely fair. As previously noted by Broad, the evaluation of (and I might add, the response to) student writing is "a critical and creative act carried out by some human beings upon the critical and creative work of others" (2009, p. 309). Human endeavors are subjective affairs, so expecting an entirely even-handed response to student work seems unlikely. Yet, there is a degree of fairness that can be attained when students design their own writing tasks. When students can create writing tasks that capitalize on 
their strengths and reflect their interests, the writing itself becomes more fair to the students. In contrast to compositions that are imposed by the instructor, the students have full ownership over their own writing tasks and thus have no one to blame but themselves if the task is too difficult, too broad, or too abstract.

Furthermore, non-prescribed writing is a more accurate reflection of how students will write in their future academic and personal endeavors. It is rare indeed that a group of individuals would write the same type of composition at the same time and for the same purposes, a point I discussed earlier in this study. When I adopted a nonprescriptive writing pedagogy, I not only engaged students in an important critical thinking process, but I also exposed students to the wide breadth of compositions possible for discussing a singular topic: homelessness.

Therefore, I conclude that the benefits of a non-prescriptive writing pedagogy far outweigh the perils of such a pedagogy, especially because those perils fall primarily within the purview of the instructor, not the students. I cannot help but think that students like Aaron would have made far less progress if I had designed all the writing tasks for the semester. If I had given all students, say, a four-page persuasive essay at the beginning of the semester, I do not imagine Aaron would have fared well. In fact, he might have felt discouraged and incompetent and as a result, disengaged from the course and the work associated with the course. Instead, by designing his own writing tasks, Aaron was able to begin with a shorter, more manageable composition and work his way into a longer, more well-sustained argument by the end of the semester. For Aaron, this gradual increase in expectations — expectations that he imposed on himself — resulted in considerable growth for him. 
Taking Paul and Shannon's work into account, it is possible that they benefitted less from this non-prescriptive writing pedagogy. I suspect that both Paul and Shannon would have fared well in almost any composition course of almost any design. Both students possessed strong writing skills at the beginning of the semester, and both students were committed and serious in their approaches to the course. While they both no doubt appreciated the opportunity to pursue a wide range of genres, and both seemed quite excited about the work they produced over the course of the semester, I doubt that either one gained much significant growth from the course. In all honesty, both students could have most likely opted out of the first year writing course altogether and done just fine in their subsequent academic endeavors. Fortunately, neither Paul nor Shannon purposefully designed simplistic writing tasks for themselves, so their work was, I believe, quite meaningful and valuable, even if it did not significantly improve their writing abilities.

Then, there is Karl. As difficult as it is to admit, I believe Karl would have benefitted from a more prescriptive writing pedagogy. Karl, more than other students in the course, designed relatively easy writing tasks for himself. I saw little evidence of him stretching himself or challenging himself. He appeared only marginally present in the course as a participant and as a writer. Just as Karl troubled my narrative of student autonomy over their own writing, so he troubles my understanding of a non-prescriptive writing pedagogy. And as difficult as it is to admit this, I appreciate Karl for challenging my understandings of so many things. I may never have an ideal approach to a first year composition course, but at least I will enter my next course with a heightened awareness of the complex issues at play. And for that, I thank Karl. 


\title{
CHAPTER V \\ RECIPROCITY AND THE INVISIBLE COMPOSITION CLASSROOM
}

\begin{abstract}
Initial Goals of the Study
When I set out to conduct this study, I held a number of goals I hoped to achieve. First, I wanted to explore whether the social development of a composition classroom influenced the writing students attempted within that setting. More specifically, I intended to demonstrate how the social dynamics of a classroom intersected with the composition risks students were willing to take. I began this study believing that, on some level, this social layer of the classroom held considerable sway over the kinds of writing students were willing to undertake, assuming they were given a choice. In reflecting on my research, my initial inklings about the intersection between the social environment and student compositions were confirmed. By using linguistic politeness theory as an illuminating lens, I was able to show how students in my particular composition classroom were perhaps overly polite when reviewing one another's writing, as well as how they minimized their own expertise and hesitated to impose on one another extensive revision suggestions. Through data analysis, I was able to demonstrate that the social relationship students had with one another arose in part through the peer review process and was likewise evidenced by the peer review process. Furthermore, the students appeared to sense the risk they were taking in their compositions and responded
\end{abstract}


to those risks with more than a modicum of care. While I never intended to prove a cause-effect relationship between the classroom social environment and risky composition, I nonetheless confirmed that the social environment was at least a consideration for students as they engaged in different stages of the composing process. Students took one another's face and identity needs into account as they completed the required writing of the course.

Another goal I held for this study was to examine how I responded to student writing and the influence my response had upon students. I discovered a number of interesting conclusions through this aspect of my study, not the least of which was that my teacher response was different for every student. The responses I offered students were uniquely tailored to what I perceived to be their needs at that time. It appears, then, that a concise, clear definition of teacher response is both impractical and unnecessary. Instructors cannot predict in advance how they will respond to any given composition, or any given student, in any given semester. The art of responding to student writing is just that — an art. And art often defies definition and standardization.

However, because I chose to enact a self-study, there were a number of revelations that I did not anticipate nor predict. Self-study operates on the premise that conclusions and theories arise from the data and are therefore initially unknown, so it was no surprise that some of my findings were revealed only through the research process.

When conducting qualitative, observational research, one strategy researchers use is referred to as figure ground reversal ${ }^{8}$. Using this technique, the observer intentionally

\footnotetext{
${ }^{8}$ I extend my gratitude to Dr. Beth Hatt, Illinois State University, for introducing me to this concept in her qualitative research methods course at Illinois State University.
} 
directs her attention to where the action is not taking place. She makes an effort to observe what is happening in the background in order to understand more fully the entire scene. She intentionally attempts to see what is initially unseen, to notice that which is not, at first, noticed. The researcher asks herself what is happening in the background and how that background action informs the foreground action. This figure ground reversal strategy also applies to my study. By attending to what was unfolding in the background of the classroom - more specifically within the social layer-I have been able to understand better the collective entity that was my composition classroom.

This figure ground reversal has revealed to me an invisible classroom of sorts, an invisible classroom that contributed in both minor and significant ways to the overall experience of my first year composition course.

The Invisible Composition Classroom

One part of the invisible classroom arose during the peer review process. Beyond the previously mentioned politeness strategies that students used during the peer review, there was an invisible resistance in the students' actions as they engaged in this mandated activity. I explicitly designed the peer review assignment so that students would be positioned to critique the work of their peers. While I allowed room for words of encouragement during peer review, I nonetheless wanted students to offer suggestionsreal suggestions - that would help them improve their writing. In a sense, I wanted students to play the role of instructor, to offer critiques, suggestions, and corrections. Here, it is important to note that there are many different ways that readers can interact with others' texts. I use the term review to refer to the process of offering suggestions, corrections, and guidance on a composition. I use the term response to refer to the 
process of offering an interested reaction to a composition without the critique or correction. Response allows the writer to maintain control over the piece, whereas review exerts a certain amount of outside authority over the piece. ${ }^{9}$

Upon closer scrutiny of students during the peer review process, I see now that students pushed back against my request to critique their peers' compositions. Rather than review their peers' writing, they responded to it. On some level, the students overruled my directions and engaged in the peer review process in a way that they knew was more appropriate and more suited to their individual and collective needs. They did not merely defer to my directions, but instead crafted a response to one another that would marginally meet my demands but at the same time, address one another's face and identity needs. This invisible shift in their response contributed to the social environment and may have made students feel safer sharing their writing with one another.

Another invisible layer of the classroom likewise relates to the notion of response. I termed my own way of interacting with students' texts as a response- teacher response, to be specific. However, as I reflect on the ways I interacted with students and their texts, I now realize that the term teacher response was a misnomer. Of course, at times I did respond — and only respond — to students' texts. But most of the time, I both responded and reviewed their texts. I reacted to their texts emotionally, but I also gave suggestions, corrections, and guidance with an eye toward improving their compositions. My response, it seems, tipped more toward review.

\footnotetext{
${ }^{9}$ I extend my gratitude to Dr. Jan Neuleib and Dr. Bob Broad, both of Illinois State University, for pointing out to me that there is, indeed, a distinct difference between review and response.
} 
So, it strikes me now that what I referred to as peer review was taken up by students as peer response, and what I referred to as teacher response was taken up by me as teacher review. This irony was invisible to me during the course, but through the selfstudy process, I can now see that my terms and the concepts that underpin those terms were imprecise and at times inappropriate given the roles both students and I played in the classroom. Therefore, because my language was less than precise, so, too, was my thinking.

It appears that I will need to rethink my peer "review" and teacher "response" concepts and to articulate more clearly what I mean by these processes. By reframing the peer review process as a peer response process, students will understand that I want them respond to one another's writing, not critique it. I will align my expectations of students with what I believe will build a more cohesive classroom community. Ideally, students will then feel more comfortable engaging with one another through their compositions and will not feel pressure to do something that undermines their emerging social cohesion.

A final invisible factor that arose during the semester related not to students' face and identity needs, but rather to mine. Since the semester concluded, I have been somewhat haunted by one of my focus students: Karl. I have, quite frankly, a lingering frustration when I consider my work with Karl. I feel that I, on some level, failed him as a teacher. He never appeared to engage fully with the course, with the writing process, or with me, for that matter.

As a result of my reflection on my work with Karl, I have come to realize that I, like the students, also have face and identity needs in the composition classroom. While 
my composition identity is mostly solidified and stable, my composition instructor identity is far less secure. I began this study recounting my own insecurities as I approach each new semester. I mentioned that I am often apprehensive about creating a cohesive classroom community and I wonder if I will be able to create meaningful learning opportunities during each semester-long course. Due to my own insecurity, I now realize that I need to believe that I am being helpful to students, for when I think I am being helpful, my positive face needs are met and my composition instructor identity is confirmed and upheld. I want my input to be valued by students, and I want students to value the same things I value, to appreciate the same things that I appreciate. Yet, Karl eschewed my comments and suggestions. He, in essence, threatened my positive face by rejecting my review of his work, and in so doing, failed to meet my face needs.

Students like Aaron, on the other hand, made me feel valued. He practically hung on my every suggestion. I felt quite accomplished when he successfully enacted my suggestions - and he enacted nearly all of them. As a result, I felt I served a valuable purpose in his composition life. In fact, Aaron was quite vocal in his appreciation of my expertise and often thanked me for meeting with him and for helping him become a better writer. Aaron aptly addressed my positive face needs as an instructor, and I felt accomplished when I worked with Aaron.

I likewise felt valued when I responded to Paul and Shannon's work. Paul, Shannon, and I shared the same values and the same enthusiasm for composition. Neither student ever bemoaned an assignment, but rather approached each assignment with creativity, interest, and investment. They fed my positive face needs by aligning themselves with my interests. It was always a pleasure to work with them, and although I 
enjoyed working with Aaron because he was so invested, I drew a different kind of gratification by working with adept students like Paul and Shannon.

But then there was Karl. My work with Karl somewhat rattled my identity as a composition instructor. Karl offered no appreciation, no acknowledgement, no application of my suggestions, and so my positive face needs went entirely unmet with Karl.

This notion that instructors also have face needs is a new revelation to me. I now understand that there is a reciprocity of face and identity in the composition classroom. Students have face and identity needs, but so do instructors. When everyone involved upholds one another's face and identity needs, things run smoothly. But when I encounter students like Karl, my insecurities arise. Karl did not reciprocate my attempts to address his face needs, and in the end, my frustration with him became more and more evident.

Certainly, an instructor has an obligation to be more emotionally mature than the students, but instructors are human and as such respond to students emotionally at times. I responded to all the students emotionally—sometimes with joy, curiosity, enthusiasm— but also with frustration. Much of my response was shaped by my own face and identity needs. Had it not been for Karl, this invisible layer of the classroom might have remained invisible. Only through self-reflection and a careful analysis of my "response" to Karl have my own face and identity needs been revealed.

\section{My Emerging Understanding}

I began this study stating that I hoped to generate a new understanding about composition that supported risk-taking by students. I acknowledged that my understanding would arise from the unique classroom configuration of my first year 
composition course, but that others might be able to generalize my findings in order to understand better their own composition courses. Now, having analyzed the data from my study, I have come closer to establishing my own emerging theory of composition. I may never have a clear, concise theory that is easily quotable or tossed about in academic circles, but I have arrived at some worthwhile understandings of my own that will inform my future work with first year writers.

First, I contend that students are more likely to engage in the work of the figured world of the composition classroom when they feel a certain social cohesion within that setting. When students feel relatively safe within the social environment of the composition classroom, they may be more likely to take composition risks that yield growth. However, there is an interesting but invisible social layer to the composition classroom that influences this sense of safety and cohesion, a layer that is made more visible through the use of such theoretical frameworks as linguistic politeness theory. By applying a number of concepts from linguistic politeness theory, previously unseen facets of the composition classroom are unveiled — issues of face and identity for both the students and the instructor. I contend that when instructors are attuned to these aspects of the social fabric of the composition classroom, they are better able to design their instructional tasks so that they uphold the emerging social closeness of the composition classroom rather than undermine it. Finally, when students feel socially supported in the composition classroom, they are more likely to engage in — and remain engaged in - the composing process, which in turn results in more writing and ideally, better writing. Creating better writers is, indeed, one over-arching goal of the composition classroom as 
it is manifested in the university, so remaining attuned to the social dynamics in the composition classroom in one way meets this over-arching goal.

I have created a graphic that summarizes this emerging composition theory:

Figure 2. The Invisible Composition Classroom

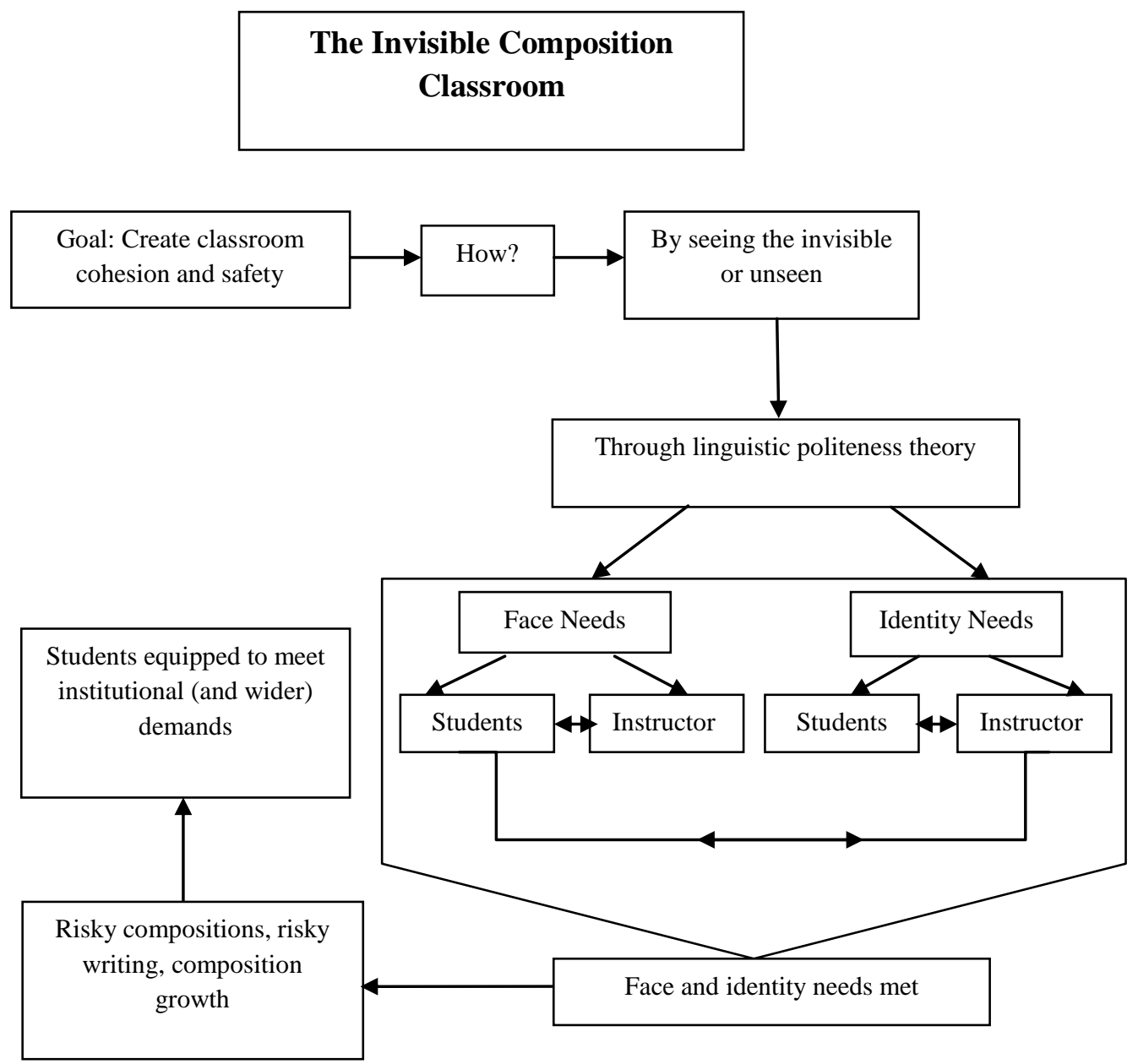


While there may be some near-universal characteristics of most composition classrooms, I suspect that other composition instructors who endeavored to unveil their own invisible classroom might find some other unique characteristics and phenomena. No two composition classrooms are the same, so applying a universal composition theory is impractical and, in a sense, a waste of time. But, by remaining open to the unique social dynamics of each classroom configuration, instructors may be better equipped to respond to the needs that arise. By remaining aware of the invisible composition classroom, instructors come a bit closer to creating the productive, worthwhile composition classrooms they seek.

Berlin once notably stated, "in teaching writing we are tacitly teaching a version of reality and the student's place and mode of operation in it" (p. 257, 2003, in Villanueva). I might add that we must also allow students to teach us their own version of reality and how they prefer to operate in it so that we can design classroom environments that work in tandem with the organic, natural classroom.

\section{Limitations}

As with all research, there are limitations to my self-study. I used a decidedly small sample: only twelve students. Due to this small class size, students were more able to build a social connection with one another. Also, the structure of the course was discussion-based, so students had ongoing opportunities to interact with one another around the content, which in turn helped them get to know one another better. In short, it was much easier to build social cohesion in this smaller, more intimate classroom setting than it would have been in a much larger classroom. 
Additionally, the site of my research, MLAU, is a small university of only approximately 2100 students. The students who are attracted to MLAU (and to whom MLAU is attracted) are typically middle to upper middle-income students who were academically successful in high school. While students come to MLAU for any number of reasons, all must meet the rigorous admission standards. Therefore, students in my first year composition course were, for the most part, very serious about their own academic success. Furthermore, because most students came from similar socio-economic backgrounds, they exhibited similar social interactions: they were mostly polite, kind, and tolerant of one another and rarely contradicted one another outright.

Finally, of the thirteen students in the class, twelve of whom agreed to participate in my research, only one student identified herself as non-white. This lack of ethnic diversity further created a homogenous environment that, no doubt, influenced my findings. Therefore, replicating this study in a different environment would most likely yield different results—-but that is the point. Each composition classroom has an invisible layer, a layer that is unseen, unpredictable, and unique unto itself.

This study, then, is a call to all composition instructors to turn a careful eye toward what is going on in the background, to see the as-yet unseen, and to allow themselves to learn from this new vision. And so, I end this study where I began: In almost any composition classroom, there is much more going on than meets the eye. 


\section{REFERENCES}

Addison, J., \& McGee, S. J. (2010). Writing in high school/Writing in college: Research trends and future directions. College Composition and Communication, 62(1), 147-179.

Anson, C. (1997). In our own voices: Using recorded commentary to respond to writing. New Directions for Teaching and Learning. 69, 105-113.

Anson, C. (2000). Response and the social construction of error. Assessing Writing, 7, 521.

Anson, C. M., Dannels, D. P., Flash, P., \& Housley Gaffney, A. L. (2012). Big rubrics and weird genres: The futility of using generic assessment tools across diverse instructional contexts. Journal of Writing Assessment, journalofwritingassessment.org.

Arundale, R. B. (2006). Face as relational and interactional: A communication framework for research on face, facework, and politeness. Journal of Politeness Research: Language, Behavior, and Culture, 193-216.

Bagley, S. S. (2010). Students, teachers and alternative assessment in secondary school: Relational Models Theory (RMT) in the field of education. The Australian Educational Researcher, 37, 83-105.

Bal, M. (2002). Travelling concepts in the humanities: A rough guide. Toronto: University of Toronto Press.

Berlin, J. (2003). Contemporary composition: The major pedagogical theories. In Villanueva, V. (Ed.). (pp. 255-272). Cross-talk in Comp Theory: A Reader. Urbana, IL: National Council of Teachers of English.

Berman, J. (2006). Risky writing: Self-disclosure and self-transformation in the classroom. Amherst, MA: University of Massachusetts Press.

Bizzell, P. (2003). Cognition, convention, and certainty: What we need to know about writing. In Villanueva, V. (Ed.). (pp. 387-411). Cross-talk in Comp Theory: A Reader. Urbana, IL: National Council of Teachers of English. 
Brammer, C. \& Rees, M. (2007). Peer review from the students' perspective: Invaluable or invalid? Composition Studies, 35(2), 71-85.

Broad, B. (2009). "Portfolio scoring": A contradiction in terms. In Huot, B., \& O’Neill, P. (Eds.). Assessing writing: A critical sourcebook (301-314). Boston, New York: Bedford/St. Martin's.

Broad, B. (2003). What we really value: Beyond rubrics in teaching and assessing writing. Logan, UT: Utah State University Press.

Broad, B., \& Boyd, M. (n.d.). Rhetorical writing assessment: The practice and theory of complementarity. Journal of Writing Assessment, 2(1), 7-20.

Brown, P., and Levinson, S. C. (1987). Politeness: Some universals in language usage. New York: Cambridge University Press.

Buhagiar, M. A. (2007). Classroom assessment within the alternative assessment paradigm: Revisiting the territory. The Curriculum Journal, 18(1), 39-56.

Burnham, C. (2001). Expressive pedagogy: Practice/theory, theory/practice. In Tate, G., Rupiper, A., \& Schick, K. (Eds.). A guide to composition pedagogies. (pp. 19-35). New York: Oxford University Press.

Chen, R. (2001). Self-politeness: A proposal. Journal of Pragmatics, 33, 87-106.

Ching, K. L. (2007). Peer response in the composition classroom: An alternative genealogy. Rhetoric Review, 26(3), 303-319.

Cho, Y. H. \& Cho, K. (2011). Peer reviewers learn from giving comments. Interaction Science, 39, 629-643.

Cole, J. B. (2006). Toxic feedback: Helping writers survive and thrive. Lebanon, NH: University Press of New England.

Cooper, C. R., \& Odell, L. (1999). Evaluating writing: The role of teachers' knowledge about text, learning, and culture. Urbana, IL: National Council of Teachers of English.

Covill, A. E. (2012). College students' use of a writing rubric: Effect on quality of writing, self-efficacy, and writing practices. Journal of Writing Assessment, journalofwritingassessment.org.

Culpeper, J., Bousfield, D., and Wichmann, A. (2002). Impoliteness revisted: with special reference to dynamic and prosodic aspects. Journal of Pragmatics, 35, 15451579. 
Edgington, A. (n.d.). "What are you thinking": Understanding teacher reading and response through a protocol analysis study. Journal of Writing Assessment, 2(2), 125-148.

Flores, B. (2004). Deracination and the D.I.S. in the first-year writing classroom. Teaching English in Two Year Colleges, March, 260-272.

Flynn, D. (2008). Using peer-review effectively in large, diverse classes. The International Journal of the Humanities, 5(12), 65-71.

Freeman, D. (1998). Doing teacher research: From inquiry to understanding. New York, NY: Heinle and Heinle Publishers.

Gipps, C. (1999). Socio-cultural aspects of assessment. Review of Research in Education, 24, 355-392.

Glaser, B. G., \& Strauss, A. L. (1967, 1999). The discovery of grounded theory: Strategies for qualitative research. New Brunswick, NJ: Aldine Transaction Publishers.

Glesne, C. (2006). Becoming qualitative researchers: An introduction. Third Edition. Boston, MA: Pearson.

Goffman, E. (1967). Interaction ritual: Essays on face-to-face behavior. New York, NY: Pantheon Books.

Graziano-King, J. (2007). Assessing student writing: The self-revised essay. Journal of Basic Writing, 26(2), 73-92.

Grice, H. P. (1975). Logic and conversation. In Cole, P. and Morgan, J. L. (Eds.). (pp. 41-58). Syntax and Semantics 3: Speech Acts. New York: Academic Press.

Hester, V. (n.d.). When pragmatics precede pedagogy: Post-process theories of assessment and response to student writing. Journal of Writing Assessment, 3(2), 123-144.

Holland, D., Skinner, D., Lachicotte, W., \& Cain, C. (1998). Identity and agency in cultural worlds. Cambridge, MA: Harvard University Press.

Huot, B. (2002). Toward a new discourse of assessment for the college writing classroom. College English, 65(2), 163-180.

Huot, B. (2002). (Re) Articulating writing assessment for teaching and learning, Logan, UT: Utah State University Press. 
Huot, B., \& O’Neill, P. (Eds.). (2009). Assessing writing: A critical sourcebook. Boston, New York: Bedford/St. Martin's.

Huot, B., O’Neill, P., \& Moore, C. (2010). A usable past for writing assessment. College English, 72(5), 495-517.

Inoue, A. B. (2005). Community-based assessment pedagogy. Assessing Writing, 9, 208238.

Itakura, H. (2013). Hedging praise in English and Japanese book reviews. Journal of Pragmatics, 45, 131-148.

Jesnek, L. M. (2011). Peer editing in the $21^{\text {st }}$ century college classroom: Do beginning composition students truly reap the benefits? Journal of College Teaching \& Learning, 8(5), 17-24.

Johnson, D. M. and Yang, A. W. (1990). Politeness strategies in peer review texts. In Lawrence F. Bouton and Yamuna Kachru (eds.) Pragmatics and Language Learning, 1, 99-110.

Karkkainen, E. (2012). I thought it was very interesting: Conversational formats for taking a stance. Journal of Pragmatics, 44, 2194-2210.

Kluger, A. N., and DeNisi, A. (1996). The effects of feedback interventions on performance: A historical review, a meta-analysis, and a preliminary Feedback Intervention Theory. Psychological Bulletin, 119(2), 254-284.

Kutz, E., \& Roskelly, H. (1991). An unquiet pedagogy: Transforming practice in the English classroom. Portsmouth, NH: Boynton/Cook Publishers, Heinemann.

LaPlante, D. \& Ambady, N. (2003). On how things are said: Voice tone, voice intensity, verbal content, and perceptions of politeness. Journal of Language and Social Psychology, 22, 434-441.

Lee, A. (2000). Composing critical pedagogies: Teaching writing as revision. Urbana, IL: National Council of Teachers of English.

Lindeman, E. (2001). A rhetoric for writing teachers, $4^{\text {th }}$ Edition. New York: Oxford University Press.

Lizzio, A., \& Wilson, K. (2008). Feedback on assessment: Students' perceptions of quality and effectiveness. Assessment and Evaluation in Higher Education, 33(3), 263-275. 
Locher, M. A. (2006). Polite behavior within relational work: The discursive approach to politeness. Multilingua, 25, 249-67.

Locher, M. A., and Watts, R. J. (2005). Politeness theory and relational work. Journal of Politeness Research, 1, 9-33.

Mao, L. R. (1994). Beyond politeness theory: 'Face' revisited and renewed. Journal of Pragmatics, 21, 451-486.

Meier, A. J. (1995). Passages of politeness. Journal of Pragmatics, 24, 381-392.

Mellen, C., and Sommers, J. (2003). Audio taped response and the two-year-campus writing classroom: The two-sided desk, the "guy with the ax," and the chirping birds. Teaching English in the Two-Year College, September, 25-39.

Mills, S. (2004). Class, gender, and politeness. Journal of Pragmatics, 24, 381-392.

Park, I. (2012). Seeking advice: Epistemic asymmetry and learner autonomy in writing conferences. Journal of Pragmatics, 44, 2004-2021.

Pryor, J., \& Crossouard, B. (2010). Challenging formative assessment: Disciplinary spaces and identities. Assessment and Evaluation in Higher Education, 35(3), 265-276.

Pryor, J., \& Crossouard, B. (2008). A socio-cultural theorization of formative assessment. Oxford Review of Education, 34(1), 1-20.

Ratcliffe, K. (1999). Rhetorical listening: A trope for interpretive invention and a "Code of Cross-Cultural Conduct”. College Composition and Communication, 51(2), 195-224.

Samaras, A. P. (2011). Self-study teacher research: Improving your practice through collaborative inquiry. Los Angeles, CA: Sage Publications, Inc.

Schapiro, B. Negotiating a third space in the classroom. Pedagogy, 9(3), 423-439.

Sommers, J. (2013). Response rethought. . . again: Exploring recorded comments and the teacher-student bond. Journal of Writing Assessment, journalofwritingassessment.org.

Sommers, N. (2008). The call of research: A longitudinal view of writing development. College Composition and Communication, 60(1), 152-164. 
Sommers, N., Rutz, C., \& Tinberg, H. (2006). Re-Visions: Rethinking Nancy Sommers's "Responding to student writing," 1982. College Composition and Communication, 58(2), 246-266.

Sommers, N., \& Saltz, L. (2004). The novice as expert: Writing the freshman year. College Composition and Communication, 56(1), 124-149.

Speck, B. W. and Jones, T. R. (1998). Direction in the grading of writing?: What the literature on the grading of writing does and doesn't tell us. In Zak, F. and Weaver, C. C. (Eds.). The Theory and Practice of Grading Writing: Problems and Possibilities. pp. 17-29. New York: State University of New York Press.

Spencer-Oatey, H. (2005a). (Im)Politeness, face and perceptions of rapport: Unpackaging thei bases and interrelationships. Journal of Politeness Research, 1, 95-119.

Spencer-Oatey, H. (2005b). Rapport management theory and culture. Intercultural Pragmatics, 2-3, 335-346.

Stellmack, M. A., Keenan, N. K., Sandidge, R. R., Sippl, A. L., \& Konheim-Kalkstein, Y. L. (2012). Review, revise, and resubmit: The effects of self-critique, peer review, and instructor feedback on student writing. Teaching of Psychology, 39(4), 235244.

Stiggins, R. and Chappuis, J. (2005). Using student-involved classroom assessment to close achievement gaps. Theory into Practice, 44(1), 11-18.

Straub, R. (Ed.). (2006). Key works on teacher response: An anthology. Portsmouth, NH: Boynton/Cook Publishers, Heinemann.

Tate, G., Rupiper, A., \& Schick, K. (Eds.). (2001). A guide to composition pedagogies. New York: Oxford University Press.

Treglia, M. O. (2009). Teacher-written commentary in college writing composition: How does it impact student revisions. Composition Studies, 37(1), 67-86.

Trees, A. R., Kerssen-Griep, J., \& Hess, J. A. (2009). Earning influence by communicating respect: facework's contributions to effective instructional feedback. Communication Education, 58(3), 397-416.

Villanueva, V. (ed.).(2003). Cross-talk in comp theory: A reader. Urbana, IL: National Council of Teachers of English.

Wallace, D. L. (2011). Compelled to write: Alternative rhetoric in theory and practice. Logan, UT: Utah State University Press. 
Walvoord, B. E., \& Anderson, V. J. (1998). Effective grading: A tool for learning and assessment. San Francisco, CA: Jossey-Bass Publishers.

Wenger, E. (2000). Communities of Practice and Social Learning Systems. Organization, 7, 225-46.

Wenger, E. (1998). Communities of Practice: Learning, meaning, and identity. Cambridge University Press.

Wiggins, G. (1998). Educative assessment: Designing assessments to inform and improve student performance. San Francisco, CA: Jossey-Bass.

Williamson, M. (2009). The worship of efficiency: Untangling theoretical and practical considerations in writing assessment. In Huot, B., \& O'Neill, P. (Eds.). Assessing writing: A critical sourcebook (57-80). Boston, New York: Bedford/St. Martin's.

Williams, J., \& Kane, D. (2009). Assessment and feedback: Institutional experiences of student feedback, 1996-2007. Higher Education Quarterly, 63(3), 264-286.

Wolfson, N. (1988). The bulge: A theory of speech behavior and social distance. In Jonathon Fine (ed) Second Language Discourse: A Textbook of Current Research, 21-38.

Yancey, K. B. (2009). In Huot, B. and O’Neill, P. (eds). Assessing writing: A critical sourcebook. Bedford/St. Martin's: New York.

Yorke, M. (2003). Formative assessment in higher education: Moves toward theory and the enhancement of pedagogic practice. Higher Education, 45, 477-501.

Zak, F., \& Weaver, C. C. (eds.). (1998). The theory and practice of grading writing: Problems and possibilities. Albany, NY: State University of New York Press.

Ziv, N. D. (2006). The effect of teacher comments on the writing of four college freshmen. In R. Straub (Ed.) Key works on teacher response: An anthology. (pp. 94-111). Portsmouth, NH: Boyton/Cook Publishers, Heinemann. 


\section{APPENDIX \\ SAMPLE STUDENT COMPOSITION}

Dear Reader,

I am writing in response to your letter concerning the authenticity of Criminal of

Poverty, with regards to the question of authorship. In your letter, you expressed the opinion that this book could not possibly have been written by Tiny, aka Lisa GrayGarcia, for a number of reasons. These include the level of literacy and eloquence expressed by the narrative as well as the organization of the book. You contended that, because Tiny received no formal education, there is no conceivable way that she could have written this piece on her own. In your letter, you also conveyed frustration that no co-author was credited and attacked the City Lights Foundation for this "oversight".

Respectfully, I must inform you that you are quite mistaken. As a representative of the City Lights Foundation, I can assure you that Tiny did indeed pen this book without the assistance of a co-author. As is standard procedure, the manuscript was carefully edited and revised by members of the foundation, but I have it under good authority that Tiny was the sole author of Criminal of Poverty. I do not require that you take this assurance on faith however. As befits the vehemence of your letter, I will counter it with equally strong points to support my aforementioned claim.

To begin, I would propose that the writing level expressed by the book's narrative exactly fits with the level of education that Miss Gray-Garcia received. Much of the basic 
sentence structure reveals a rather limited grasp of grammar. I say this with no disrespect towards Tiny; in fact, I believe that she is aware of this fact and feels that there is no shame in it, seeing as she was denied any basic education as a child. For example, on page 56 of Criminal of Poverty, Tiny talks about her fulfilling experience in Mexico and how happy she and her mother were with the social companionship that they found there. Tiny discusses her happiness as it was expressed through her dancing: "I was lifted off into a world of sound and heat existing just above the neon-lit floor squares... The music was goofy hotel-rock, but it didn't matter- we were a family now, you don't judge your family." (Gray-Garcia, 56) The first sentence of this fragment is constructed more-or-less properly, with good flow and elegant metaphor. The second sentence, however, is a sharp contrast to this phrase; it uses the term "hotel-rock", which is an unfamiliar concept to most people as well as an awkward joining of two unrelated words with a dash mark. This phrase is also clumsy and choppy, using an inelegant adjective ("goofy") and using an abrupt switch in subject without a conjunction. On the following page, Tiny states that, "having been well-indoctrinated into Americanness, my first destination was Gigante, the local supermercado, a tribute to all that is western, large and facile- although I was confused by just how super that super was." (57) Again, two words at the beginning of this fragment are unnecessarily joined with a dash mark. The words "well" and "indoctrinated" need not have been combined; stating these two words separately would have been grammatically correct. This is followed by the term "Americanness", which is not a real word. Finally, the phrase "just how super that super was", while grammatically proper, is also confusing and rather graceless. This poor grasp of basic sentence structure plagues Miss Gray-Garcia throughout the whole book, and is a testament to her poor 
education as a child. It also points to the conclusion that Tiny wrote this book without any sort of major assistance, as any decent and professional co-author would have corrected these mistakes.

In your letter, you mentioned that Gray-Garcia could not have learned the "big words" that she uses in Criminal of Poverty. You claim that words such as "derivative", "aeronautic", "bludgeoning", and "elusive" are beyond the level of education that Tiny received. If you peruse Miss Gray-Garcia’s personal website however at www.tinygraygarcia.com, you will find that she is in the business of public speaking and rhetoric (Gray-Garcia, Lisa). To engage in activities such as this, one must command a wide vocabulary and Tiny has met many colorful people over the course of her life. It would have been fairly simple for her to merely pick up these terms in conversation; education would not have been required for Tiny to learn those words. On page 212 of Criminal of Poverty, Miss Gray-Garcia describes her ability to command language fairly easily:

"I had no formal experience or education... but I deeply understood the ways in which people could access their voice, and I intuited styles of getting at it that included creative writing exercises, sensory exercises, and consciousness-raising sessions. It was the result of a natural and longpracticed inclination to advocate and inspire people in crisis, which I had done for my mom for years. I was, as my mom would tell me, an organic intellectual." (Gray-Garcia 212) 
This quote perfectly illustrates my point, in Miss Gray-Garcia’s own words. Tiny says that she was just naturally able to work creatively with words and rhetoric, with no institutionalized education being necessary.

In addition, you stated your belief that the book's organization is far too advanced for someone with a limited education. I would propose that, on the contrary, the configuration exhibited in Criminal of Poverty actually makes quite convincing evidence that Miss Gray-Garcia wrote this book herself. The assembly of this piece is not especially commendable. On page 84 , Tiny introduces the subject of the romantic relationship that she and her mother shared with a man named Miguel:

"I will never forget that night. Something very disturbing and different happened... I could no longer differentiate between who was in the relationship with Miguel, and a vague feeling of love-desperationattraction-incest set in, never to truly go away... The threat of covert incest/ abuse experiences between a fatherless child and the mother's boyfriend are the bane of all single mothers... My mother worked very hard at not letting that ever happen to me, dropping men if they so much as looked at me or spoke in an inappropriate way. But in the end it was a testimony to our level of desperation... that she only weakly considered that possibility with Miguel, and then went on to devise 'our next move' to get Miguel to stay." (Gray-Garcia, 84)

After this intriguing section of the story, Gray-Garcia moves on to a completely different subject without any follow-up or resolution to the issue. In fact, this particular topic of the "love-desperation-attraction-incest" is never brought up or discussed again in any 
detail. I propose that it is not even described thoroughly in this segment. Tiny mentions that her mother had not allowed this kind of situation to happen in the past. Who could this have happened with? Miss Gray-Garcia discusses her mother's boyfriends in great detail throughout Criminal of Poverty, but she never brought this affair to the forefront before; it was just inserted in a seemingly random manner into this passage. This is a confusingly organized installment of the story to say the least.

This perplexing pattern of compilation repeats itself in later portions of the book. You may have noticed, while reading Criminal of Poverty, that events were not always mentioned in chronological order. In the thirtieth chapter, Tiny talks about her adopted sister that her mother Dee took into the family during their "first glimpse of [financial] stability". (Gray-Garcia, 203) She goes on to say that her sister ended up being taken away from Dee by Child Protective Services. This subject is then dropped until page 254, when Tiny describes the deterioration of the relationship between Dee and her unnamed adopted daughter. This chronological inconsistency is confusing to the reader, as they were first informed of the sister's entire fate with Dee and Tiny ending with her removal from the household, then drawn back into the story somewhere near the middle when the adopted girl and Dee were fighting. Miss Gray-Garcia's organizational talents are nowhere near perfect, I do not think she would mind admitting, and they are well below the level typically associated with formalized education.

Even when Lisa Gray-Garcia has described her experience with writing Criminal of Poverty, she describes it as being emotionally and intellectually difficult, but never mentions a co-author. In a quote from an article from the San Francisco Gate, GrayGarcia states 
"I knew the opening scene [of the book]. I knew when I started putting pen to page that I had to begin where things fell apart for me and my mom personally... But even though I knew the beginning, it was really difficult. After I wrote about 100 pages, I started to realize it needed to go back further...” (Reyhan Harmanci)

In her own description of the struggles that she faced when beginning her piece, Tiny talks about a form of writers' block and organizational challenges, but never mentions getting major assistance from an outside source for her book.

I hope you will examine my arguments and conclude that Miss Gray-Garcia was the only author of Criminal of Poverty. There is no reason for the credibility of the City Lights Foundation to be attacked. We are a non-profit, independent bookstore and publishing organization devoted to allowing the voices of America's alternative culture to be heard (City Lights Books). The foundation takes great pride in helping someone like Lisa Gray-Garcia to tell her inspiring and significant story, and would never dream of falsifying any sort of information associated with our publications.

Despite the fact that Criminal of Poverty represents a story that is composed and delivered powerfully, it was written by Miss Gray-Garcia alone. Her poor grasp of grammar and messy organization are evidenced in the piece, and support the fact that she wrote the book without a co-author's help. You make valid and respectable points to the contrary, but let me assure you that what you saw as Miss Gray-Garcia's writing prowess is simply an illustration of the skills she has acquired in many years of public speaking and her work with Poor Magazine. Thank you for your feedback; we at the City Lights Foundation always appreciate a dedicated reader sharing their thoughts. 
Sincerely,

Student Name 